\title{
Technology Evaluation for Conditioning of Hanford Tank Waste using Solids Segregation and Size Reduction
}

\author{
SRNL \\ M. L. Restivo \\ M. E. Stone \\ D. T.Herman \\ D.P. Lambert \\ M. R. Duignan
}

PNNL

G. L. Smith

B. E. Wells

G. J. Lumetta

C. W. Enderlin

H. E. Adkins

\section{April 2014}

Savannah River National Laboratory Savannah River Nuclear Solutions, LLC Aiken, SC 29808

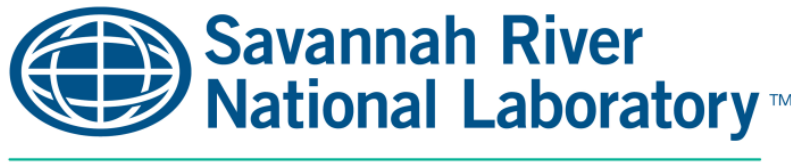

OPERATED BY SAVANNAH RIVER NUCLEAR SOLUTIONS
Pacific Northwest National Laboratory P.O. Box 999

Richland, WA 99352

\section{Pacific Northwest}

NATIONAL LABORATORY

Proudly Operated by Battelle Since 1965 
SRNL-STI-2013-00472

PNNL-23030

Revision 0

\section{DISCLAIMER}

This document was prepared in conjunction with work accomplished under Contract No. DEAC09-08SR22470 with the U.S. Department of Energy.

This work was prepared under an agreement with and funded by the U.S. Government. Neither the U. S. Government or its employees, nor any of its contractors, subcontractors or their employees, makes any express or implied: 1. warranty or assumes any legal liability for the accuracy, completeness, or for the use or results of such use of any information, product, or process disclosed; or 2. representation that such use or results of such use would not infringe privately owned rights; or 3. endorsement or recommendation of any specifically identified commercial product, process, or service. Any views and opinions of authors expressed in this work do not necessarily state or reflect those of the United States Government, or its contractors, or subcontractors.

Printed in the United States of America

Prepared for

U.S. Department of Energy 
SRNLSTT-2013-00472

PNNL-23030

Revision 0

\section{REVIEWS AND APPROVALS}

\section{LRAD AUTHORS:}

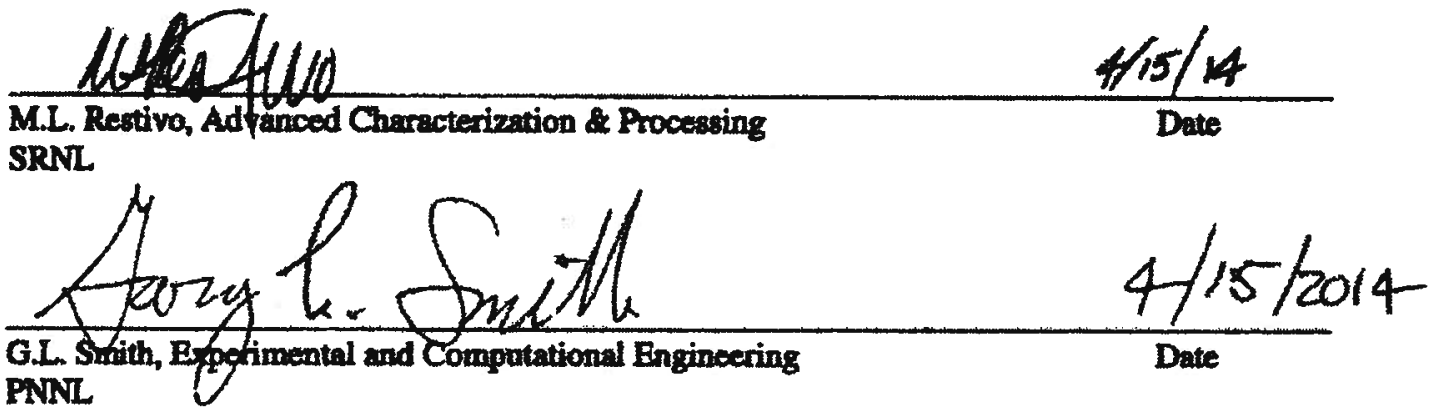
PNNL

TECENICAL REVIEW:

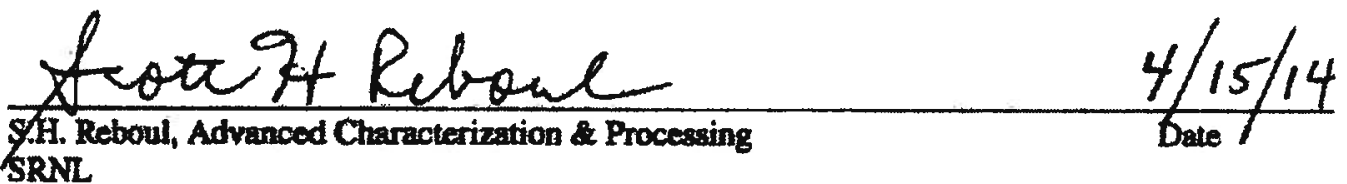
SRNL

\section{APPROVAL:}

\section{Comni C. Stemn}

C.C. Herman, Hanford Programs Manager SRNL

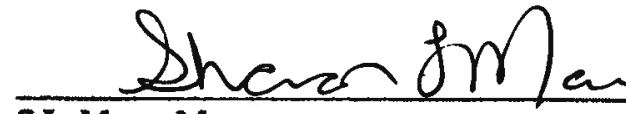

S.L. Marra, Manager

SRNL Environmental \& Chemical Process Technology Research Programs

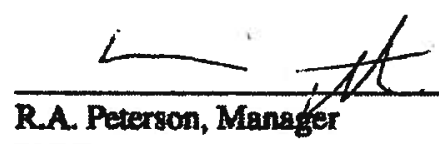

PNNL
$4 / 15 / 14$

Date

$4 / 16 / 14$

Date

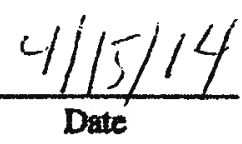


SRNL-STI-2013-00472

PNNL-23030

Revision 0

\section{ACKNOWLEDGMENTS}

The authors would like to thank the following individuals for their expertise and input:

SRS Personnel

Stephen Smith, SRR, LLC, DWPF Facility Engineering-Process Chemistry

Robert Leishear, SRNL Standards Laboratory

John McCullough, SRR, LLC, Tank Farm Facility Engineering, Mechanical

Michael Poirier, SRNL Advanced Characterization and Processing

David Stefanko, SRNS Infrastructure Services-Mechanical Engineering

Kevin Fox, SRNL Engineering Process Development

ORP Personnel

Chris Harrington, Interface Management, WTP Start-up and Integration Commissioning

Isabelle Wheeler, Deputy FPD Waste Feed Delivery, Tank Farms Projects

Jian-Shun Shuen, Waste Feed Delivery, Tank Farms Programs Division

The Authors would like express their appreciation for SRNL's Connie Herman for her tireless efforts to keep this report on track.

Additionally, it should be noted that Michael Stone, David Herman, Mark Duignan, and Dan Lambert provided instrumental input, guidance, and support on short notice, leading to a much improved final document.

Finally, the Authors would like to acknowledge the synergies realized in the cross linking of theory and application in this national laboratory collaboration.

Funding for this task was provided through two Inter-Entity Work Orders (IEWOs) from the Department of Energy - Office of River Protection (DOE-ORP). The PNNL IEWO is MORV00090, while the SRNL IEWO is MORV00091. 
SRNL-STI-2013-00472

PNNL-23030

Revision 0

\section{EXECUTIVE SUMMARY}

The Savannah River National Laboratory (SRNL) and the Pacific Northwest National Laboratory (PNNL) team performed a literature search on current and proposed technologies for solids segregation and size reduction of particles in the slurry feed from the Hanford Tank Farm (HTF). The team also investigated technology research performed on waste tank slurries, both real and simulated, and reviewed academic theory applicable to solids segregation and size reduction. This review included text book applications and theory, commercial applications suitable for a nuclear environment, research of commercial technologies suitable for a nuclear environment, and those technologies installed in a nuclear environment, including technologies implemented at Department of Energy (DOE) facilities. Information on each technology is provided in this report along with the advantages and disadvantages of the technologies for this application.

Consideration of the technology applicability included:

- Impacts on waste stream properties;

- Integration with existing equipment, processes, and facilities;

- Process control;

- Life cycle and reliability of equipment; and

- Nuclear safety and containment.

All technologies can be scaled for full production. Therefore, throughput considerations were not considered limiting for all the technologies assessed. However, the criterion should be a consideration in the final selection of the equipment for plant implementation once the processing throughput requirements are determined.

An initial consideration for defining system requirements is whether size reduction is to be performed internal or external to a waste tank. Size reduction within the vessel likely requires all of the waste be processed for size reduction as incorporation of a separations process in an in-tank system will be more challenging than an external system. Size reduction of all the waste is not desirable since only a small fraction of the waste is expected to be above the particle size limits.

Based on the review, the technologies considered most promising for Hanford application can be subdivided into those applicable to size reduction and those applicable to solids segregation.

Size reduction technologies that appear promising include:

- $\quad$ Stirred media mills

o Able to handle dense and a broad size range of particles, are less susceptible to wear than high speed rotary grinders, and have been effectively used at the Savannah River Site (SRS) to grind zeolite remaining in Tanks 18 and 19

- Homogenizers

o Higher throughput than stirred media mills, but high rotational speed and close fitting components would be more susceptible to wear

o Used at multiple DOE sites and are thus considered at a high level of technical maturity

- Some technologies appear to have promise but are untested with nuclear waste

o Ultrasonics may be able to perform the size reduction without rotary seals or other high maintenance components. 
o Pin mills offer the flexibility to control the amount of grinding with rotational speed, an easily controlled process variable.

Solids segregation technologies that appear promising include

- Hydrocyclones for segregation

o Successfully used in commercial nuclear applications and have a high level of technical maturation.

- Screening

o Higher separation efficiency than cyclones

A combined size reduction and solids segregation technology process that appears promising involves

- Initial size separation of the effluent from the primary transfer pump using a centrifugal screener with the oversized particles diverted to a size reduction process.

- Size reduction of the oversized particles using an immersion grinder mill, and then recycle of the feed to the centrifugal screener. This grinding circuit is shown in Figure 3-5.

o The immersion grinder mills could utilize one of the following technologies: Stirred ball mill (similar to the Hockmeyer used for Tank 18/19 zeolite grinding) or a homogenizer (similar to the IKA ${ }^{\circledR}$ grinder used for the West Valley Demonstration Project (WVDP)).

In selecting the size reduction technology, it must be considered that centrifugal pumps will be used to mobilize the sludge during waste retrieval and in preparation for feeding the WTP. The pumps will apply shear to the particles resulting in some size reduction, especially in loose agglomerates. However, the pumps may be less efficient than other processes, may not be able to achieve fine particle sizes, and may be ineffective on hard particles. The potential also exists that over-shearing could occur resulting in negative impacts on slurry rheology.

Technologies for solid/liquid separation, which have been successfully used for HLW processing at SRS, were also included in this report for completeness. They are not considered traditional size reduction and solids segregations technologies as described above but can be useful in preparing a waste steam to more efficiently segregate or size-reduce solids. They have been successful in SRS applications to prevent operational problems in the Defense Waste Processing Facility (DWPF) with respect to the receipt of large or slow/fast settling particles. The technologies in use at SRS may also have value for direct feed applications to the vitrification facility since the concerns with solids handling is reduced. The applicable technologies include mixing with centrifugal pumps, washing with gravity settling/decanting, cross-flow filtration and rotary microfiltration.

It is noted that the final particle size specification for the WTP WAC is still being refined as technical issues are being resolved for the processing facilities. The current draft specification for incorporation in ICD-19 for HLW feed to the Pretreatment Facility includes a maximum particle size of 310 microns as part of the specification and that size limit was utilized during this review. Changes to the final particle specification, including the selected methods for control, could impact the selection for the type of grinding circuit as well as the individual components in the circuit. Processing options such as direct HLW vitrification could lead to significant changes in the particle size requirements and the technologies would need to be reassessed for applicability.

The laboratories have provided an initial screening of the available technologies for performing size reduction and solids segregation in a radioactive slurry environment. Additional information on how the 
system will fit with the Hanford flowsheet and on performance testing in this application is required prior to performing a final selection of equipment to be used for size reduction/segregation:

- $\quad$ Finalized particle size requirements for the treated feed

The particle size specification is currently in draft form and is still under review. In addition, changes in processing strategy (e.g. direct HLW or the technical studies being performed to resume Pretreatment engineering, procurement, and construction) could impact the final particle size required. While it is possible to design a size reduction process with some flexibility to handle changes in the final particle size specification, the resulting system will be somewhat more complex than a system designed with a set particle size specification.

- Characterization of the feed after retrieval

The characterization of the feed stream is critical to properly designing the size reduction/segregation system. For example, a better understanding of the percentage of the feed that must be ground to size would help to properly size the grinding circuit to meet throughput requirements.

Once the required information is available, a down select should be performed with input from the national laboratories, system engineering, operations, and the necessary stakeholders. This down select process should select a primary and secondary option for the size segregation and the grinding processes. Testing of the proposed grinding circuit should then be performed to evaluate the effectiveness and robustness of the circuit in a flowsheet representative of what will be used at Hanford prior to installation. The testing should include a Reliability, Availability, Maintainability, and Inspectability (RAMI) evaluation. Once the testing is complete, a final selection of the size reduction/segregation system can be performed. 


\section{TABLE OF CONTENTS}

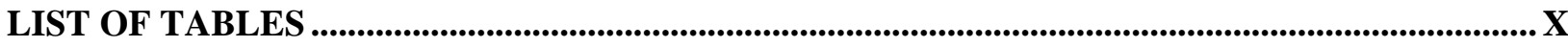

LIST OF FIGURES ................................................................................................................................................

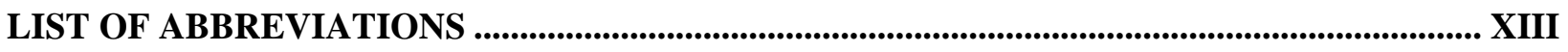

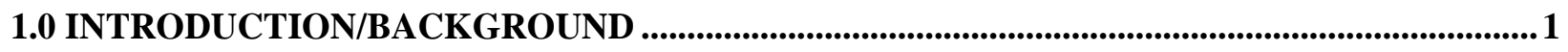

1.1 INTRODUCTION

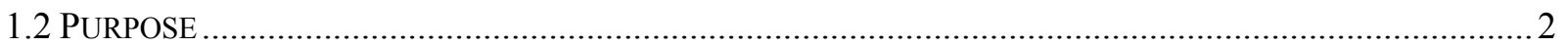

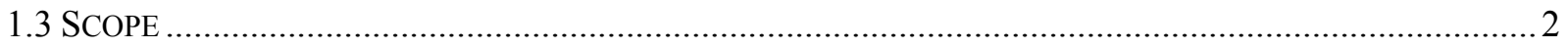

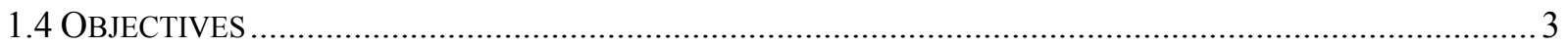

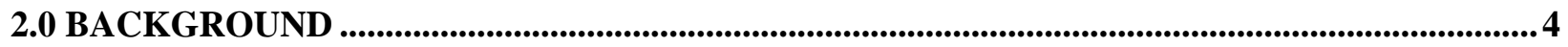

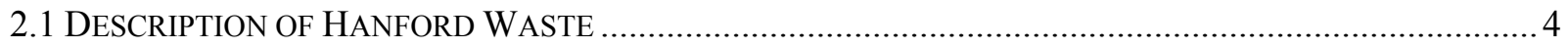

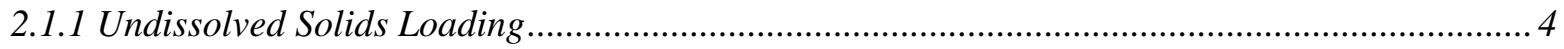

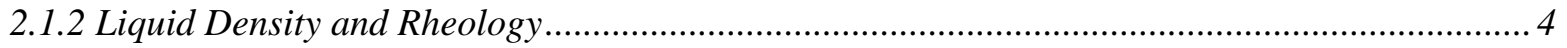

2.1.3 Solid Particle Size, Density and Morphology ............................................................................ 4

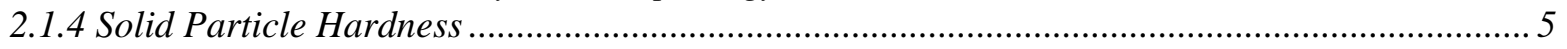

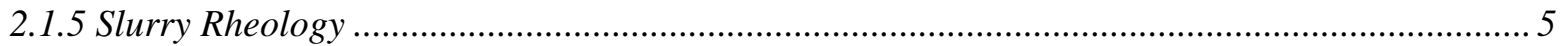

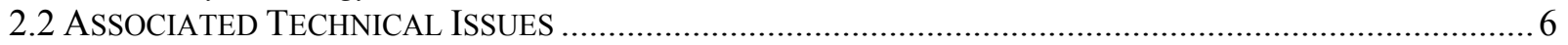

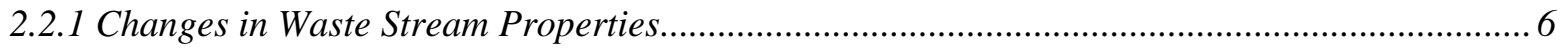

2.2.2 Integration with Existing Equipment, Processes, and Facilities ............................................... 7

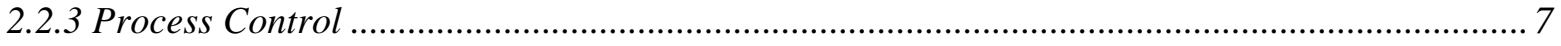

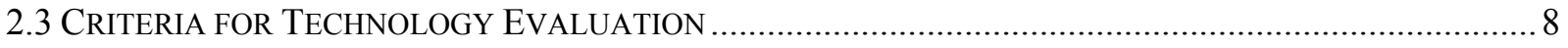

3.0 MINERAL INDUSTRY PRACTICES AND EQUIPMENT …......................................................9

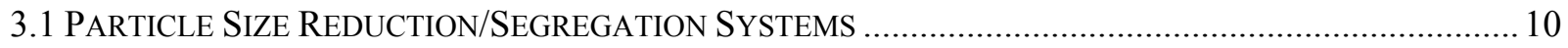

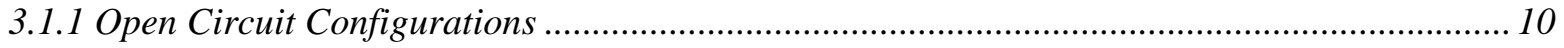

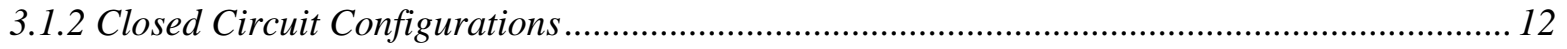

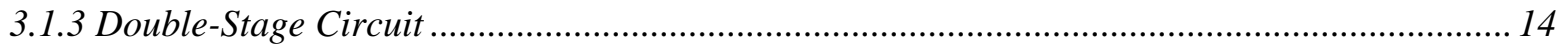

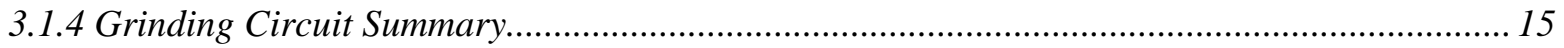

3.2 PARTICLE SIZE REDUCTION/COMMINUTION BY GRINDING ................................................... 16

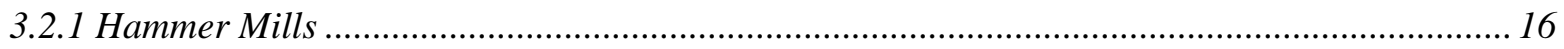

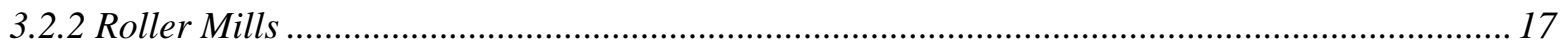

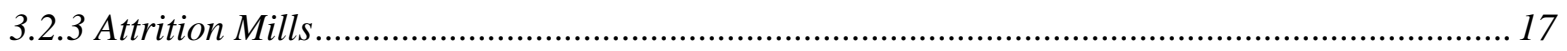

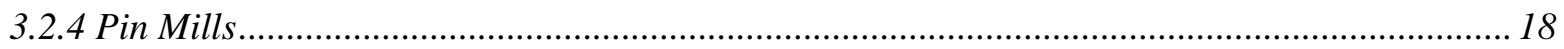

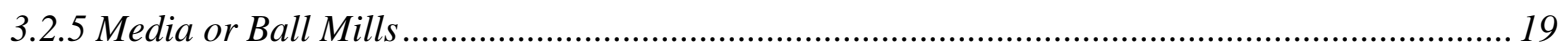

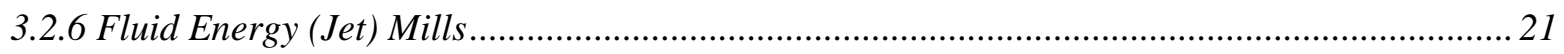

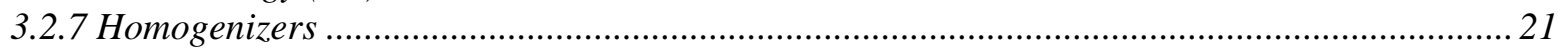

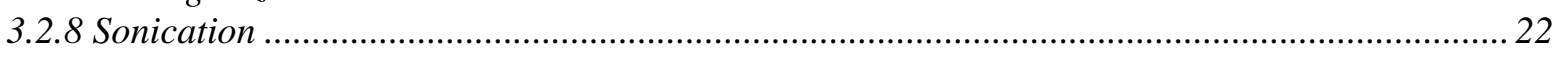

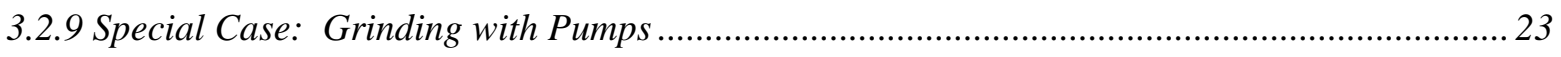

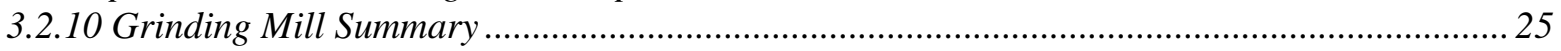

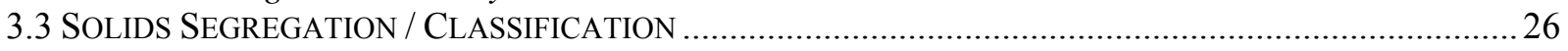

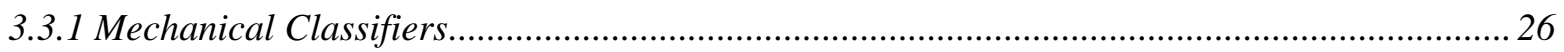

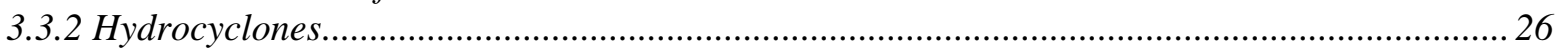

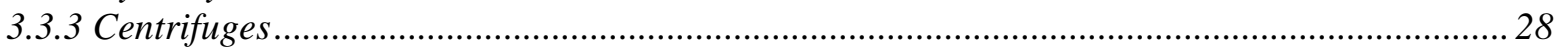

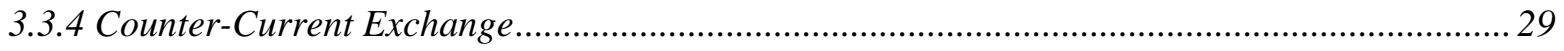

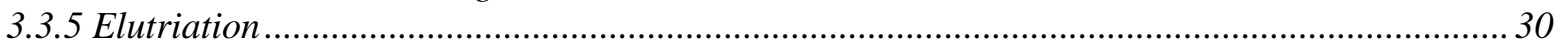




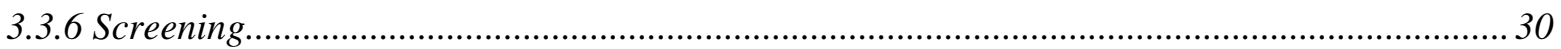

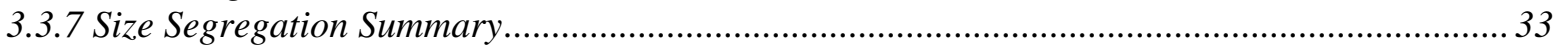

4.0 CASE STUDIES OF SOLIDS SEGREGATION AND SIZE REDUCTION IN NUCLEAR

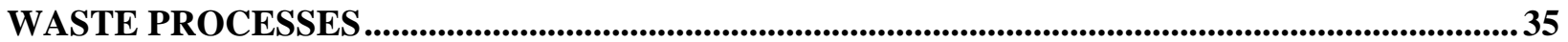

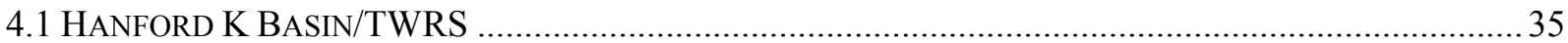

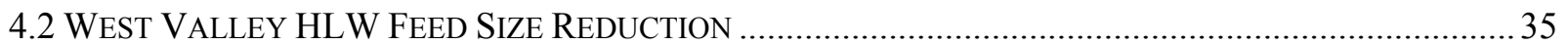

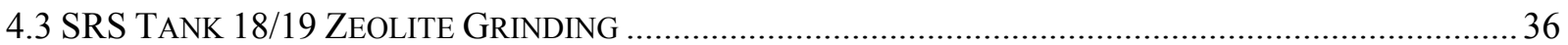

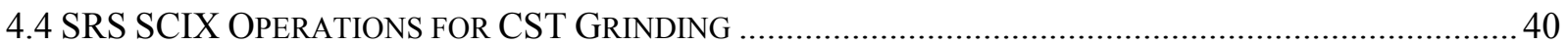

4.5 SRS SCIX OPERATIONS FOR CST GRINDING USING SONICATION …......................................... 43

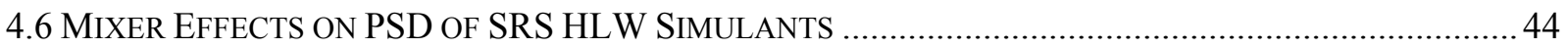

4.7 HYDROCYCLONE FOR DWPF DECONTAMINATION FRIT SEPARATION ........................................... 45

4.8 SCREENING/SIEVING OF HANFORD ION EXCHANGE RESIN............................................................. 47

4.9 SLURRY PUMP MODIFICATIONS PROPOSED BY CURTISS WRIGHT FLOW COMPANY-SMP VENDOR 51

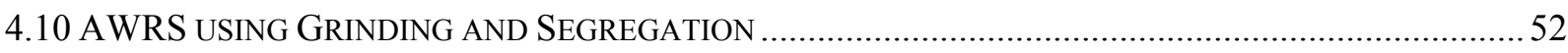

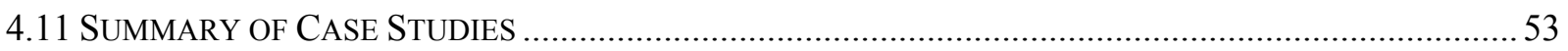

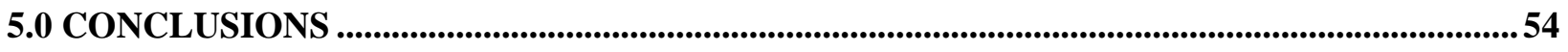

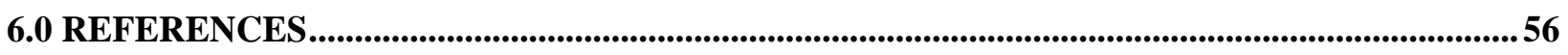

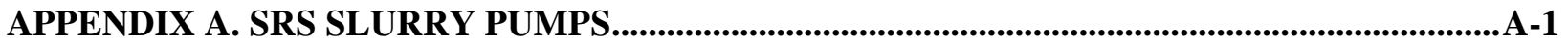

APPENDIX B. SOLIDS-LIQUID SEPARATIONS AT SRS .....................................................

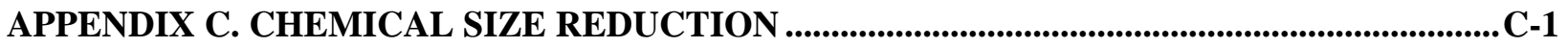

APPENDIX D. ALTERNATIVE SIZE SEGREGATION TECHNOLOGIES ..............................D-1

APPENDIX E. ADDITIONAL DOCUMENTS REVIEWED .........................................................E-1 
SRNL-STI-2013-00472

PNNL-23030

Revision 0

\section{LIST OF TABLES}

Table A- 1. Historical Information for the Use of Slurry Pumps at the $\mathrm{SRS}^{66}$ A-5

Table B- 1. Nuclear Industry Installations of Centrifuge/Decanter Systems ........................................ B-11 


\section{LIST OF FIGURES}

Figure 3-1. Typical Mineral Processing Flowsheet …..................................................................... 9

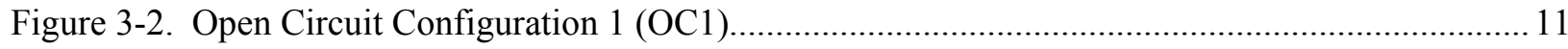

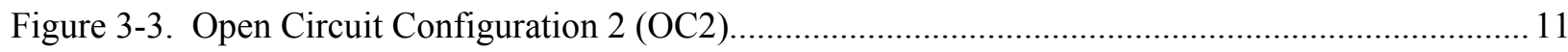

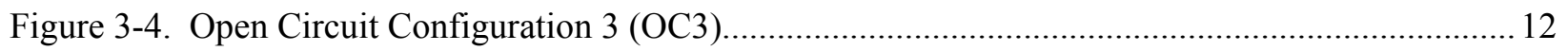

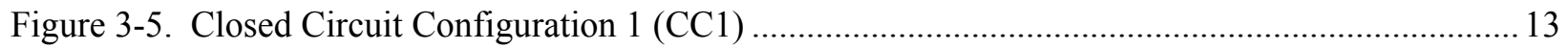

Figure 3-6. Closed Circuit Configuration 2 (CC2) …...................................................................... 14

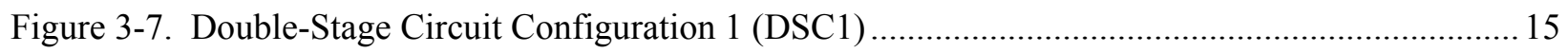

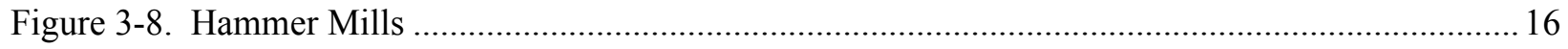

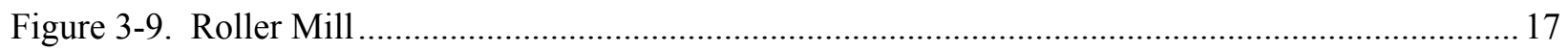

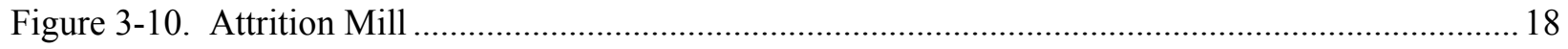

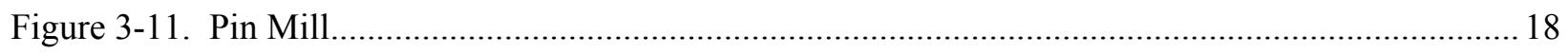

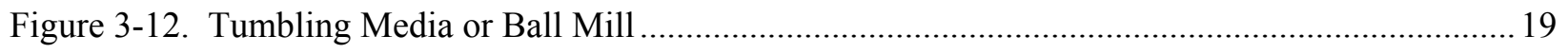

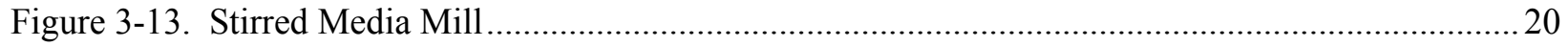

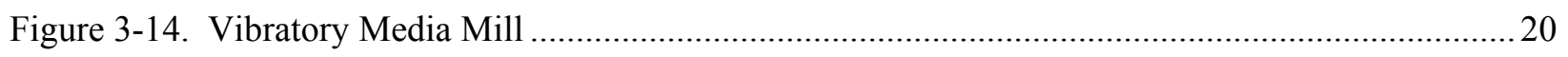

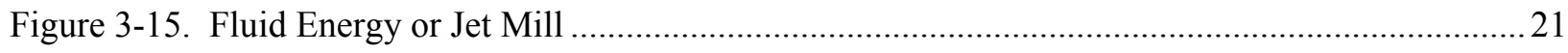

Figure 3-16. Homogenizer or Dispersion Mixer................................................................................ 22

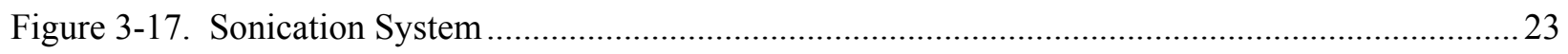

Figure 3-18. Cyclone Operation (a) and Regions of Similar Particle Size (b)...................................... 27

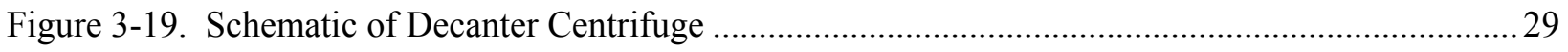

Figure 3-20. Inclined Screen for Processing High Shear Strength Materials ....................................... 31

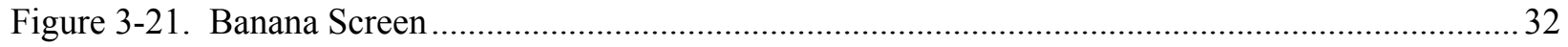

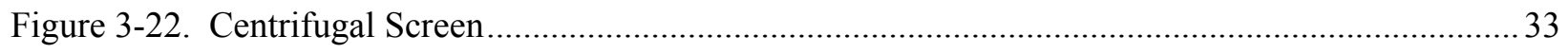

Figure 4-1. SRS Tanks 18 and 19 Installed Grinder System Schematic................................................ 38

Figure 4-2. Hockmeyer Immersion Mill Adapted for In-Tank use ......................................................... 39

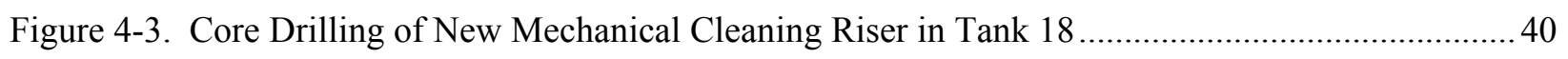

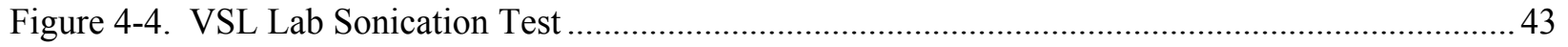

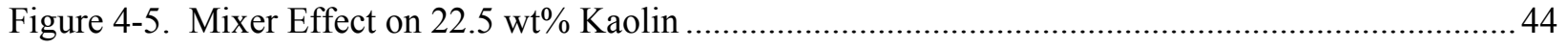


Figure 4-6. PSD Shift after One Hour of High Shear Mixing .......................................................... 45

Figure 4-7. Internal Dimensions of Warman Hydrocyclone Tested ..................................................... 47

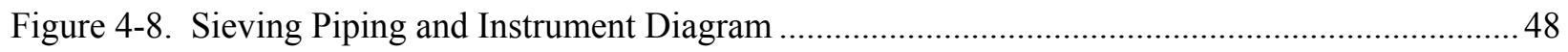

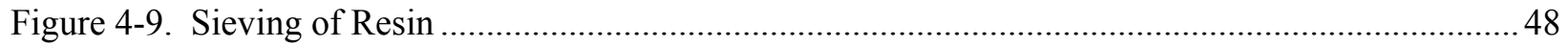

Figure 4-10. Applications of Vibratory Sieve ................................................................................ 50

Figure 4-11. Curtiss Wright Flow Control Company Modified Mixer Pump Model .............................. 51

Figure A - 1. Current SRS Slurry Pump Designs. .............................................................................

Figure A - 2. SRS Tank Farm Slurry Pump Schematic .................................................................... A-3

Figure A - 3. SRS Tank Farm Submersible Mixer Pump. ...................................................................

Figure B - 1. Cross-Flow Filtration Concept …….......................................................................... B-3

Figure B - 2. Principle of Filtration for SpinTek ${ }^{\circledR}$ System............................................................. B-5

Figure B - 3. Diagram of Rotary Filter Principle of Operation............................................................ B-5

Figure B - 4. Cylindrical Element (Candle) Pressure Filter............................................................... B-7

Figure B - 5. Schematic of filter configurations for liquid process system applications ........................ B-8

Figure C - 1. Influence of Caustic Leaching and Washing on the Group $1\left(\mathrm{BiPO}_{4}\right.$ sludge) Waste PSD.. C-4

Figure C - 2. Influence of Caustic Leaching and Washing on the Group $2\left(\mathrm{BiPO}_{4}\right.$ salt cake) Waste Solids

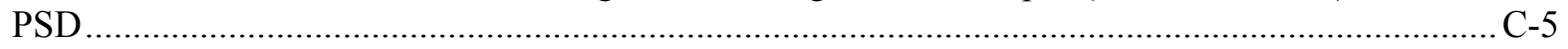

Figure C - 3. Mean Volume Distributions for Sept '08 Pre- and Post-Dissolution Samples.................... C-6

Figure D - 1. Initial Tank Solids Presentation Prior to Testing ......................................................... D-3

Figure D - 2. Final Heel Deposition with Optimized Parameters ....................................................... D-3

Figure D - 3. Six Stage Counter-current Decantation Circuit for SRS Sludge Washing ........................ D-5 


\section{LIST OF ABBREVIATIONS}

\begin{tabular}{|c|c|}
\hline AWRS & Advanced Waste Retrieval System \\
\hline BW & Bingham Willamette slurry pump \\
\hline $\mathrm{CC}$ & Closed circuit \\
\hline $\mathrm{CCD}$ & Counter-current Decantation \\
\hline СPC & Chemical Process Cell \\
\hline CST & Crystalline silicotitanate \\
\hline CUA & Catholic University of America \\
\hline DNFSB & Defense Nuclear Facilities Safety Board \\
\hline DOE & Department of Energy \\
\hline DSC & Double-stage circuit \\
\hline DSTs & Double-Shell Tanks \\
\hline DWPF & Defense Waste Processing Facility \\
\hline EM & Environmental Management \\
\hline ES & Energy Solutions \\
\hline FACTS & Functional and Checkout Testing of Systems \\
\hline FTIR & Fourier transform infrared spectroscopic \\
\hline GP & Goulds Pump \\
\hline HF & Hydrofluoric acid \\
\hline HLW & High-Level Waste \\
\hline HSTP & Hanford Submersible Transfer Pump \\
\hline HTF & Hanford Tank Farms \\
\hline HWFL & Hanford Waste Flow Loop \\
\hline ICD & Interface Control Document \\
\hline IEWO & Inter-Entity Word Order \\
\hline IKA & IKA ${ }^{\circledR}$ Works, Inc.(company name) \\
\hline LAW & Low-Activity Waste \\
\hline LPI & Lawrence Slurry Pump \\
\hline $\mathrm{MCU}$ & Modular Caustic Side Solvent Extraction Unit \\
\hline MFT & Melter Feed Tank \\
\hline MTD & Mass Tool Delivery \\
\hline MWRS & Mechanical Waste Removal System \\
\hline NTU & Nephelemetric Turbidity Units \\
\hline $\mathrm{O} / \mathrm{F}$ & Overflow \\
\hline
\end{tabular}


SRNL-STI-2013-00472

PNNL-23030

Revision 0

\begin{tabular}{|c|c|}
\hline $\mathrm{OC}$ & Open circuit \\
\hline ORP & Office of River Protection \\
\hline PB & Pit Bull Pump \\
\hline PNNL & Pacific Northwest National Laboratory \\
\hline PSD & Particle size distribution \\
\hline PT & Pretreatment Facility \\
\hline PUREX & plutonium-uranium solvent extraction process \\
\hline RAMI & Reliability, Availability, Maintainability, and Inspectability \\
\hline RPP & River Protection Project \\
\hline SCIX & Small Column Ion Exchange \\
\hline SEM & Scanning Electron Microscope \\
\hline SME & Slurry Mix Evaporator \\
\hline SMP & Submersible Mixer Pump \\
\hline SRNL & Savannah River National Laboratory \\
\hline SRR & Savannah River Remediation, LLC \\
\hline SRS & Savannah River Site \\
\hline SSTs & Single-Shell Tanks \\
\hline THOREX & Thorium-uranium solvent extraction process \\
\hline ТP & Transfer Pumps \\
\hline TT\&QAP & Task Technical and Quality Assurance Plan \\
\hline TTJ & Telescoping Transfer Jet \\
\hline TTP & Telescoping Transfer Pump \\
\hline TWRS & Hanford Tank Waste Remediation System \\
\hline $\mathrm{U} / \mathrm{F}$ & Underflow \\
\hline UDS & Undissolved solids \\
\hline VSL & Vitreous State Laboratory of the Catholic University in America \\
\hline VKE & Vibratory-Kinetic Energy \\
\hline WAC & Waste Acceptance Criteria \\
\hline WFD & Waste Feed Delivery \\
\hline WMC & Waste Mixing Chamber \\
\hline WRPS & Washington River Protection Solutions \\
\hline WTP & Hanford Tank Waste Treatment and Immobilization Plant \\
\hline WVDP & West Valley Demonstration Project \\
\hline WVNS & West Valley Nuclear Services \\
\hline
\end{tabular}


SRNL-STI-2013-00472

PNNL-23030

Revision 0

\subsection{Introduction/Background}

\subsection{Introduction}

The safe removal and treatment of weapons production legacy nuclear wastes from underground storage tanks is a high priority activity at the U.S. Department of Energy (DOE) Hanford Site. Timely waste treatment is needed to avoid further contamination of the subsurface environment and it is a critical step in the site remediation and closure process. Currently there are approximately 56 million gallons of waste generated from past defense nuclear processing and waste management operations stored in 177 underground tanks at the Hanford Site. These storage tanks are comprised of 149 single-shell tanks (SSTs) and 28 double-shell tanks (DSTs). Until recently, the only known tanks to have leaks were the SSTs; however, one of the waste feed delivery (WFD) DSTs, AY-102, has now been determined to have a leak in the inner shell. This has placed greater urgency on removing and treating the tank waste for environmentally compliant disposal.

The baseline method used for retrieving high-level waste (HLW) from the Hanford waste tanks includes jet mixer pumps (for tank-to-tank or tank to process transfers) and sluicing (for SST retrieval) to mobilize waste material. Once mobilized, waste is kept in suspension with the jet mixer pumps and then removed from the tank using centrifugal transfer pumps.

Based on characterization of core samples that have been taken from the Hanford tanks, concerns have been raised that some waste slurry particles may not be able to be readily processed within the Hanford Tank Waste Treatment and Immobilization Plant (WTP) mixing and transfer systems ${ }^{1,2,3}$ and whether the Hanford Tank Farms (HTF) WFD system has the potential to transfer the existing waste slurry particles to the WTP. ${ }^{4}$ Some of the larger or higher density sludge particles will be difficult to process through the WTP Pretreatment Facility (PT) unit operations (e.g., mixing tanks, pumps, pipeline transport, sampling loops, etc.) and/or could potentially build up in the PT, cause plugging, criticality issues, accelerate erosion, and/or hinder mixing and sampling.

Any sludge particles that are mobilized by mixing are pumped and transported via the HTF WFD system to the WTP and are assumed to progress through the PT unit operations without size changes since intentional size reduction is not part of the current waste retrieval and processing flowsheets. Solid particles are filtered from the liquid fraction, washed and leached as needed, and then are pumped to the HLW vitrification facility and converted into borosilicate glass. To avoid any potential complications from the larger or higher density particles, the DOE Office of River Protection (ORP) is investigating the feasibility of separating and/or size reducing these particles from the bulk of the waste slurry being transported from the HTF before they are transferred to the WTP PT. Segregated wastes could then be processed via additional processing systems to an acceptable form that would be inserted into the current WTP process stream. Conditioning the waste slurry particles could involve separation via classification and/or particle size reduction.

To address technical issues involved in WTP feed from HTF, the DOE Office of Environmental Management (EM) has tasked the Savannah River National Laboratory (SRNL) and the Pacific Northwest National Laboratory (PNNL) to jointly address technology gaps involving the Waste Feed Acceptance and Product Qualification aspects of the WTP feed. To commission and empower both laboratories to address these technical concerns, two Inter-Entity Work Orders (IEWO) were generated that detail the requirements and deliverables for this collaboration. ${ }^{5,6}$ As described in these IEWOs, SRNL and PNNL were tasked with delivering a report documenting the reviews performed to address and 
overcome the technology gaps identified in the Hanford feed to WTP. A Task Technical \& Quality Assurance Plan (TT\&QAP) ${ }^{7}$ was developed by SRNL to document the technical and quality related requirements necessary for the laboratories to collaborate in a technical exchange of ideas and process knowledge to minimize those identified risks associated with WTF feed to WTP. Section 4.0-B of the SRNL TT\&QAP specifies the deliverables associated with the SRNL IEWO, and includes the requirements for the review of both nuclear and commercial technologies in achieving appropriate size reduction and solids segregation necessary to minimize those identified risks.

\subsection{Purpose}

This document has been developed to identify and evaluate potential solutions for addressing WTP limitations associated with processing Hanford slurry particles. Sludge particles with challenging combinations of size and density can exceed slurry mobilization, mixing, and transport limits within the WTP PT, build up in the PT, and potentially cause operational issues. DOE ORP has tasked the national laboratory team with investigating the feasibility of adding subsequent waste conditioning for solids segregation and size reducing the challenging solids ${ }^{i}$ constituents of the Hanford waste from the bulk of the waste slurry being transported from the HTF to the WTP. The results of the effort will be used by ORP to make cogent decisions on technologies that should be considered, developed, and tested for processing of the Hanford nuclear waste sludge to meet WTP feed acceptance criteria. This decision should be made with consideration of the current framework for treating Hanford wastes, including considerations for impact on the overall WTP throughput.

\section{$1.3 \underline{\text { Scope }}$}

To meet the objectives, this effort utilized literature searches within the mineral, mining, and nuclear waste processing industry and the experience of the labs associated with defense waste processing and supporting system development, design, and testing. The review of nuclear applications for slurry solids segregation and size reduction focused on those within the DOE complex. The known Hanford waste properties presented are those pertinent to slurry solids segregation and size reduction, which include solids loading, solid particle size and density, solid particle hardness, solid morphology and waste rheology. Solids segregation includes both segregation of solids from a slurry supernatant and segregation of solids into different sizes.

Components associated with a subsequent waste conditioning system that were reviewed included slurry pumps, classifiers, and comminution technologies. Integration of components into slurry particle segregation and size reduction systems included open and closed circuit grinder/classifier systems that utilize mechanical and chemical size reduction methods. Components reviewed included those relevant to slurry particle segregation (particles segregated based upon their settling velocity through a viscous fluid), size reduction (segregated particles are size reduced to target properties and then reinserted back into waste stream, i.e., no orphan streams), and solids separations.

Guidance for evaluating and identifying potential options for a subsequent waste conditioning system included impacts on waste stream properties; integration with existing equipment, processes, and facilities; process control; life cycle and reliability of equipment; and nuclear safety and containment. Promising technologies were identified based on this high level review and the understanding that waste

${ }^{\mathrm{i}}$ Throughout this report the term solids refers only to undissolved solids in a slurry. 
feed criteria are still being refined and need to be addressed before a Hanford solution can be developed and finalized.

A critical input in determining technologies for appropriately conditioning waste streams for further downstream processing is the actual properties of the feed and the requirements of downstream operations. The technologies evaluated were consequently governed by flexible requirements, as future changes/determinations in feed characteristics and/or conditioning requirements may have significant impacts on these current evaluations.

\section{$1.4 \underline{\text { Objectives }}$}

The main objective of this document is to assess identified technologies for slurry particle segregation, size reduction, and solids separations that have potential application to resolving the issues associated with the potential disconnect between the current waste slurry and the WTP PT acceptance and operating limits. The document is to provide DOE ORP information to assess options for obtaining slurry solids segregation and size reduction for the Hanford waste to meet WTP PT waste acceptance criteria. The specific information to be provided within this document includes:

- A definition of the problem associated with the Hanford waste and WTP acceptance and operating limits that includes the waste properties that are specific to slurry solids segregation and size reduction.

- Identification of the current technologies available (both individual components and integrated systems) to accomplish slurry solids segregation and size reduction with the potential to satisfy the target waste feed envelope.

- A review of past applications of slurry solids segregation and size reduction within the nuclear industry to obtain knowledge of systems that may be successfully deployed and lessons learned from past operations.

- Guidance to be used for developing system and operational requirements, methodology, and process design for slurry solids segregation and size reduction. This guidance is to also aid with decision-making and down-selection processes associated with any subsequent Hanford waste conditioning system.

- Slurry solids segregation and size reduction system concepts recommended for further evaluation to achieve a final integrated Hanford waste conditioning system.

- Identified advantages/disadvantages for each technology and the research and development needs prior to implementation for Hanford.

Additional information is provided on technologies that have been considered or are currently in use for solid/liquid separation of Savannah River Site (SRS) HLW. These technologies have been successful in mitigating solids mixing, transfer, plugging, and corrosion problems in the Defense Waste Processing Facility (DWPF) ${ }^{\text {ii }}$, as shown in Appendix B. They may have applicability to Hanford should decisions be made to by-pass the PT Facility and to feed directly to either the Low Activity Waste (LAW) or HLW facilities. In addition, a listing of documents reviewed but not used as references in this document is shown in Appendix E.

ii The DWPF Waste Acceptance Criteria limits the new product feed stream particle size to 177 microns. This control was implemented based on mixing and erosion studies, sampling, and experience as described in Section 4.4. 
SRNL-STI-2013-00472

PNNL-23030

Revision 0

\subsection{Background}

\subsection{Description of Hanford Waste}

The waste at Hanford is comprised of liquid and solids phases. Precipitated salts are prevalent in the waste and make up a large fraction of the total solids in the waste slurries. The soluble salts are expected to be dissolved during sludge retrieval; therefore the "sludge" portion (i.e. undissolved solids) is considered applicable for this task. ${ }^{8}$ A review of the WFD system concluded that the WFD can transfer the existing sludge waste material to the WTP. ${ }^{4}$ It is noted that the liquid and solid phase characteristics of Hanford sludge waste have significant variability, ${ }^{9}$ and characterization of the wastes is limited, especially for samples that will be retrieved and mixed in the manner that is anticipated for WTP operations. A summary of the waste properties with significance to solid segregation and size reduction based on the material processing industry that are applicable to Hanford waste include the following:

- Undissolved solids loading;

- Liquid density and rheology;

- Solid particle size, density and morphology;

- Solid particle hardness; and

- Slurry rheology.

\subsubsection{Undissolved Solids Loading}

The undissolved solids loading for Hanford waste tanks varies significantly by tank. In addition, the undissolved solids loading will be dependent on the retrieval methods utilized and the point in the process that size reduction or size segregation is performed. The feed streams for the size reduction/segregation system are expected to contain less than 20 weight percent undissolved solids. ${ }^{4}$

\subsubsection{Liquid Density and Rheology}

Based on available data, the density of the liquid phase is expected to range from 1.0 to 1.5 grams per milliliter, while liquid (supernate) viscosity is expected to be less than $15 \mathrm{cP}{ }^{4}$

\subsubsection{Solid Particle Size, Density and Morphology}

\section{$\underline{\text { Particle Size and Density }}$}

Measurement of the particle size of Hanford tank waste has been performed on a number of core samples from the tanks. Particle sizes greater than 1,000 microns have been observed. Determination of particle density is very challenging; consequently, values for particle density are based on crystalline density of pure compounds determined to be in the waste based on modeling and engineering judgment. Crystalline densities as high as $19 \mathrm{~g} / \mathrm{ml}$ were estimated for selected particles, while agglomerates of gibbsite had a particle density of $1.43 \mathrm{~g} / \mathrm{ml}^{4}$

The actual tank waste will have a wide range of particle sizes and densities. The particle size may be impacted by the retrieval of the waste while the particle densities may not be well represented by the densities of pure crystalline materials. The size reduction/segregation equipment must have sufficient operating flexibility to handle a wide range of initial conditions based on anticipated variation of the properties from tank to tank at Hanford. 
The Interface Control Document (ICD) for Waste Feed (ICD-19, Revision 5) ${ }^{10}$, specified a mean size particle $\leq 11 \mu \mathrm{m}$, but did not specify a maximum particle size. Several of the waste acceptance criteria are still being refined, and in Revision 6 of ICD-19 that was just recently issued ${ }^{11}$, a limit for a maximum particle size was added for HLW, which was still to be determined, and the limit for HLW and LAW feed was changed to a median particle size $\leq 11$ microns. A draft maximum particle size of 310 microns is under review for inclusion in ICP-19, Revision 6 for HLW feed to the PT facility and is the basis for this review. ${ }^{\text {ii }}$

\section{Morphology}

The morphology of the sludge particles is not well specified. Given that the sludge is a mixture of a large number of different minerals, a wide variety of particle shapes and structures is expected. As stated above, the size reduction and segregation system would need to have a significant amount of operational flexibility to be able to handle a wide range of initial conditions.

\subsubsection{Solid Particle Hardness}

Wells ${ }^{12}$ provides a list of sludge waste compounds and hardness values selected to represent anticipated Hanford compounds (as determined from the literature). The particle hardness range of the species selected to represent the sludge was 3 to 8 Mohs. As with the density values, these hardness values represent the solid-phase compound crystal or primary particles; consequently, they do not take into account agglomeration, and they may not be representative of the hardness of actual sludge waste solids. It should be noted that in a system as complex as HLW sludge, the hardness of individual species (particularly components that represent a small fraction of the waste) likely do not govern the size reduction process. The most prevalent undissolved solids phase in Hanford tank sludge waste is gibbsite, with an assumed hardness of 3.5 Mohs.

\subsubsection{Slurry Rheology}

Hanford slurries with sufficient undissolved solids loading can be characterized rheologically as nonNewtonian, that predominately behave as Bingham plastic fluids. The data indicates that slurries with approximately $10 \mathrm{wt} \%$ solids can have Bingham yield stress values of less than $1 \mathrm{~Pa}$ to greater than 10 $\mathrm{Pa}^{4}$ However, these measurements were taken from core samples materials, so they may not be representative of waste that has gone through the retrieval process. As with other processing parameters, the ability to handle a range of initial conditions will be necessary for any equipment selected to perform size reduction and segregation processes.

iii 24590-WTP-ICD-ENG-13-0001, "ICD-19 Interface Change Form”, draft, has been approved by Washington River Protection Solutions (WRPS) and WTP but is currently with ORP for approval. 
SRNL-STI-2013-00472

PNNL-23030

Revision 0

\subsection{Associated Technical Issues}

The size reduction and size segregation processes must be able to achieve the particle size required while minimizing impacts to the waste feed delivery and WTP. These impacts could include:

- Changes in waste stream properties that can impact existing downstream processes;

- Integration with existing equipment, processes, and facilities;

- Process control; and

- Life cycle and reliability of equipment.

A summary discussion for each of these issues follows and is intended to provide an initial set of items to consider when reviewing past efforts and identifying potential options.

\subsubsection{Changes in Waste Stream Properties}

\section{$\underline{\text { Rheological Properties }}$}

Changes in the rheological properties of the waste feed are expected to be the most significant impact from any size reduction process, particularly if the process generates a large number of fines during the size reduction, with an increase in yield stress and plastic viscosity (consistency) expected. The increased yield stress could result in feed that exceeds the WTP limits for receipt. ICD-19, ${ }^{10,11}$ places an upper limit of $1 \mathrm{~Pa}$ and $10 \mathrm{cP}$ for the Bingham yield stress and consistency, respectively, for HLW delivered to the WTP.

The extent of the impact on rheological properties will be a function of the final particle size targeted compared to the particle size of the waste feed. The minimization of fines will reduce the impact of the size reduction on yield stress and should be considered a key characteristic of the size reduction process specified.

\section{Settling Rates / Critical Velocity}

A decrease in overall sludge settling rates and critical velocities will likely be observed as the particle size decreases. As with rheology, this impact will be related to the amount of size reduction required and the number of fines produced. A decreased settling rate is one of the primary goals of the size reduction process as fast settling of large solids is the primary driver for eliminating these particles.

\section{Filtration Rates}

The filtration rates of wastes slurries is a function of particle size. As the particles size is reduced, a decrease in filtration rate should be expected. As with rheology, the impact will be related to the amount of size reduction required and the number of fines produced.

\section{Temperature Impacts}

Size reduction processes can result in an increase in slurry temperature, which can impact the chemistry of the system (e.g. dissolve material into solution that can precipitate downstream as the process stream cools). These impacts can be mitigated by incorporating cooling into the size reduction process as needed. 


\section{Abrasion}

The creation of fines increases migration of particulate matter into the tight clearances between moving surfaces and increases abrasive wear.

\section{Mitigation of Downstream Impacts}

The production of fines during size reduction processes is an important consideration as the production of a large number of fines is expected to significantly increase the downstream impacts from the size reduction process. A primary goal of the size reduction process should be to achieve the particle size required for WTP acceptance of the feed while minimizing fines formation.

As discussed above, the particle size limits for waste feed acceptance are still under review. Significant changes to this requirement will have large impacts on the appropriate processing technologies. As such, flexibility in the addressed technologies was a major driving factor. This clarification would provide greater definition on the appropriate technologies to be implemented in pre-conditioning of the waste prior to transfer and processing.

\subsubsection{Integration with Existing Equipment, Processes, and Facilities}

The integration of any size reduction/segregation process with the existing facilities is dependent on where these processes are applied in the WFD system. At a high level, the WFD consists of the waste tank and associated retrieval equipment, the transfer line, and receipt to the WTP. In addition, the tank farms baseline planning includes a Hanford Waste Flow Loop (HWFL) (previously referred to as the "certification test loop") that will be integrated with the WFD and allow real-time measurement of some of the waste feed properties while waste is being circulated through the transfer piping and back to the original source tank. ${ }^{13}$ The specified retrieval/transfer pump ${ }^{14,15}$ is deployed through the tank riser and pump pit and provides flow to the HWFL and to cross-site transfer line. The tank farm baseline calls for the system to have the capability to route waste to the HWFL for characterization and return the characterized flow stream back to the waste tank.

An initial consideration for defining system requirements is whether size reduction is to be performed internal or external to a waste tank. Size reduction within the vessel requires all of the waste be processed for size reduction as opposed to an external system that includes separations processes, which would reduce the amount of solids to be processed for size reduction. For internal processing, the current structure must support the weight of the equipment or excess loads would need to be transferred beyond the vessel perimeter.

If size reduction is performed external to the waste tank, then the HWFL can be plumbed to evaluate waste both prior to or following size reduction. Size reduction equipment could be considered for skid mounted and used for multiple waste tank applications.

\subsubsection{Process Control}

The implementation of a size reduction system requires selection of the metrics to define the system performance and identification of instrumentation that can be used to provide process control for the system. In addition, identification of the sampling protocol and analytical data needed should be considered in the system design for metrics that cannot be performed online. 
Parameters associated with control of size reduction operations include:

- Particle size and size distribution of feed and product streams; and

- Specific operating parameters of size reduction equipment (e.g., rotational speed, operating frequency, recirculation load, retention time, operating/feed pressures and temperatures, feed rate, power consumption ${ }^{\text {iv }}$ ).

The operating tolerance associated with the process needs to be defined and understood and includes both the variation of input conditions to be accommodated and the requirements associated with the product (output) stream. Evaluation considered technologies designed to handle a wide range (large magnitude) of input variability; these systems often have a greater amount of excess capacity and robustness incorporated into the design. A rapidly changing feed is not anticipated within a campaign, but could occur if the feed to the sizing equipment is significantly inhomogeneous within the campaign. Variation is also anticipated between the different campaigns. Although the technologies may be sufficient to handle rapidly changing feed conditions, more sophisticated control schemes may be required. In addition, tightening the tolerances for the acceptability of the product requires greater control be built into the system.

\subsection{Criteria for Technology Evaluation}

The following criteria were used to consider appropriate technologies for size reduction and segregation of the sludge waste prior to processing in WTP:

- Adaptability of technology to a radioactive environment;

o History of use in radioactive service

o Long term maintenance issues

- Equipment size limits dictated by Hanford tank geometries and tank dome loading considerations, or the loading limitations and geometry of the proposed Tank Waste Characterization and Staging Facility;

- Ability to achieve size reduction needed.

o Minimization of downstream impacts

o Flexibility of technology to accommodate changes in feed characteristics (variation of waste from tank to tank)

o Maturation of proposed technologies

\footnotetext{
${ }^{\text {iv }}$ A number of correlations exist to compare power consumption to size reduction: Bond's law ${ }^{16}$, Holmes law ${ }^{17}$, Rittinger's law ${ }^{18}$, and Kick's Law ${ }^{19,20}$. Whether these correlations would prove useful for control of the size reduction of Hanford waste feed would require testing.
} 


\subsection{Mineral Industry Practices and Equipment}

The mining and mineral processing industries practices have been reviewed for applicability to the Hanford Tank Wastes. A good summary of mineral and slurry processing technologies can be found in Wills' Mineral Processing Technology ${ }^{21}$, the Slurry Systems Handbook ${ }^{22}$, and the Unit Operations in Chemical Engineering ${ }^{23}$. This section summarizes a review of the mechanical means of size reduction; a review of chemical processes is in Appendix C.

In the mineral industry, size reduction and solids segregation is rarely performed independently. The initial mining operations often provide a feed stream that contains large boulders as well as smaller rocks. Initial screening of dry feed separates the large boulders from the smaller pieces, then the large boulders are fed to crushers. Dry screening and size reduction by crushing continues until the feed is reduced to approximately $1 / 4$ " to $1 / 2$ " in diameter. Further size reduction is typically performed in wet mills and is commonly called grinding to distinguish from the large scale crushing operations.

Throughout the process, segregation is performed to both reduce the amount of material fed to the crushers and grinders as well as to prevent overgrinding of the material. A simplified size reduction system used in the mineral industry is shown in Figure 3-1, most systems will have multiple crushing steps and some use separate screening systems for the crushed material. Other types of classifiers can be used after grinding, but hydrocyclones are becoming the dominant technology. Given the current state of the Hanford waste, crushing operations are not necessary and only grinding operations will be discussed in detail.

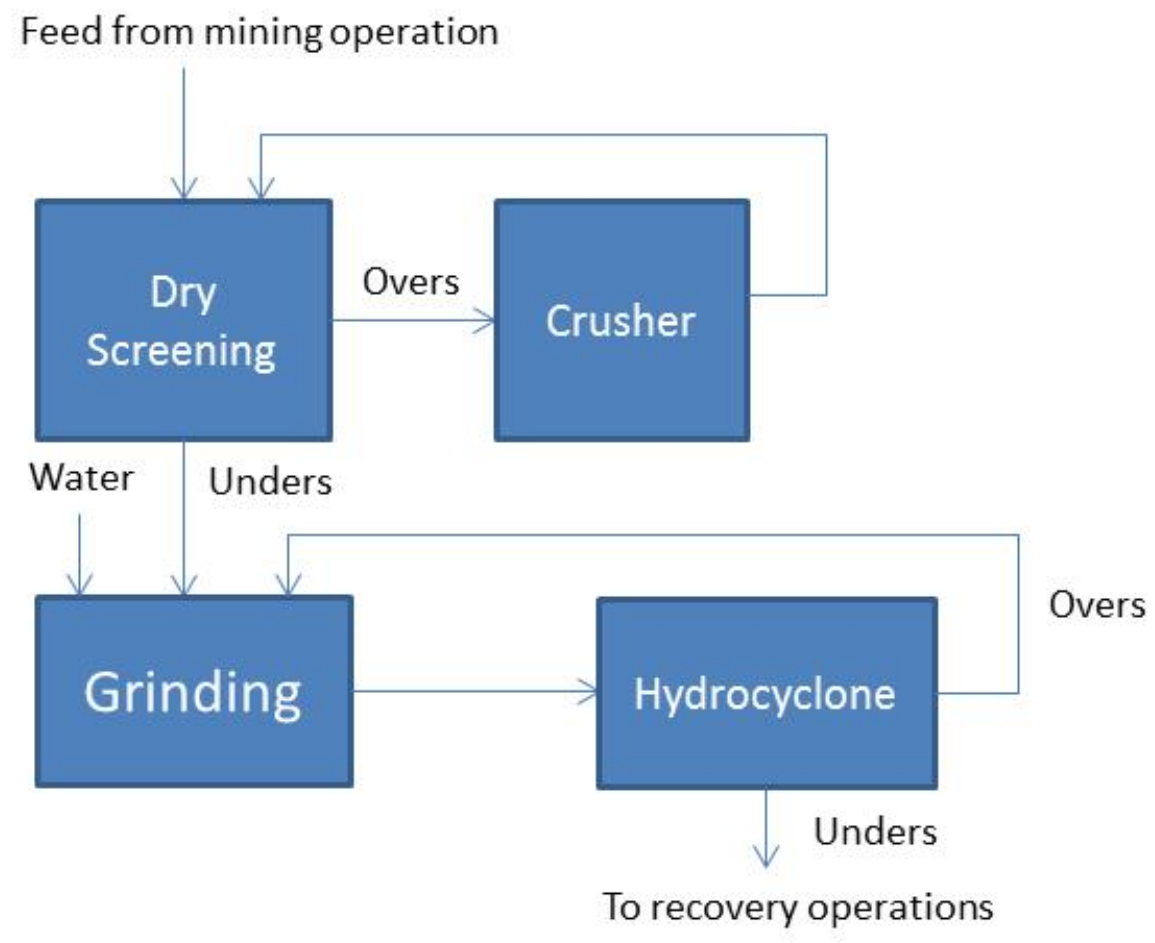

Figure 3-1. Typical Mineral Processing Flowsheet 


\subsection{Particle Size Reduction/Segregation Systems}

Industrial grinding of particles may be done either dry or wet. Wet grinding is the most common in mineral processing, has been the process used in past nuclear waste processing schemes (see sections below), and would most likely be the case for grinding Hanford waste slurry particles. Advantages of wet grinding for Hanford waste slurries include: a) readily adaptable to current slurry retrieval and transport processes; b) no dust generation problems in radioactive, remote environment; c) ability for wet classifiers to be used (e.g., hydrocyclones), and wet mill operations are able to handle higher capacity per unit volumes; and d) ability for use of standard waste slurry handling methods such as pumps, valves, and pipes for transport. The nature of the stored nuclear waste is wet, so dry grinding will not be discussed.

As described above, size reduction and solids classification are rarely performed independently. The combination of size reduction and classification is commonly referred to as the grinding circuit. Two types of circuit designs are used, either an open (OC) or closed circuit (CC). In an OC, the feed stream has a once-through pass of material that gives little control of particle size distribution, and feed rate is usually lower to ensure sufficient particle size reduction. This often produces overground particles, which may produce rheological properties that are difficult to handle. In a closed circuit, the feed stream particles of the proper size/density are removed by appropriate classifiers and fed forward into the process while oversize/density particles are returned to the milling, grinding unit operations. Therefore, there is no need to complete the necessary particle size/density reduction in a single pass, which has shown to increase the capacity of closed circuits by $35 \%{ }^{21}$ and over ground particles are minimized.

Open and closed circuit grinder/classifier systems may also be combined into a double-stage circuit (DSC). An example would be a rod mill for coarse grinding in an open circuit, which passes the ground/process slurry stream to a closed circuit containing a ball mill and classifier whereby the classifier underflow ("recirculation load") is cycled back to the ball mill and the output of the ball mill is again fed back to the classifier; the overflow of the classifier is fed forward into the process.

The following discussion provides a high level overview of potential mechanical configurations that can be employed for size reduction and segregation. The summary of the concepts will address advantages, disadvantages, impact on control/monitoring, and potential issues associated with application to Hanford waste. This summary will also address configurations referring to general components such as separators/classifiers, grinders, and pumps and will not attempt to detail specific models.

\subsubsection{Open Circuit Configurations}

Open circuits consist of a single pass of the feed stream through the process and therefore, material will not be subjected to processing by a component more than once. In more complex open circuit systems a fraction of the feed stream may be segregated and bypass some components. Branching of the circuit allows separation to occur based on process criteria and reduces the load on downstream components.

The simplest open-circuit concept is a one-component system such as some form of grinder pump, which is depicted by Figure 3-2 as OC1. The grinder pump consists of pumping components designed to impart energy to the material for size reduction or the pump shaft also powers a coupled size reducer that is integrated into the inlet portion of the pump. The open-circuit concept of OC2, depicted in Figure 3-3, which contains both a pump and a grinder, is the same as $\mathrm{OC} 1$ except the two components have defined roles that do not overlap. This is the form of the reduction circuits evaluated for Hanford K-Basin ${ }^{24}$ and West Valley Demonstration Project (WVDP) ${ }^{25}$ that are discussed in Section 4.0. 
SRNL-STI-2013-00472

PNNL-23030

Revision 0

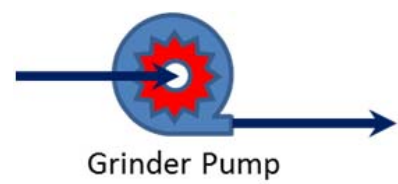

Figure 3-2. Open Circuit Configuration 1 (OC1)

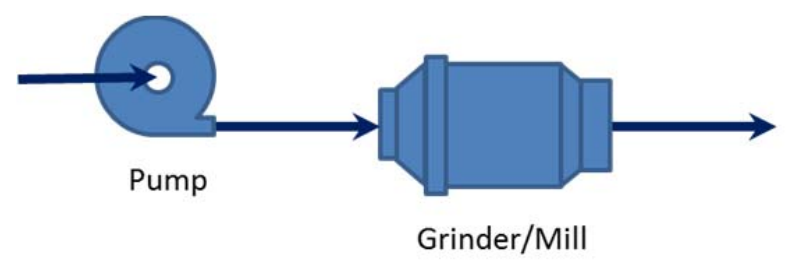

Figure 3-3. Open Circuit Configuration 2 (OC2)

Open circuit systems are applicable for systems that require small size reduction ratios and have large tolerances on the particle size distribution (PSD) of the output stream. These concepts lend themselves to selecting/designing components that can be installed within the waste vessels.

Advantages of open circuit concepts compared to closed circuit ones include:

- Equipment costs are less expensive;

- Integration and retrofitting into existing systems is simplified; and

- Process control requirements are minimized and less complex than close circuit options.

Disadvantages associated with open circuit systems include:

- Systems are operationally inefficient for size reduction accomplished per energy input;

- Entire feed stream is processed, which can result in excess fines or broadening of total PSD;

- System can reduce but not eliminate amount of larger size particles as oversized particles are still allowed to pass through system; and

- Limited control over PSD of output stream with size variations trending with variations in the feed stream.

The disadvantages associated with the open circuit system can be addressed with added components and complexity. The addition of separator(s) allow for branching of the closed loop system. The basic concept is presented as OC3 in Figure 3-4, in which the feed stream initially passes through a classifier/separator, e.g., hydrocyclone. The overflow $(\mathrm{O} / \mathrm{F})$ stream, which meets process requirements, bypasses the size reduction process and is often referred to as the scalped feed. The underflow (U/F) stream from a separator is directed through size reduction equipment the same as either OC1 or OC2. Assuming a single process stream exists (as opposed to a segregation/split feed process), a second booster pump will be required for the flow paths to be merged. The scalped feed improves efficiency by reducing the load on the size reduction equipment and reduces the impact on the lower end of the PSD (i.e. overgrinding, excess fines). A similar concept was evaluated and tested as part of the Advanced Waste Retrieval System (AWRS) at the WVDP. ${ }^{24}$ 
SRNL-STI-2013-00472

PNNL-23030

Revision 0

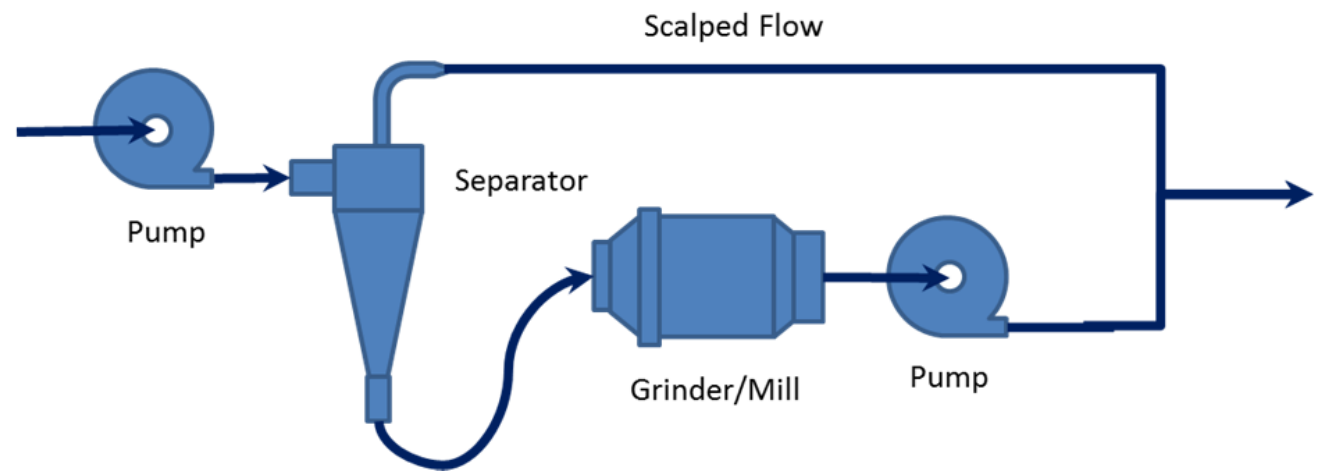

Figure 3-4. Open Circuit Configuration 3 (OC3)

From the basic concepts of OC1, OC2, and OC3, additional concepts can be formulated. The added complexity can be grouped into:

- Size reduction (e.g., grinders/mills) equipment being placed in series to refine the PSD of the output stream and reduce the occurrence of oversized particles. For such designs, the selection of the size reduction equipment is often selected to handle incremental shifts in the size reduction process (i.e., coarse to medium, medium to fine, fine to ultra-fine).

- Additional separators to allow acceptable U/F streams to be pulled from the reduction sequence to reduce over grinding and increase operating efficiency by reducing the load/required capacity of downstream size reduction equipment.

These additional features will increase control capability for an open loop system but can tend to be a "sledge hammer" approach that can increase equipment costs over those for closed-circuit options. Such measures are more often taken when retrofitting existing systems that need to accommodate a change in operating conditions or to take advantage of existing equipment with excess capacity.

While increases in the number of stages for size reduction will reduce the potential for oversize particles, the complete elimination requires some form of screening, filtering or final separation that sends the oversized material to a diverted material stream that is recycled back to the grinding process.

\subsubsection{Closed Circuit Configurations}

Closed circuit systems consist of some form of size classifier that re-circulates oversized material back through the size reduction equipment for further processing. The simplest of closed circuits would be the addition of a separator downstream of OC1 or OC2 that diverts oversized material back to a source tank. Re-circulation of the material back through the size reduction process would be dependent on the mixing, mobilization, and entrainment of the in-tank system and could result in large residence times for recirculated material, which could result in a change in the relative concentration of larger size material (or specific constituents) in the feed stream.

Advantages of closed circuit systems include:

- Minimizes/eliminates over grinding of material by removing fines upstream of size reduction processes;

- Mitigates oversized particles in the final output stream;

- Increases process capacity and operational efficiency relative to energy input;

- Can accommodate significantly tighter tolerances on PSD of final output stream; 
- Changes in input feed stream have reduced impact on properties of output stream; and

- Increase in system control allows for greater flexibility in accommodating variances in feed stream or application to different feed streams.

Disadvantages of closed circuits include:

- Increased complexity in design and control systems;

- Additional systems required may have significant impact on existing systems, i.e. heat loading from additional equipment, etc;

- Potentially increased equipment costs depending on throughput requirements;

- Inclusion of a separation process increases the need for understanding the feed stream; and

- Often requires greater design effort and system modifications for retrofitting existing processes.

The basic concept of a closed circuit is the single loop presented in Figure 3-5 as CC1. The O/F from the downstream separator provides an output stream that meets process requirements and the U/F recirculates through the size reduction equipment (i.e., could include a set of grinders in series) with a circulating load that is greater than the feed stream. CC1 results in all material making at least one pass through the size reduction process. Similar concepts were evaluated for application at SRS for the Small Column Ion Exchange (SCIX) project. $^{26,27}$ An upstream separator can be added to produce a scalped stream that is merged with the output flow downstream of the size reduction process, which is depicted in Figure 3-6 as CC2.

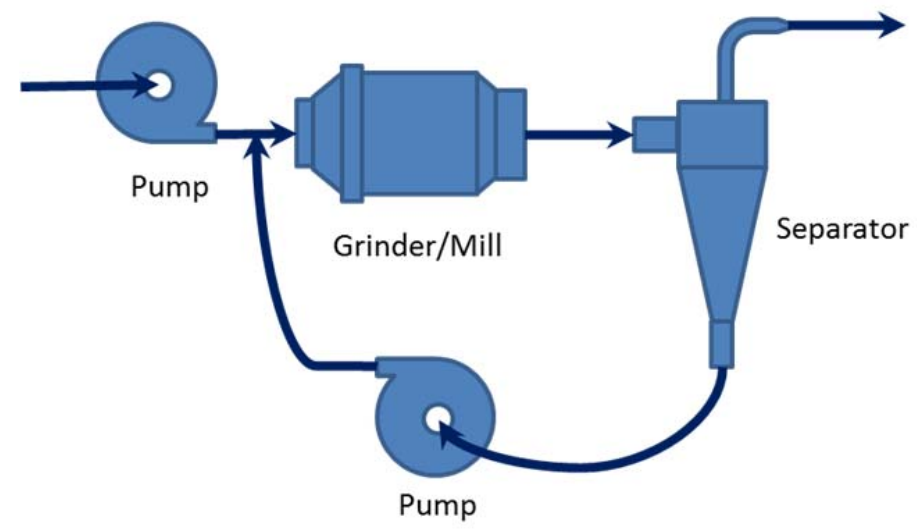

Figure 3-5. Closed Circuit Configuration 1 (CC1) 
SRNL-STI-2013-00472

PNNL-23030

Revision 0

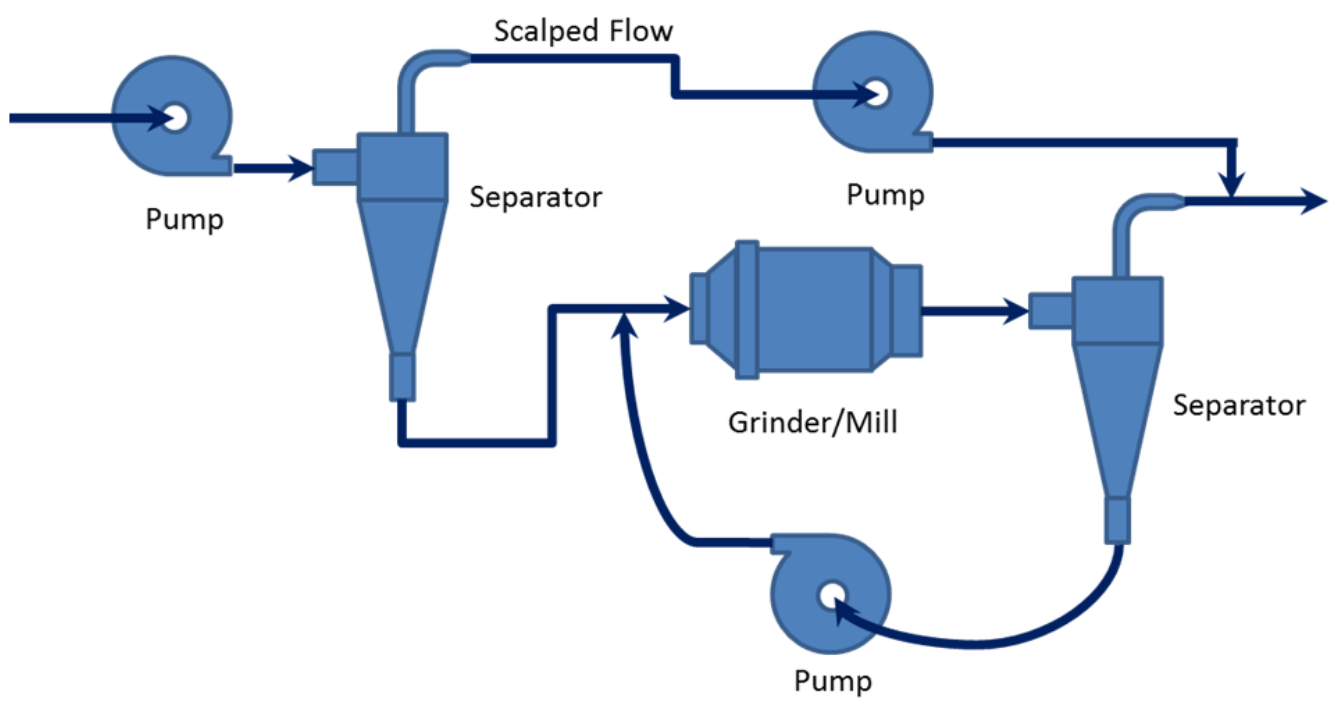

Figure 3-6. Closed Circuit Configuration 2 (CC2)

Closed loop circuits allow a great deal of flexibility in potential configurations that can be used to reduce equipment cost, improve operating efficiency, refine final PSD, and reduce variation in output stream. Capacity requirements and costs associated with processing a small fraction of the feed stream can be accommodated by segregating material and running it through a parallel closed circuit. Increased system control and refinement of output stream properties can be accomplished by nesting closed circuit loops.

\subsubsection{Double-Stage Circuit}

The combination of open loop and closed loop flow circuits is referred to as a double-stage circuit. The concepts for double-stage circuits consist of continual processes and intermittent/batch double-stage applications. A typical double-stage circuit configured for continual operation is presented in Figure 3-7 as DSC1. The open circuit is applied upstream of the closed circuit and allows an initial size reduction of the entire feed stream prior to any segregation and re-circulation of the flow stream. This configuration has become more popular as the relative cost of high throughput grinders has decreased. Such configurations are applied to feed streams that have wide size distributions and/or contain significant coarse material. A variation on the DSC1 is the application of OC3 upstream of the closed circuit. This is unnecessary for most applications, because the size reduction applied by the open circuit grinder is for coarse material and has minimal effect on fines. 
SRNL-STI-2013-00472

PNNL-23030

Revision 0

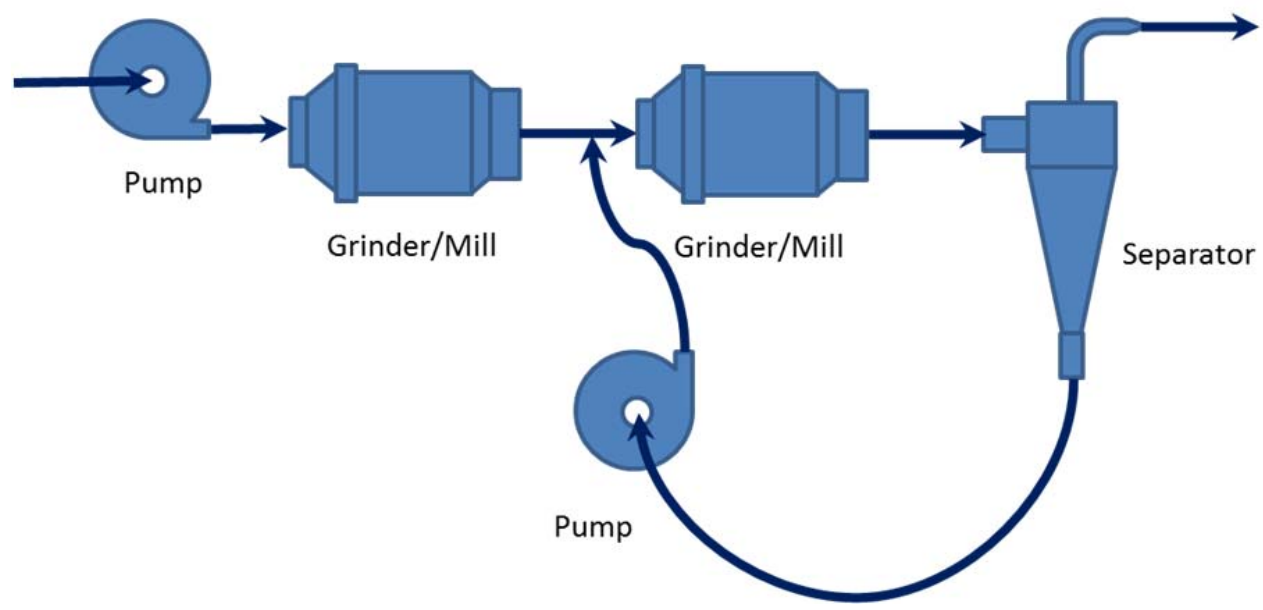

Figure 3-7. Double-Stage Circuit Configuration 1 (DSC1)

A batch/intermittent DSC configuration consists of operating an OC with the output diverted back to the feed vessel, to create a CC, until acceptable properties for transfer are achieved. The system is then operated as an OC or a secondary pump performs the transfer. OC1 or OC3, with the application of valving could be configured to operate as a batch/intermittent DSC. The application of an intermittent DSC to a waste tank could be coupled with the HWFL for characterization of the re-circulated process stream.

The application of a DSC does not create any additional design or control issues other than those for the $\mathrm{CC}$ design. If batch processing can be accommodated to meet throughput requirements (i.e., parallel processing of feed source vessels), then the intermittent DSC can provide increased control and minimized pass-through of oversized particles that is achieved with a CC with the simplicity and low cost associated with an OC.

\subsubsection{Grinding Circuit Summary}

When selecting the type of grinding circuit to be utilized, the simplest system that can accomplish the goals of the size reduction process is typically selected. An open circuit with no classification prior to grinding is the simplest circuit available, but this type of circuit often cannot meet all the objectives specified. Adding classification and recycle aids in the control and throughput of the grinding circuit at the cost of additional complexity.

A large portion of the material in the tanks likely will meet the particle size specification and will not need to be ground. Placement of a separator prior to the grinder would prevent overgrinding of feed that already meets specifications as well as significantly reduce the load on the grinder. A separator on the grinder outlet would allow greater throughput, allow control of overgrinding, and prevent any oversized particles that passed through the grinder from being transferred to downstream processes. 


\subsection{Particle Size Reduction/Comminution by Grinding}

Once a grinding circuit is selected, the specification of individual components for the system is performed. The heart of any grinding circuit is the mill. Categories of grinding mills include hammer mills and impactors, roller-compression mills, attrition mills, pin mills, media mills, and fluid-energy mills. High shear mixers (commonly called homogenizers or dispersion mixers) are also commonly used.

\subsubsection{Hammer Mills}

Hammer mills consist of a rotating set of "hammers" inside a grinding chamber. See Figure 3-8 for a picture of two commercially available hammer mills. Grinding is performed upon impact of the feed with the high speed rotating hammers. A screen is typically installed on the exit to keep particles over the size required in the milling chamber. Cutting mills are similar to hammer mills except that the hammers are replaced with sharp edged "cutters". Hammer mills are typically used for coarse grinding with final particles sizes above 100 microns. Control of final particle size is controlled by the openings in the bottom screen.

\section{$\underline{\text { Advantages }}$}

Hammer mills grind material until it is small enough to exit through the screen and have higher throughput than media mills. The equipment has a smaller footprint than tumbling mills.

\section{$\underline{\text { Disadvantages }}$}

The high rotational speeds and use of limited grinding surfaces can lead to excessive wear and higher maintenance costs. In addition, efficiency is impacted by the wearing of surfaces. The mill can also experience problems with heat generation and can become clogged more easily than a media mill.
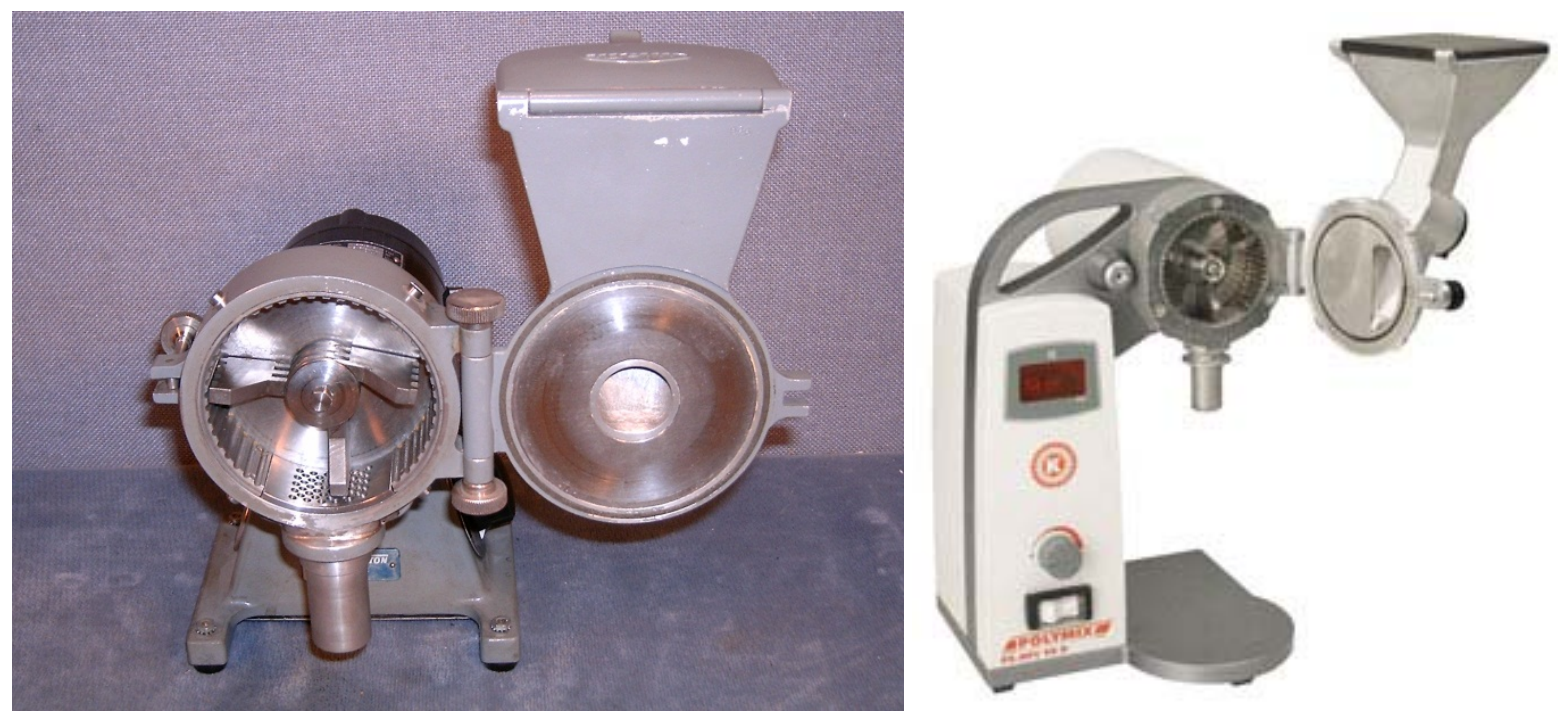

Figure 3-8. Hammer Mills 


\subsubsection{Roller Mills}

Roller-compression mills grind particulate by passing the feed between two rotating cylinders. See Figure 3-9 for a typical vendor supplied roller mill. As with the hammer mills, roller mills are typically used in applications where the final particle size is greater than 100 microns. Final size is controlled by the gap between the rollers. This mill is not recommended for radioactive service due to the tight clearances needed between the end of the rollers and the housing to prevent bypass.

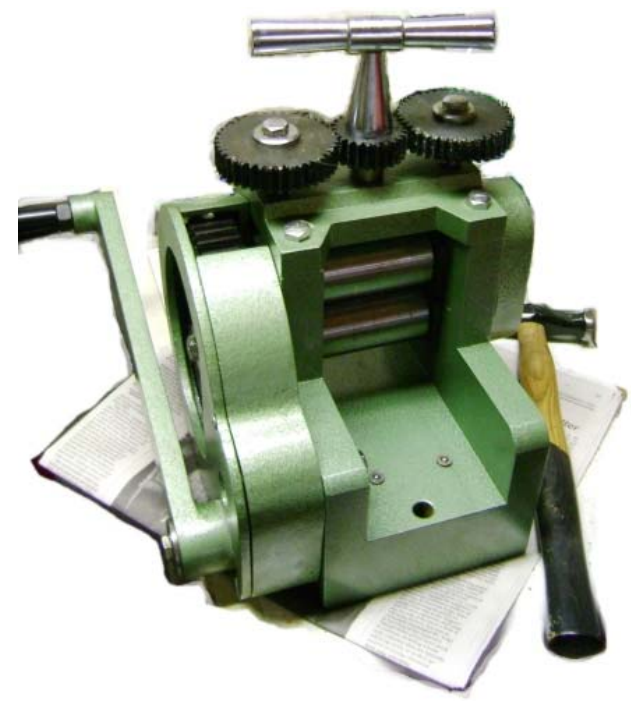

Figure 3-9. Roller Mill

\subsubsection{Attrition Mills}

Attrition mills, sometimes referred to as disk mills, have similar final particle size limitations as the roller mills and consist of two closely spaced rotating disks. Material is fed through a passageway in the center of the fixed disk and is crushed, sheared, and impacted into pieces as it is moved towards the circumference of the disk and ground product exiting from the edges of the disks. Disk mills are capable of processing hard, brittle, and tough materials up to 8 Mohs. Figure 3-10 depicts a picture of a commercially available attrition mill. Final particle size is determined by the distance between the grinding disks.

\section{$\underline{\text { Advantages }}$}

Attrition mills grind materials until it is small enough to exit between the disks and have a higher throughput than media mills. Attrition mills can be used in both batch and continuous processes. Attrition mills are suitable grinders for hard materials like carbides and hard metals. ${ }^{28}$

\section{$\underline{\text { Disadvantages }}$}

The high rotational speeds can lead to excessive wear and higher maintenance costs. In addition, the efficiency is impacted by the wearing of the surfaces. The mill can also experience problems with heat generation and can become clogged more easily than a media mill. 
SRNL-STI-2013-00472

PNNL-23030

Revision 0

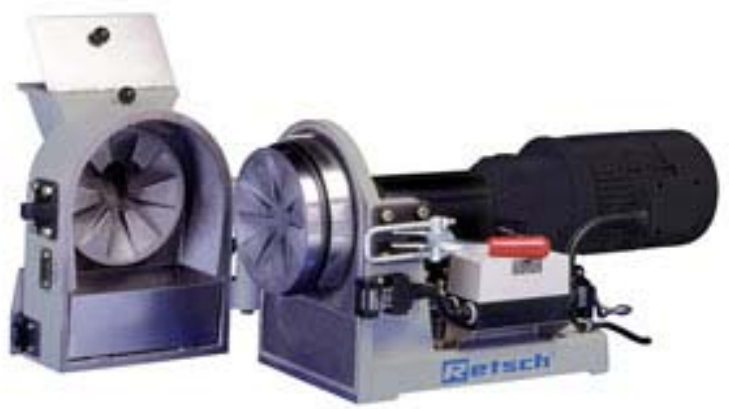

Figure 3-10. Attrition Mill

\subsubsection{Pin Mills}

Pin mills consist of a rotor/stator pair with protruding rods, or pins on the rotor. Figure 3-11 depicts a typical commercially available pin mill. The feed is fed between the rotor and stator and is ground by impacting the rotating pins. In some designs, counter-rotating disks are utilized. The pin mill speed controls the amount of grinding performed. This mill is typically used for grinding friable material, but has been used for mineral grinding and can achieve final particle sizes in the 30 to 350 micron range.

\section{$\underline{\text { Advantages }}$}

Final particle size is adjusted by rotational speed, an easily variable process parameter that means the mill is more controllable than other types.

\section{$\underline{\text { Disadvantages }}$}

As with hammer mills, high rotational speeds are utilized to perform the milling. Efficiency is less impacted by wear, but higher maintenance than media mills should be expected.

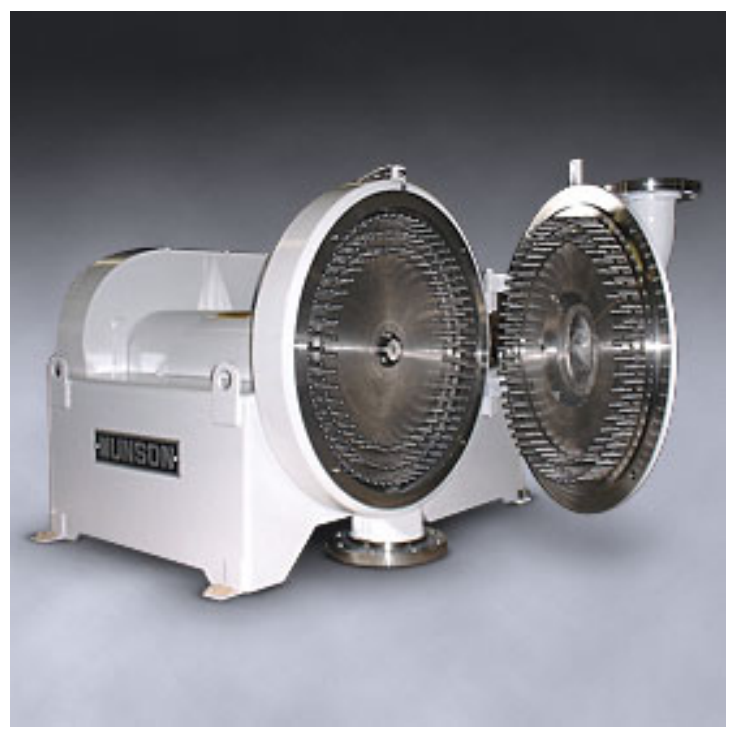

Figure 3-11. Pin Mill 


\subsubsection{Media or Ball Mills}

Media mill types generally fall into two different categories: a) tumbling mills with usually coarsegrinding, producing particles with a size range of $40-300$ microns; and b) stirred mills with usually finegrinding, producing particles with fine $(15-40$ microns) and ultra-fine ( $<15$ microns $)$ size ranges. Tumbling mills typically use metallic rods or balls as the grinding media, and stirred mills use a stirrer to impart motion within the mill and uses metallic or ceramic grinding media. Size reduction of the particles is achieved by fracture, impact, and attrition/abrasion.

There are three general types of tumbling mills: autogenous, ball, and rod mills. Each of these types is made up of a horizontal drum shaped cylinder that is rotated on its central axis and contains the grinding media (e.g., balls or rods). See Figure 3-12 for an example of a tumbling media or ball mill. The slurry is fed in one end of the rotating mill, ground by interaction with the grinding media with the particle size reduced stream coming out the other end. Autogenous or semi-autogenous grinding mills employ larger crushed particles, typically ore particles in the mining industry, from the processing stream as grinding media; as such, would not likely be a good candidate for nuclear waste slurry processing. Ball and rod grinding media can be made from a variety of materials and are usually high chromium steel in the mining and mineral industry and ceramic media in the ceramic powder processing industry. Rod mills are usually considered as either coarse or fine grinding machines, while ball mills are often the final grinding stage as balls have a much higher surface area per unit weight than rods. Both ball and rod mills may be charged with an assortment of different diameter balls or rods so as to provide the desired grind.

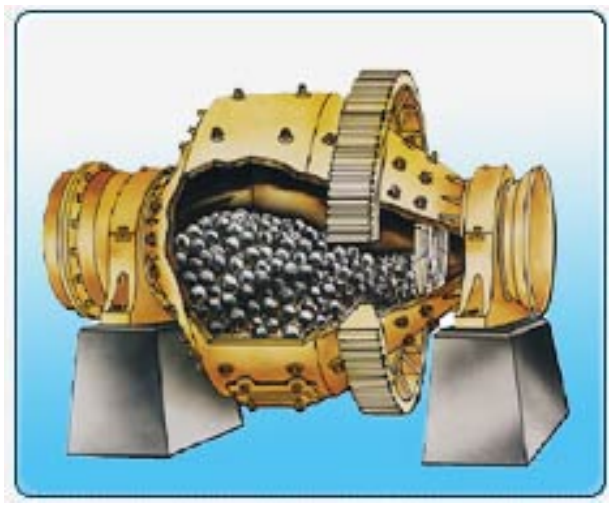

Figure 3-12. Tumbling Media or Ball Mill

In stirred mills, the usually drum shaped cylinder is oriented either horizontally or vertically and does not move. The motion of the grinding media is imparted via an internal stirring mechanism. The internal stirrer usually has disks or pins of various designs attached to the central rotating shaft which agitate the grinding media. ${ }^{29}$ The selection and sizing, ball/bead size and composition, effects of slurry rheology for stirred mills have been examined for various mineral systems ${ }^{30-34}$ and would need to be developed and tested for the specific nuclear waste slurry processing environment. These stirred mills or attrition mills (see Figure 3-13) have been successfully tested for nuclear application in grinding uranium oxide powders for the plutonium immobilization program. The goal of that program was to grind the starting $\sim 100$ micron oxides to particles $<10$ microns so they could be intimately mixed with the ceramic precursors to produce ceramic waste forms. ${ }^{35}$ In addition, the Hockmeyer grinder used to grind Zeolite from Tank 18 and 19 at SRS is a type of stirred mill, as described in Section 4.0. 
SRNL-STI-2013-00472

PNNL-23030

Revision 0

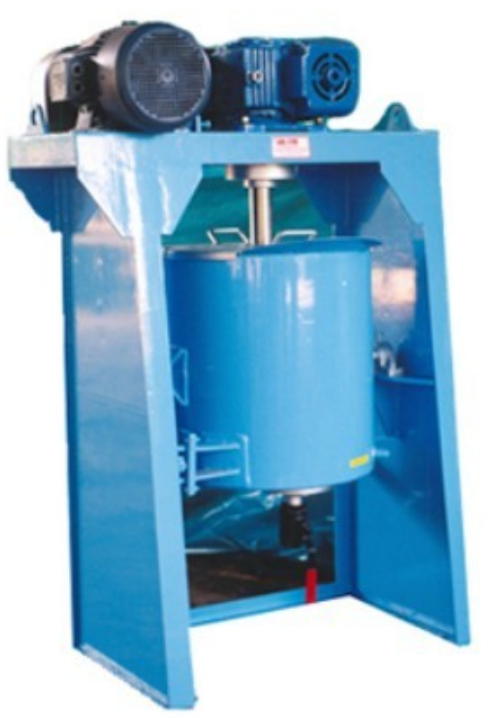

Figure 3-13. Stirred Media Mill

Vibratory mills are another mill type that may be used in a continuous batch grinding circuit that produce a fine particle size down to the tens of micron range. See Figure 3-14 for a typical vibratory media mill. Motion of the grinding media, usually balls or rods, is produced by 'shaking' the cylinders/tube in which the slurry and grinding media are contained. For example, the mill body may be mounted to springs and by rotation of an eccentric mechanism driven by a motor which creates the vibratory motion. Advantages of vibratory mills are their smaller size compared to other types of mills.

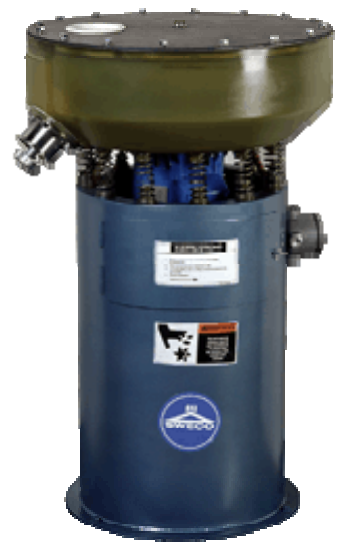

Figure 3-14. Vibratory Media Mill 


\section{$\underline{\text { Advantages }}$}

Media mills are less impacted by wear than other mills and have been proven effective throughout the mineral industry as well as selected applications in the nuclear industry. Rod mills function as a coarse screening operation as material must pass through the rods to exit the mill. Thus, classification is often not required on the exit stream from rod mills. Stirred mills can be connected directly to process piping and only have one rotary seal on the stirring shaft. Vibratory mills have no rotary seals.

\section{$\underline{\text { Disadvantages }}$}

Media mills typically have lower throughput than other types of mills. For a given throughput requirement, media mills will have a larger footprint. In batch mode, media mills can achieve 2-3 micron particle sizes. However, as the required particle size is reduced, grinding times can increase significantly. Tumbling mills require rotary seals on the inlet and outlet streams and have lower throughput than stirred or vibratory mills. Vibratory mills must be coupled to process piping with flexible connections.

\subsubsection{Fluid Energy (Jet) Mills}

Fluid-energy mills (jet mills) use high velocity, highly turbulent fluid streams to grind particles by interparticle attrition (see Figure 3-15). They typically are used in applications where the high energy costs and system complexity are justified by the fine particle size required ( $<10$ microns). These mills are typically only considered when other types of milling cannot achieve the fine particle size required. Final particles size is controlled by the velocities in the mill and residence time. The particle size required for the Hanford waste can be achieved by other types of mills, therefore jet mills should not be considered for this application.

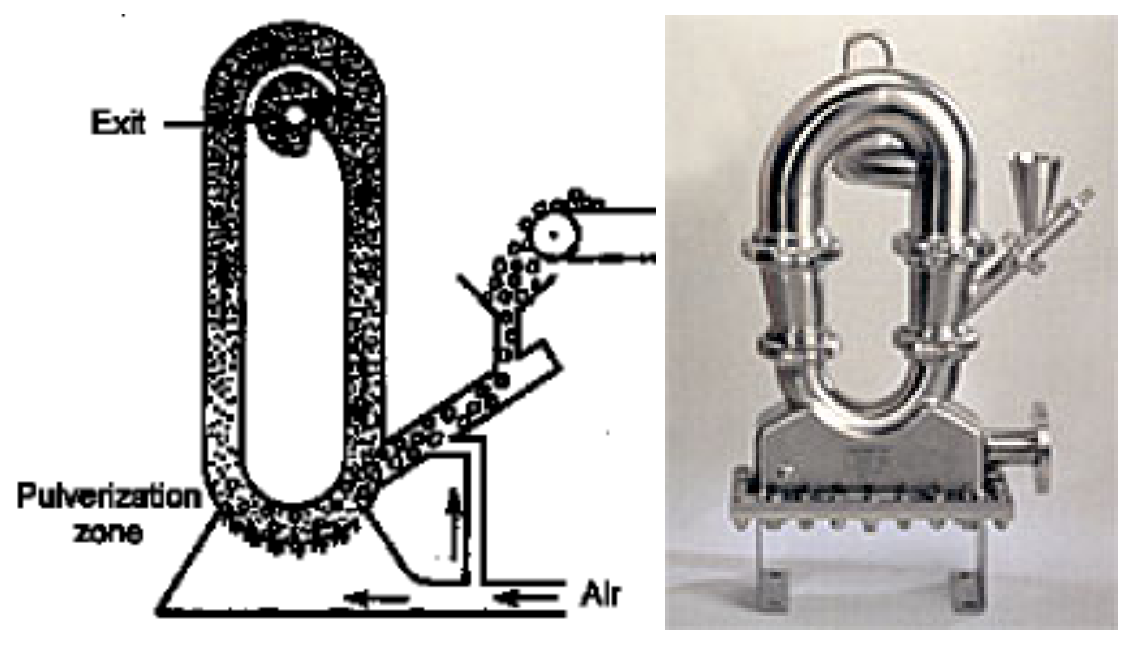

Figure 3-15. Fluid Energy or Jet Mill

\subsubsection{Homogenizers}

Homogenizers or dispersion mixers are high shear mixing heads designed to grind material by creating a region of intense shear by either passing the feed through a closely coupled rotor/stator system or through the use a specially designed agitator blade. See Figure 3-16 for pictures of these systems. The 
rotor/stator pair (known as a generator) can be configured with multiple grinding steps to perform coarse and fine grinding in one pass. Particle size is set by adjusting the gaps between the rotor stator pairs.

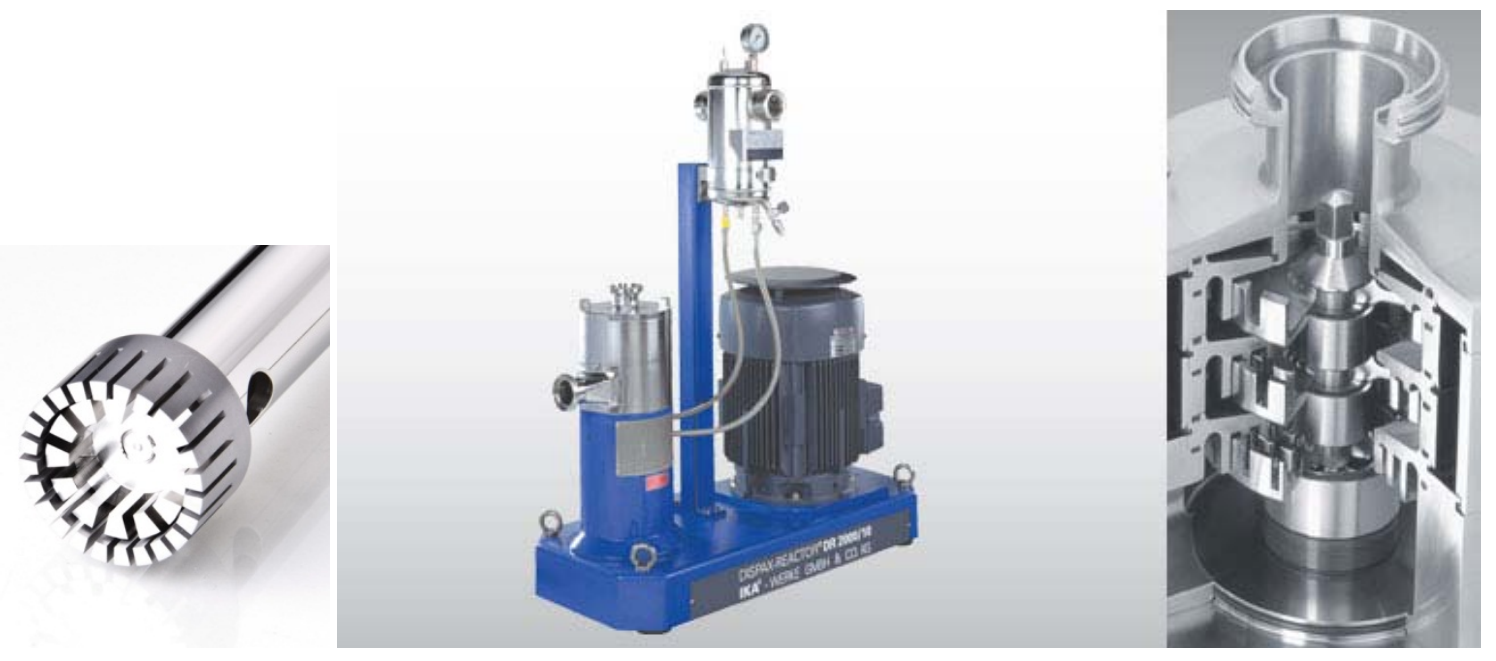

Figure 3-16. Homogenizer or Dispersion Mixer

\section{$\underline{\text { Advantages }}$}

The throughput of homogenizers is very high and pumping capacity can be built into the unit. The use of multiple stages allows very fine particle sizes to be quickly achieved from relatively coarse material.

\section{$\underline{\text { Disadvantages }}$}

As with hammer mills, rotational speeds are very high and excessive wear can result. This wear decreases efficiency and leads to higher maintenance costs.

\subsubsection{Sonication}

An additional method of mechanical particle size reduction is the use of sonication. Sonication uses high intensity ultrasonic energy to grind friable materials. A sonication system (see Figure 3-17) consists of a power supply operating at ultrasonic frequencies that supplies an electrical signal to a piezoelectric transducer causing it to vibrate at ultrasonic frequencies (typically $20 \mathrm{kHz}$ ). When such a transducer is interfaced with a liquid it causes ultrasonic pressure waves to propagate in the liquid. If the energy density is high enough this causes cavitation in the liquid and bubble formation. The bubbles grow in size until they reach a resonant size whereupon violent implosion occurs. This can be violent enough to cause friable materials to break apart. Particle size is controlled by residence time and amplitude of the generator.

\section{$\underline{\text { Advantages }}$}

Sonication would provide a relatively simple, at tank or near tank particle size reduction application potentially applicable to a nuclear environment. In addition, ultrasonic process would eliminate all rotary seals from the size reduction equipment. The technology has been demonstrated to reduce particles of large size to very small size and should be applicable to weak agglomerates. Dissipation of the small particles may have an impact on rheology that would need to be considered in the application. 
SRNL-STI-2013-00472

PNNL-23030

Revision 0

\section{$\underline{\text { Disadvantages }}$}

A disadvantage is that this relatively newly industrial incorporated technology would need significant additional research to determine if it would provide a real solution to the particle size reduction requirements for the feed to WTP. Sonication has not been applied to large scale systems, nor has it been used in a nuclear environment to our knowledge at this scale. It has been used for preparation of HLW samples for particle size analyses at SRS.

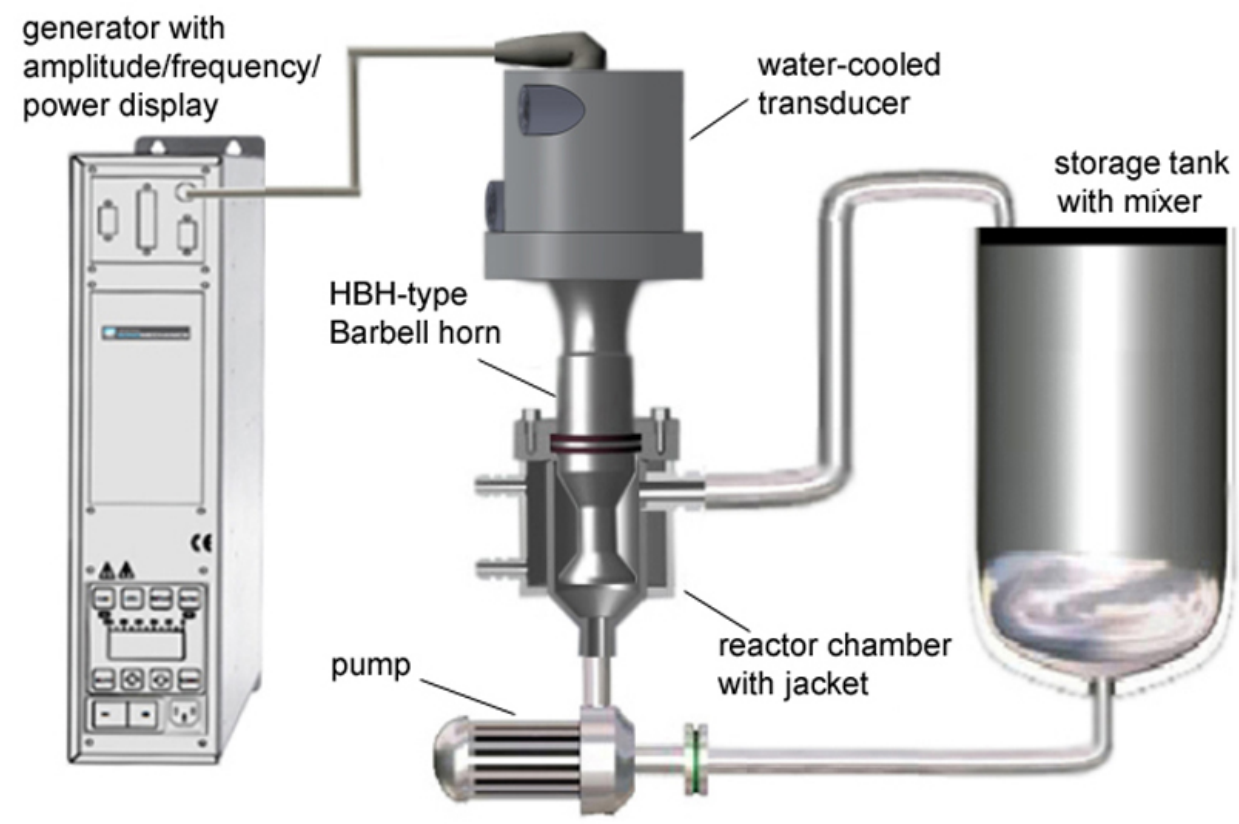

Figure 3-17. Sonication System

\subsubsection{Special Case: Grinding with Pumps}

Slurry handling pumps come in a wide range of sizes and for handling specific types and size ranges of material. A high level distinction is whether the pump is intended to just provide motive power to the process stream or if it is to perform some form of size reduction. The components of a centrifugal pump at first glance have a lot of similarity with some of the grinding mills shown above, particularly the hammer mill. However, it should be noted that pumps are specifically designed not to impart the type of impact and other shear forces typical of mills.

However, even pumps designed to minimize impact and shear forces will impart shear to the flow stream $^{36}$ and as such can erode particles or break down agglomerates of some types of undissolved solids. However, if pumps will be used to size reduce solids, which are not specifically designed to break down solids with shear, then many parameters will play a role in the success of the process, e.g., friability of particles, slurry properties, type of pump, etc. Because of this, the process could be very inefficient and may require significant processing times. Consequently, pumps have shown an ability to reduce large, 
agglomerated particles, but not specifically large, single crystal particles. However, using slurry pumps is the simplest thing to do, since pumps will be required to mix and transfer slurry.

On the other hand, some slurry pumps are designed to size-reduce particles. Centrifugal pumps designed to break down material (size reduction) within the process stream are usually for application to loose agglomerates instead of hard granular materials. These pumps tend to be grouped based on the means by which they accomplish size reduction. Common groupings include:

- Grinder pumps;

- Particle grinder pumps; Chopper pumps;

- Cutter pumps; and

- Grinder/pump combination.

\section{Grinder Pumps}

A grinder pump is a waste management device that is a submersible device usually applied to lift station applications with low flow requirements and intermittent operation. Typical ranges for municipal waste grinder pumps are 1-300 gpm. The size reduction is accomplished similar to that of a kitchen sink garbage disposal. An extension of the impeller called the "radial cutter" forces material into rotating cutter ring at the pump inlet, which acts as an upstream grinder (i.e. no pumping action). Material is further reduced in size as it passes by the impellers leading edge. Particles/debris leaving the pump is generally very finely ground. Significant torque is applied to size reduction of the material as opposed to pumping.

\section{$\underline{\text { Particle Grinder Pumps }}$}

A particle grinder pump is a true grinder designed such that the rotating components impart some motive energy to the process stream and the discharge is designed for pressure recovery. These types of grinder pumps are designed for the size reduction of granular material. However, they are limited in the amount of head they produce and significant flow rates are applied for the lower end of size reduction. For example, the DICON dispersing grinder (Model 6x3) can produce 1/16-inch particulate at approximately $100 \mathrm{gpm}$ and $30 \mathrm{ft}$ of head. Increased head is achieved at an increase in output particle size, 1/8-inch particulate at approximately $100 \mathrm{gpm}$ and $45 \mathrm{ft}$ of head.

\section{Chopper Pumps}

A chopper pump is a centrifugal pump equipped with a cutting system to facilitate chopping/maceration of debris/solids that are present in the pumped liquid. While these pumps may be referred to as grinder pumps, the cutting action resulting from the action of the sharpened leading edge of a rotating impeller against a stationary sharpened "cutter bar" distinguishes them from grinder pumps. These pumps have been designed to chop everything that enters the pump and to handle a wide range of man-made solids such as tennis shoes and nylon rope. The main advantage of this type of pump is that the chopper prevents clogging of the pump itself and of the adjacent piping, as all the solids and stringy materials are macerated by the chopping system. Chopper pumps exist in various configurations, including submersible and dry-installed design and they are typically equipped with an electric motor to run the impeller and to provide torque for the chopping system. Due to its high solids handling capabilities, the chopper pump is often used for pumping sewage, sludge, manure slurries, and other liquids that contain large or tough solids. 


\section{Cutter Pumps}

A cutter pump is a submersible pump with stationary cutting blades that are used with a close tolerance to the impeller and are in one of three configurations: external to the impeller, on a sharpened suction plate, or as spiral grooves on the internal suction plate. Size reduction is accomplished by the momentum of the solids, which carries them into the stationary cutting blades. Unlike the chopper pump, solids can pass through a cutter pump without being reduced in size.

A configuration often referred to as a grinder pump consists of a grinder being incorporated into the suction side of the pump to reduce the size of particles entering the pump. Submersible configurations of this type of pump will also employ forms of size separation after the grinder or after an initial stage that allows larger particles to be discharged from the pump allowing them to be re-entrained and passed through the grinder again.

\section{$\underline{\text { SRS Experience }}$}

Operational experience with slurry pumps at SRS is provided in Appendix A. These pumps have been utilized to mix the waste tanks for sludge retrieval, to blend retrieved waste, and to mix and heat the tank during aluminum dissolution. Extended mixing times have been shown to perform some size reduction.

\section{$\underline{\text { Advantages }}$}

The use of in-tank slurry pumps to create sludge able to be pumped and then transferred has been performed successfully for many years. The transfer pumps are needed for transport of the waste slurry, and any modifications or optimization of operations to reduce particles could be easily included in their use. The application has been demonstrated on SRS waste with loose agglomerates and easily friable particles, as discussed in Section 4.0. Solids pump handling technology can be applicable over a wide range of particle sizes.

\section{$\underline{\text { Disadvantages }}$}

Centrifugal pumps are designed to impart dynamic energy, which is converted into pressure at the pump cut line. This pressure is then used to transport fluids. Centrifugal pumps are generally designed to minimize high shear areas. They are inefficient in reducing particle sizes, and as PSD size requirements go down, the time to process goes up rapidly. However, centrifugal slurry pumps, as a mechanical process, do perform particle size reduction ancillary to their intended function. Particle grinder pumps are limited in the amount of head they produce and significant flow rates are applied for the lower end of size reduction. Additional directed research could provide more pronounced particle size reducing effects and consistency.

\subsubsection{Grinding Mill Summary}

A number of technologies are available to perform the size reduction step for the Hanford wastes with a number of different grinding mills utilized in previous operations in the nuclear waste industry. The previous experiences with grinding nuclear wastes are described in the Case Studies in Section 4. Regardless of the technology chosen, testing will need to be performed to validate the equipment selection and define operational parameters needed to achieve the objectives of the size reduction. 
As discussed in the advantages and disadvantages of the different mills, high throughput through smaller mills can be achieved by using high speed rotating devices such as hammer mills, pin mills, or homogenizers while the use of media mills may require larger equipment but the wear and maintenance issues are reduced.

\subsection{Solids Segregation / Classification}

A high level overview of classification is provided in this section. Technologies for performing the size segregation as part of the grinding circuit include screening and classification as well as elutriation and counter-current exchange.

Classification is defined as separating mixtures of particles based upon their velocity through a viscous fluid, usually air or water, focusing on wet classification (separation of particles from a slurry due to their settling rate in a fluid). Wet classification is or will be the standard process used to mobilize, retrieve and transport waste slurries at Hanford. Classifiers basically separate particles from a moving fluid via terminal velocities whereby particles will rise and exit the classifier for further processing $(\mathrm{O} / \mathrm{F})$ if their terminal velocities are less than the fluid velocity, and will sink and be removed from the classifier for further size reduction (U/F) if their terminal velocities are greater than the fluid velocity.

There are two large groups of classifiers based upon the direction of the fluid: a) horizontal current classifiers largely composed of mechanical separators using free-settling of the particles (size of particle important); and b) hydraulic classifiers using a vertical fluid current component and hindered-settling of particles (density of particle important). Examples of hydraulic/centrifugal classifiers include hydrosizers, centrifuges, and hydrocyclone classifiers.

\subsubsection{Mechanical Classifiers}

Examples of horizontal current/sedimentation classifiers include settling cones, mechanical classifiers, rake and spiral classifiers. They are usually used for clarification processes whereby particles are removed from a dilute slurry and for thickening (e.g., dewatering as with a settling cone). A large limitation of mechanical classifiers in general is their inability to produce an overflow stream of fine particles at reasonable slurry densities for further processing. Given the issues with large equipment size and the requirement to operate with dilute streams, mechanical classification should not be considered for in-line solids segregation.

\subsubsection{Hydrocyclones}

Hydrocyclones are the most widely used classifiers in a wet grinding circuit due to their relative efficiency if designed correctly, high throughput, smaller size and lower cost, and their simplicity, as they contain no moving parts. Hydrocyclones are able to separate particles from slurry over a fairly large range of sizes, i.e., 5 - 500 microns. The slurry stream is fed tangentially into the cone shaped hydrocyclone which forces the slurry to rotate. This causes centrifugal forces within the stream accelerating the settling rate of the particles forcing the denser/larger particles to settle to the bottom of the cone, underflow, with the less dense/smaller particles exiting the top of the cone, overflow. The underflow is cycled back into the grinding circuit and the overflow is moved forward for processing.

There is considerable amount of literature devoted to both the theoretical and empirical operation of a hydrocyclone, which goes back 100 years. ${ }^{37,38}$ Below, only a brief summary of the hydrocyclone operation is given. 
A hydrocyclone converts the linear momentum of the feed stream to angular momentum. As the mass travels down the cone, the angular momentum changes, leading to centrifugal forces which segregate the heavy phase material towards the cone wall, which then exits through the underflow (the apex of the cone), see Figure 3-18a. ${ }^{39}$ Conversely, the lighter phase moves away from the cone wall towards the axial centerline of the hydrocyclone, which then exits through the overflow. An experimental study showed that there are four regions of similar size distributions. ${ }^{40}$ Figure $3-18 \mathrm{~b}$ shows the regions as they exist at the minimum flow to maintain a stable vortex: region A contains the feed distribution; region $\mathrm{B}$ contains heavier particles that will be separated; region $\mathrm{C}$ contains the finer particles; and region $\mathrm{D}$ contains the entire cross section of particle sizes as they migrate to the wall. ${ }^{39}$ As the feed flow rate increases, the region $\mathrm{D}$ will extend towards the apex of the cone.
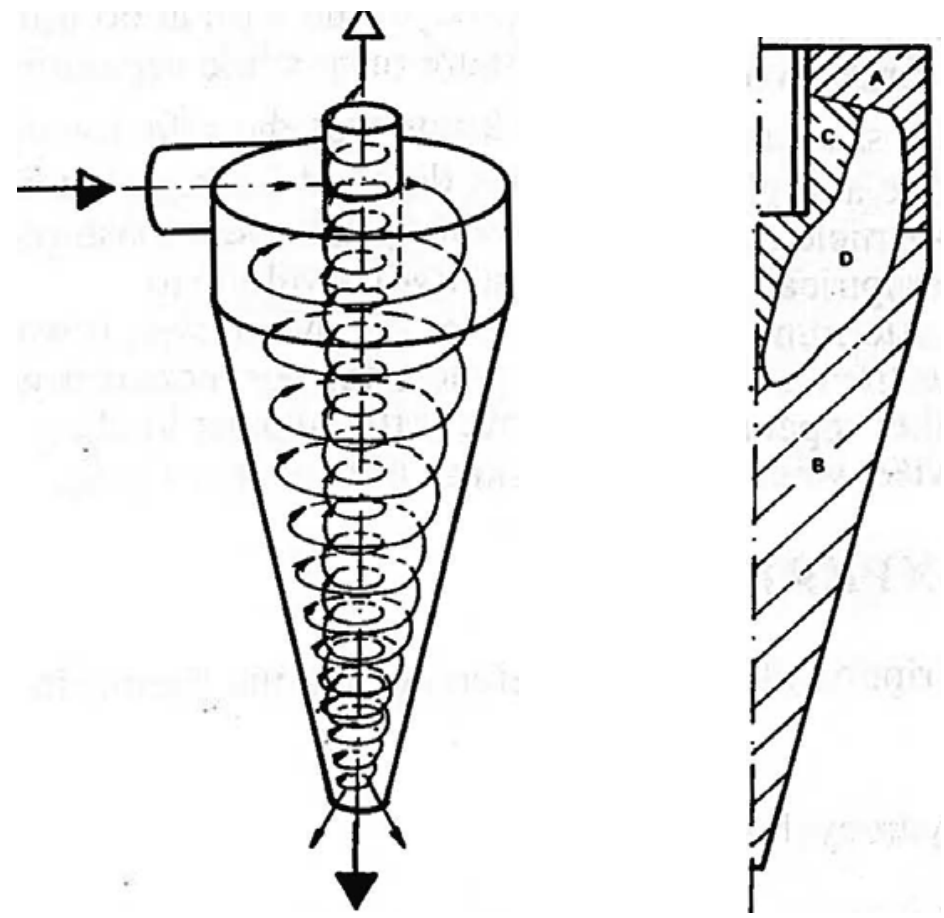

Figure 3-18. Cyclone Operation (a) and Regions of Similar Particle Size (b)

All of this movement happens through three velocity fields: tangential, vertical, and radial. As the flow enters the feed port, the mass is forced around an annular ring, which is the outside of the vortex finder. The vortex finder serves to force the slurry downwards and is the overflow port through which the inner vortex removes most of the liquid. Because of the presence of the hydrocyclone top, a secondary flow pattern exists. This secondary flow causes the lighter phases to follow the outside surface of the vortex finder, which are then immediately carried out the overflow. If there is a solid phase, this is where the smallest particle escapes the hydrocyclone. These secondary flow patterns are divided from the main downward flow by an area that is basically stagnant called a mantle. The mass that makes it past the secondary flows then begins its journey down the cone for separation. For the heavier masses that exit through the underflow, the movement is a parabolic path towards the cone wall, as they move lower in the cone. The light masses will begin down this same path, except along the way they are blocked by the heavier masses and thus forced towards the central axis. Near the central axis there will be a tight liquid or gas filled vortex which then carries the lighter masses up and out of the overflow. In general, this 
separation is independent of gravity because the centrifugal forces are substantially greater than the gravitational force.

This description of hydrocyclone operation is theoretical and actual operation may significantly deviate for specific circumstances. For a very heavy phase at low velocities gravity will play a larger role. As the heavier phase increases in the feed stream, i.e., above $1 \mathrm{wt} \%$, the individual units of that phase begin to influence other heavier phase units by unit-to-unit interactions. Therefore, separation is not solely based on centrifugal forces but by these interactions; these separation mechanisms can become quite complex. Additionally, steady state conditions are required for optimal performance. Hydrocyclone research performed at SRNL is discussed in Section 4.7.

\section{$\underline{\text { Advantages }}$}

Hydrocyclone technology is a viable consideration for particle separation for the Hanford WTP. It is a continuous process, with no moving parts, high throughput, and can be operated in any orientation; however, angling the hydrocyclone slightly above horizontal helps to empty the cone during down times.

\section{$\underline{\text { Disadvantages }}$}

This technology needs to be properly sized for the range of particles to be removed. For a wide range of particle sizes and carrier fluid rheology, several different size hydrocyclones may be needed. Moreover, for radioactive service the liner should be made of metal; therefore, the device will need to be evaluated for corrosion and erosion for long-term operation.

\subsubsection{Centrifuges}

The centrifuge relies on centrifugal force to exaggerate the density difference between the particles in a liquid, so the solids will "settle" more quickly. Thus, the centrifuge can, theoretically, completely remove even small, colloidal solids, given a long enough period of operation. Separation occurs without a physical barrier, and therefore, no place exists for trapping of the solids. Centrifuges work best with fast settling solids.

The operating principle behind the decanter centrifuge is that denser solids collect on the walls of the rotating bowl wall. The less dense liquid phase forms a concentric inner layer. The liquid or "pond" depth can vary with a maximum pond depth preferred for maximum liquid clarification.

The sedimented solid particles continuously exit from the centrifuge bowl by virtue of the action of a helical screw conveyor or "scroll" (see Figure 3-19). The scroll rotates at a slower speed than the bowl. The gearbox establishes the differential speed between the scroll and bowl. The solids are pushed out of the pond by the scroll and up the conical "beach". The centrifugal force generated by the rotating centrifuge compacts the solids and expels excess liquid. The concentrated solids discharge from the feed end of the centrifuge and the clarified liquid discharges from the opposite end. Nuclear facility applications involving centrifuges are discussed in Appendix B. 


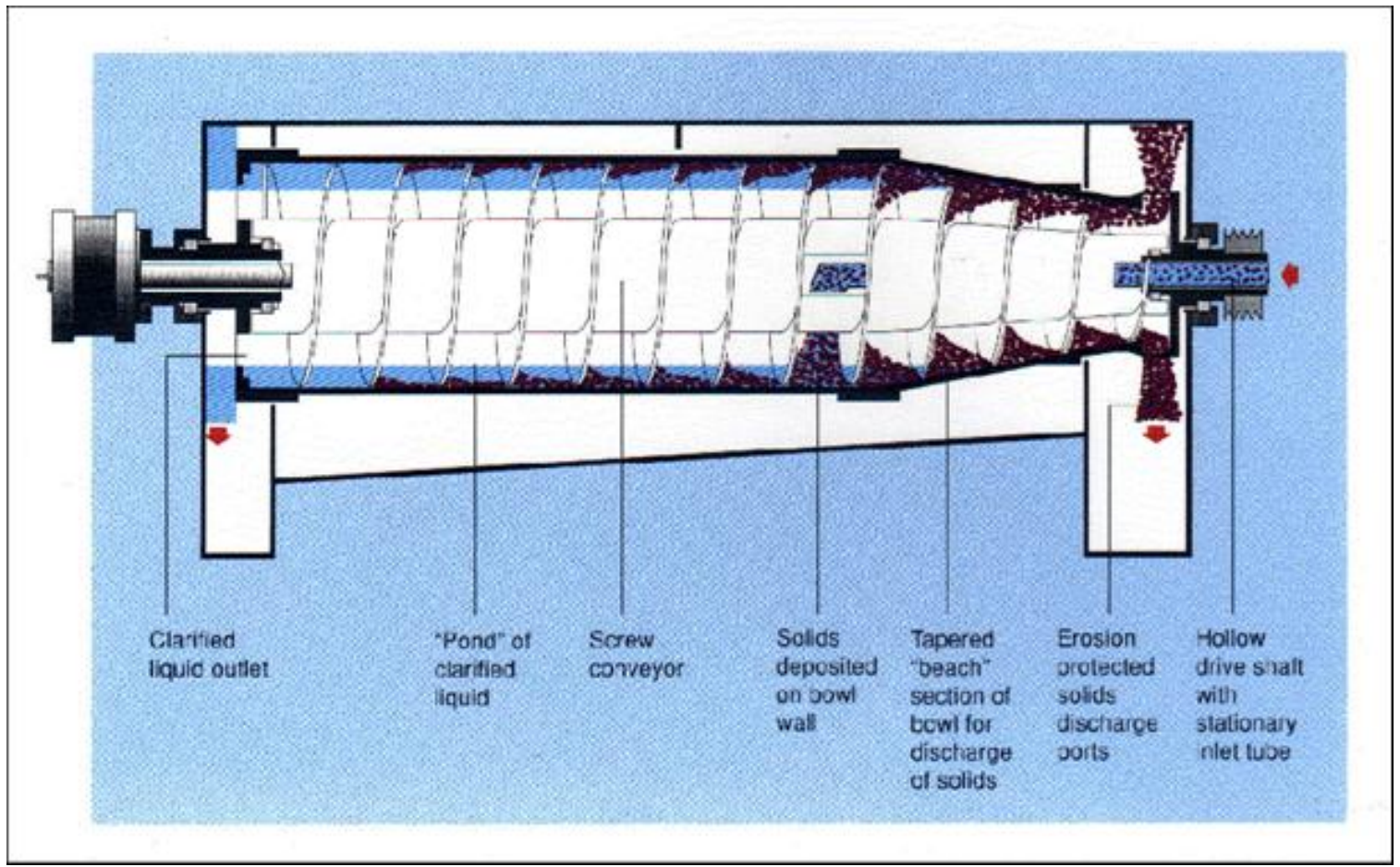

Figure 3-19. Schematic of Decanter Centrifuge

\section{$\underline{\text { Advantages }}$}

Centrifuges are used extensively in the nuclear industry.

\section{Disadvantages}

The system is more complex and less effective than other technologies. In addition, the case studies highlighted simply separated solids from liquids; size segregation has not been performed in the nuclear industry with centrifuges.

\subsubsection{Counter-Current Exchange}

An additional method of particle classification is counter-current exchange, which is considered a type of hydraulic classifier. Counter-current exchange is a mechanism occurring in nature and mimicked in industry and engineering, in which there is a crossover of some property, in this case soluble solids, between two flowing bodies flowing in opposite directions to each other. The flowing bodies can be liquids, gases, or even solid powders, or any combination of those. As a continuous process, countercurrent exchange offers high production rates compared to gravity settling, but rates would be much lower than processes such as a hydrocyclone. A case study for Counter-Current Exchange is shown in Appendix D.

\section{$\underline{\text { Advantages }}$}

Counter-current exchange process typically have higher throughput than other gravity classifiers. 


\section{$\underline{\text { Disadvantages }}$}

Counter-current exchange would likely require large processing vessels to achieve the desired throughput for size classification and numerous pumps and other support equipment. The capital cost and operating requirements for this system are expected to be much higher than available alternatives.

\subsubsection{Elutriation}

Elutriation is the process by which physical separation occurs based on particle size and density. ${ }^{41}$ Elutriation is usually performed in an upflow manner, and can be considered an inverse differential settling segregation process. Elutriation columns are used in industry and the medical field as particle separating columns imparting a constant upwards velocity, thereby allowing segregation of particles based on settling velocity. A case study for elutriation is discussed in Appendix D.

\section{$\underline{\text { Advantages }}$}

In-tank elutriation has occurred as discussed in Appendix D. The research discussed in the appendix suggests that elutriation may be useful as part of a complete treatment flowsheet.

\section{Disadvantages}

Elutriation has been tested with success in the lab, but actual operations in a real tank did not provide the expected results. Additional testing is required prior to the implementation of this technology, and additional process development is required to demonstrate the full application of this technology as one part of a complete process treatment step. In addition, once the oversized material collects in the waste tank, some method for retrieval and size reduction must still be deployed to stabilize this material.

\subsubsection{Screening}

Screening/sieving of particles is also used in the mineral processing industry and is based upon separation of particles based upon their size and is usually used in conjunction with dry crushing operations. Typically wet screening is usually limited to particles down to around $250 \mu \mathrm{m}$ in a large industrial setting (screening has been done down to particles sizes around $40 \mu \mathrm{m}$; however, fine screens are easily damaged and inefficient). Screening can be performed on a static screen, a vibrating or gyratory screen, or a rolling screen and the screen can be inclined or horizontal. A horizontal screen provides more accurate separations and vibratory/gyratory screens have much higher throughput and better separation than static screens. A "banana" screen has an inclined section that transitions to a horizontal section combining the advantages of an inclined screen with the advantages of a horizontal screen.

Trommels (or rotating screens) have much lower throughput and higher blinding issues than vibratory screens and are not considered suitable for this application. Centrifugal sieves may be applicable to this task, but they may eliminate too much water from the oversize fraction.

Vibratory/Gyratory Screening

Vibratory/Gyratory screening are generally employed when large capacity and high efficiency is required in process operations. They typically employ an eccentrically rotating mass that imparts a tangential velocity to the particles, increasing the effective screening capacity of the equipment and providing a path for the oversized effluent. Typical installations include: 
- Algae removal at water treatment plants

- Removal of water-based emulsions during paint pigmentation manufacturing

- Pharmaceutical granule size segregation

- Resin screening and purifying

- Dewatering operations in various industries

\section{Horizontal Screening}

As stated above, a horizontal screen has an higher separation efficiency but lower throughput than other screens. A horizontal screen has been demonstrated for separation of ion exchange resin particles, as shown in Section 4.8. Figure 4-10 demonstrates the application of a horizontal vibratory/gyratory screening.

\section{Inclined Screens}

Inclined screens are the dominant type of screening operation in the mineral industry due to the lower susceptibility to blinding and higher throughputs. Inclined screens have been designed to handle feeds that contain large amounts of clay particles. These screens are highly inclined to lower the susceptibility to blinding, as shown in Figure 3-20.

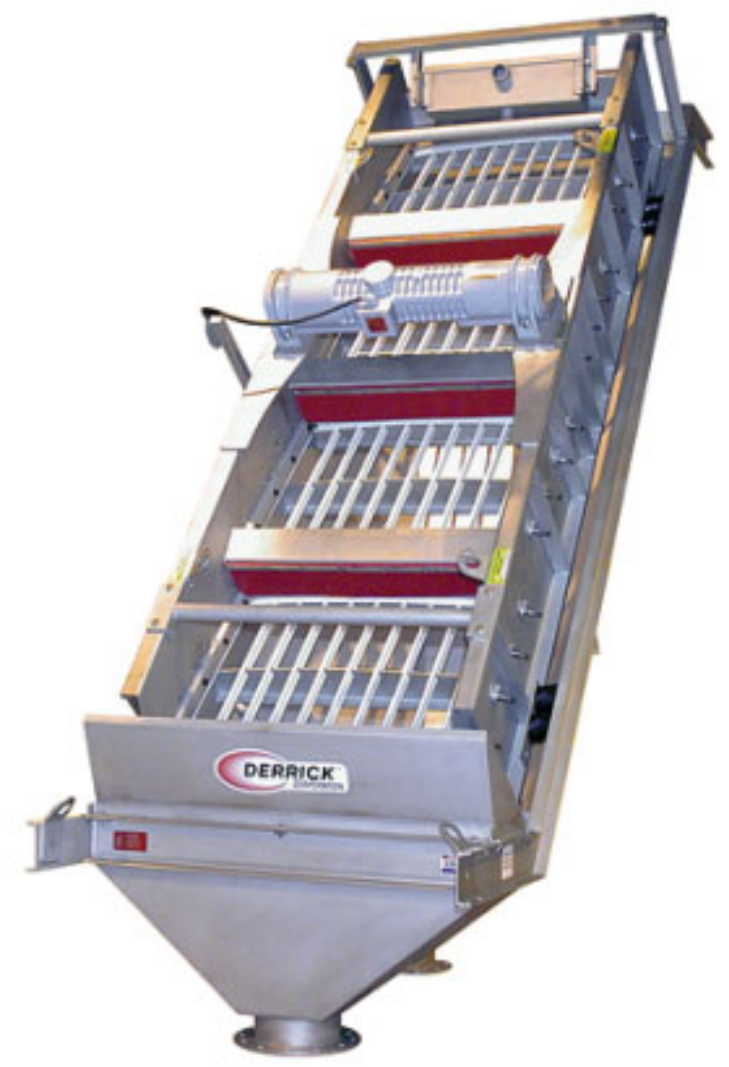

Figure 3-20. Inclined Screen for Processing High Shear Strength Materials 


\section{Banana Screen}

As stated above, a banana screen has a curved surface that starts as an inclined screen and transitions to a horizontal screen. The screen can combine the advantages of both the inclined screen and horizontal screen. See Figure 3-21.

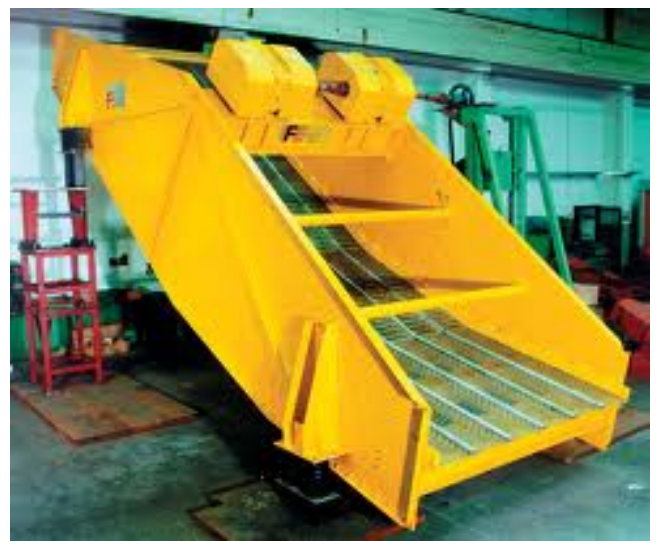

Figure 3-21. Banana Screen

\section{Centrifugal Screening}

A centrifugal screener utilizes a fixed cylindrical screen, mounted horizontally. Material is fed into the feed inlet and redirected into the cylindrical sifting chamber by means of a feed screw. Rotating, helical paddles within the chamber continuously propel the material against the screen, while the resultant, centrifugal force on the particles accelerates them through the apertures. These rotating paddles, which never make contact with the screen, also serve to breakup soft agglomerates. Over-sized particles are ejected via the oversize discharge spout. The centrifugal screen is typically smaller than vibratory screens for the same throughput. 
SRNL-STI-2013-00472

PNNL-23030

Revision 0

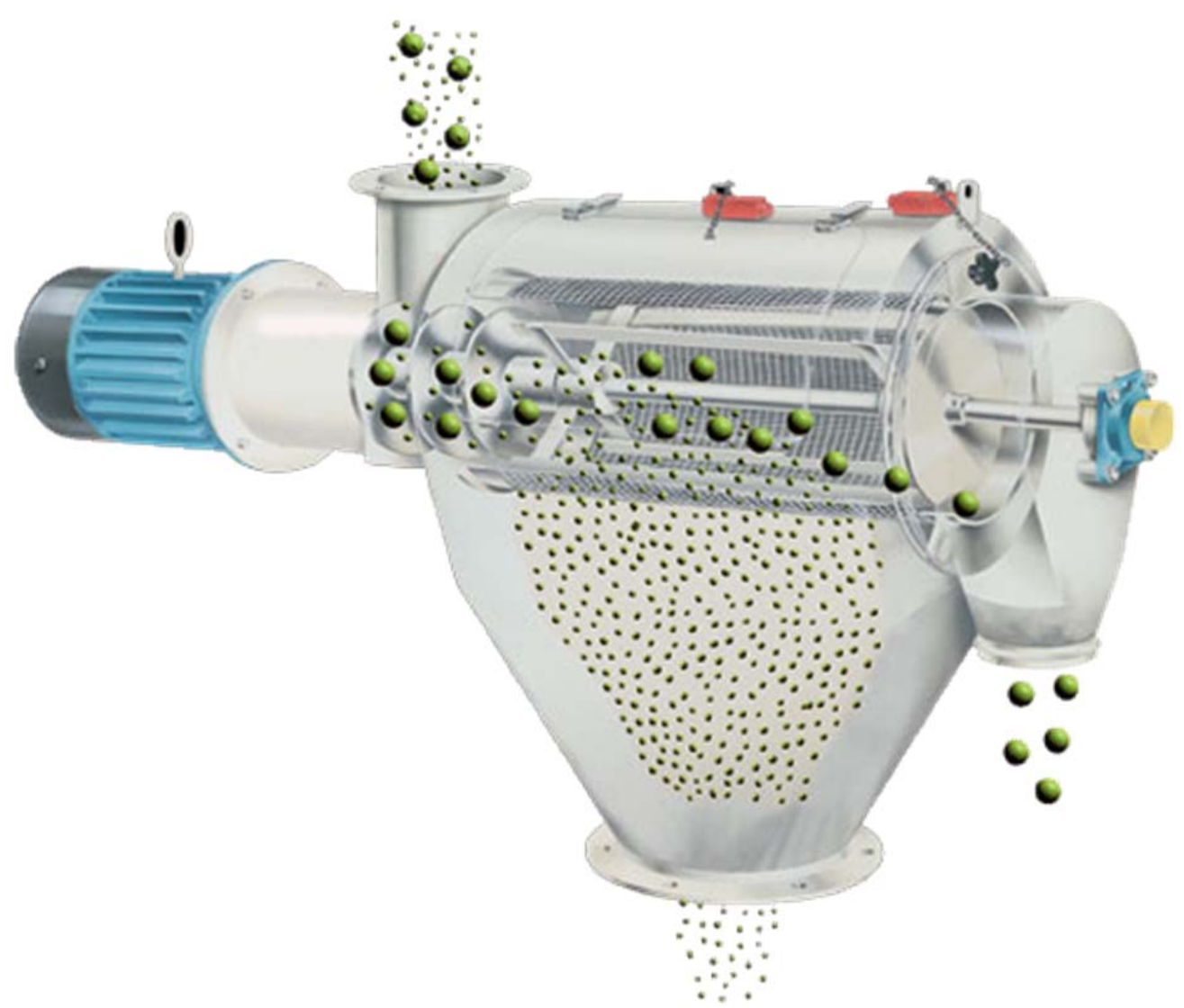

Figure 3-22. Centrifugal Screen

\section{$\underline{\text { Advantages }}$}

The advantage of sieves is that they are very simple to operate and reliable.

\section{Disadvantages}

Screening has clogging, screen wear, and maintenance issues, which may not be suitable for a radioactive, remote environment. Additionally, vibratory/gyratory screening employs the probability screening principle. This principle considers the fact that particles moving perpendicular to a screening surface are unlikely to transport across the screen when particle sizes are greater than approximately $1 / 2$ the opening size. Consequently, process efficiencies drop as greater throughput is required. Higher throughput leads to greater volumes of oversized particle flow requiring addition size reduction. Applications on actual waste slurry were not identified.

\subsubsection{Size Segregation Summary}

Of the technologies available for performing size segregation, two technologies (hydrocyclone and screens) are considered applicable. The hydrocyclone advantages include simplicity, flexibility, and throughput versus the other available technology. A disadvantage is that separation efficiency is less than 
SRNL-STI-2013-00472

PNNL-23030

Revision 0

expected from screening operations and that a small number of oversized particles would be expected to bypass the hydrocyclone. A secondary strainer would be required to preclude oversize particles from the treated feed.

Screening the feed using a wet screening process would require more complicated and larger equipment than the hydrocyclone. However, the efficiency of separation would be expected to be higher than the cyclone and a secondary strainer may not be required. It is noted that rod or needle like particles can cause lower efficiency and make the screen more susceptible to blinding. 
SRNL-STI-2013-00472

PNNL-23030

Revision 0

\subsection{Case Studies of Solids Segregation and Size Reduction in Nuclear Waste Processes}

This section provides specific examples of size reduction or solids segregation technologies used in DOE applications.

\section{1 $\underline{\text { Hanford K Basin/TWRS }}$}

An assessment of available technology for mechanically reducing K Basin uranium sludge particle size to support mixing 105-K East Basin floor and pit sludge with waste from double-shell tank (DST) 241-AW105 was performed. ${ }^{42}$ Technologies considered were open-circuit configurations.

The assessment included both size reduction processes and equipment suppliers with mechanical particle size reduction technology. The assessment used a proposed Hanford Tank Waste Remediation System (TWRS) particle size limit of 80 mesh (177 micron diameter) for the initial process acceptance criteria based on vitrification technology assessments. Conclusions and a recommendation were established based on $\mathrm{K}$ Basin sludge material characteristics and availability of industrial equipment as part of this assessment. Five devices offering three different operating principles were selected. These were two hammer mills manufactured by Pulva Corporation ${ }^{\circledR}$ and Hosokawa Micron Power Systems ${ }^{\circledR}$, a shredder manufactured by Shred Pax Systems Incorporated ${ }^{\circledR}$, a high shear rotor/stator mill manufactured by IKA Works Incorporated $^{\circledR}$ and a disk attrition mill by Glen Mills Incorporated ${ }^{\circledR}$.

General conclusions drawn from this assessment are as follows. The IKA ${ }^{\circledR}$ and Glen Mills systems tested typically handled larger process volumetric flow rates (on the order of double) than the hammer mills and shredders. The hammer mills could be used for a wide variety of particle sizes and could obtain very accurate control of particle size. The IKA ${ }^{\circledR}$ and Glen Mills grinding mills could also handle a wide variety of particle sizes and by using smaller and finer grinding teeth produce progressively smaller grinds.

Hammer mills were shown to require maintenance such as replacement of the liners to maintain efficiency making the hammer mill somewhat impractical as documented by Precechtel and Packer. ${ }^{42}$ An additional drawback to hammer mills is their tendency to clog if feed material is damp or pasty. Maintenance in a radioactive environment would be difficult. Size reduction capability of the shredder appeared to be limited to a minimum size of 6,400 micron based on available information at the time. This is believed to be due to it geometric configuration and operating principle.

\subsection{West Valley HLW Feed Size Reduction}

Evaluation and application of mechanical particle size reduction was performed for the WVDP for the purpose of having a fallback plan should the existing retrieval method utilizing sluicing, mobilization pumps, and transfer pumps prove unable to meet target tank cleanup levels due to not being able to mobilize and transport larger particles. It was later found that melter feed sample analyses were inconsistent and it was thought to be due to larger particles settling out of the sampling stream.

DiBiase $^{25}$ briefly discusses the application of an in-line grinder to reduce the size of cold chemical slurry feed particles during hot cell transfer with a target particle size of 50 microns. In this process, batch preparation of glass formers, zeolite and waste melter feeds are mixed and transferred to the hot cell. However, no details are documented regarding proposed grinder model, manufacturer, or specifics of the application. 
Kelly and Meess ${ }^{43}$ identify the application of an in-line (open circuit) grinder for reducing particles in a slurry of 840 to 300 microns size zeolite to approximately 50 microns or less before being mixed back in with plutonium-uranium solvent extraction process (PUREX) and thorium-uranium solvent extraction process (THOREX) sludge to support vitrification and WVDP processing. No details are documented regarding the proposed grinder model, manufacturer, or performance characteristics other than $65,300 \mathrm{~kg}$ of zeolite being processed within a six month period. However, WVDP staff recollection as identified in an email from Barnes in a personal communication to $\mathrm{Smith}^{44}$ indicated that there was some initial waste particle size Scanning Electron Microscopy (SEM) images (pre-washing) reported by Rykken ${ }^{45}$. These images corroborated the reported successful size reduction to 50 microns or less, using an IKA ${ }^{\circledR} 3$ stage grinder with coarse, medium, and fine rotor/stator pairs in the WVDP waste tank farm and cold chemical facility. Additional recollection is that:

- The tank farm IKA ${ }^{\circledR}$ grinder processed zeolite streams transferred from tank 8D-1 to tank 8D-2 as well as each waste transfer into the Vitrification Facility;

- The cold chemical IKA ${ }^{\circledR}$ grinder processed each batch of glass formers sent into the vitrification cell;

- The rotor and stator sets in the tank farm grinder were not changed during operation which indicates robust operation and relative longevity (lasted for entire duration of WVDP vitrification operations); and

- The cold chemical rotor and stator sets were periodically changed as the glass formers were composed of many primary crystals.

WVDP staff recollection from Meess in a personal communication to $\mathrm{Smith}^{46}$ indicated the following regarding the successful application of the $\mathrm{IKA}^{\circledR}$ grinders:

- Solids were easier to suspend from the bottoms of tanks filled with liquids and produced a more homogeneous mix of solids and liquid (slurry);

- Tank farms related size-reduced zeolite solids were closer to particle sizes of that of PUREX sludge, which produced a more homogeneous mix of sludge and zeolite in the HLW tank that was used to feed the vitrification facility;

- Successful particle size reduction meant that the solids were able to be mobilized from the tank bottoms more easily and over a wider mobilization radius as they were found to stay in suspension longer and to be able to be pumped out without resettling;

- Easier/quicker digestion of slurry samples was achieved in laboratory analysis and the samples were thought to be more representative; and

- The tank farm grinder rotor and stator sets were not changed during operation, indicating low maintenance requirements.

The rotor and stator set required periodic changing with the glass formers indicating a sensitivity to harder particles. The application was specific to an in-line grinder so is an open circuit configuration and has its associated disadvantages as discussed above.

\subsection{SRS Tank 18/19 Zeolite Grinding}

Approximately 12,440 gallons of spent zeolite was added to Tank 19 between 1963 and $1984 .^{47}$ Subsequently, 2,500 gallons of spent zeolite resin was transferred from Tank 19 to Tank 18. Due to zeolite's physical properties (i.e., large particles and fast settling), this spent resin is difficult to suspend for removal from a waste tank. ${ }^{47}$ Some sludge particles and zeolite in SRS Tanks 18 and 19 mounds required grinding to reduce the particle size as part of sludge removal and tank closure. ${ }^{48}$ These solids 
were recovered using the Mechanical Waste Removal System (MWRS) in Tank 18 and Tank 19. The recovered solids were size reduced using a Hockmeyer ${ }^{\circledR}$ Immersion Ball Mill Grinder, which was part of the Waste Mixing Chamber (WMC). ${ }^{49,50}$ The ball mill is a stirred milled with a small milling chamber as shown along with the overall system schematic in Figure 4-1.

The WMC, including the Hockmeyer ${ }^{\circledR}$ Immersion Ball Mill Grinder, was extensively tested. "Proof of Concept" testing of the particle size reduction was completed at the Hockmeyer ${ }^{\circledR}$ Kitty Hawk, North Carolina Facility ${ }^{51}$ and a Full Scale Demonstration was completed at the TMR Associates ${ }^{\circledR}$ facility in Lakewood Colorado. ${ }^{52}$

Approximately 6,700 gallons (4,300 gallons of wet solids and 2,500 gallons of free liquid) in Tank 18 and approximately 16,800 gallons (15,000 gallons of wet solids and 1,800 gallons of free liquid) in Tank 19 were left behind in mounds after Tanks 18 and 19 were emptied. ${ }^{50}$ The remaining solids and liquid were retrieved using an additional 250,000 gallons of water. The resulting slurry was pumped to Tank 7 through the WMC (installed in riser 7) to reduce the particle size to $<38$ microns (mean between 5 and 20 microns). ${ }^{49}$ Previous testing has indicated the initial particle sizes to be $250-600$ microns. ${ }^{48}$ Total hours of operation of the Hockmeyer ${ }^{\circledR}$ grinder were 970 hours. $^{50}$ 


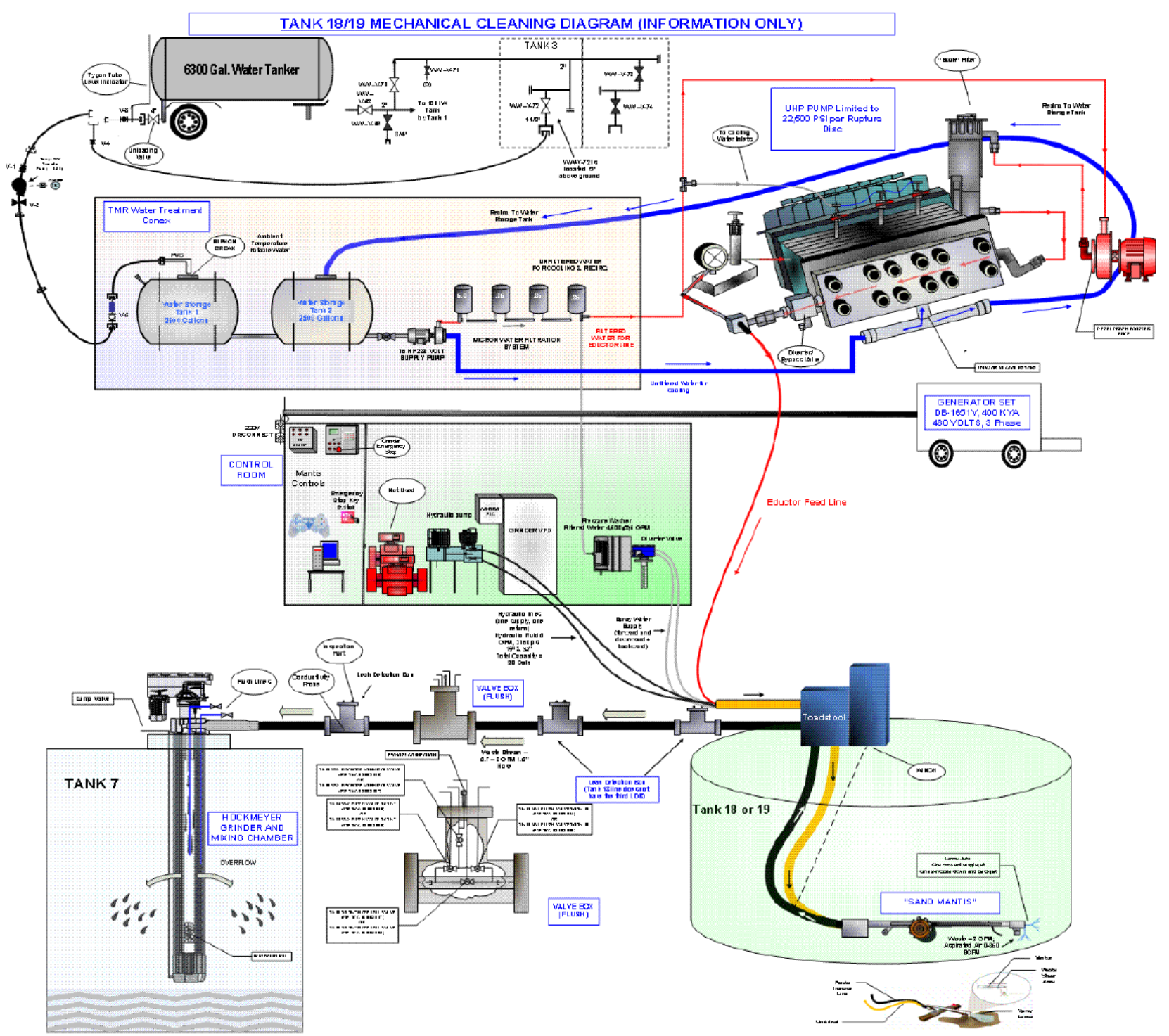

Figure 4-1. SRS Tanks 18 and 19 Installed Grinder System Schematic 
The Hockmeyer immersion mill adapted for in-tank use was used in Tank 7 to reduce the particle size of zeolite and residual sludge in SRS Tanks 18 and 19. Figure 4-2 shows the mill during installation.
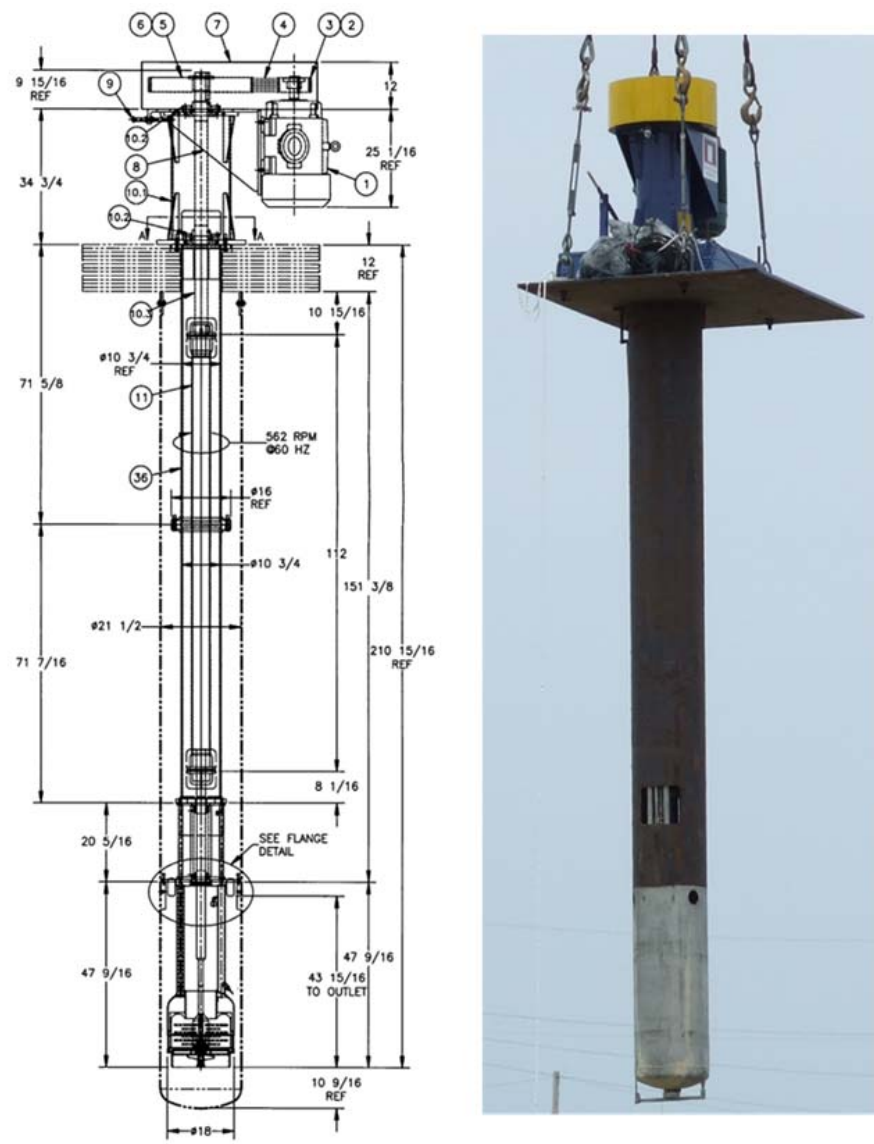

Figure 4-2. Hockmeyer Immersion Mill Adapted for In-Tank use

To assist in this mechanical cleaning of Tanks 18 and 19 of the SRS Tank Farm, a riser was required to allow the installation of the MWRS, called the Mantis. This required the core drilling of a 24 " hole for access, as all other riser plugs were utilized. This is shown below in Figure 4-3, and is provided to show the ability to provide additional access risers in an existing tank. 
SRNL-STI-2013-00472

PNNL-23030

Revision 0

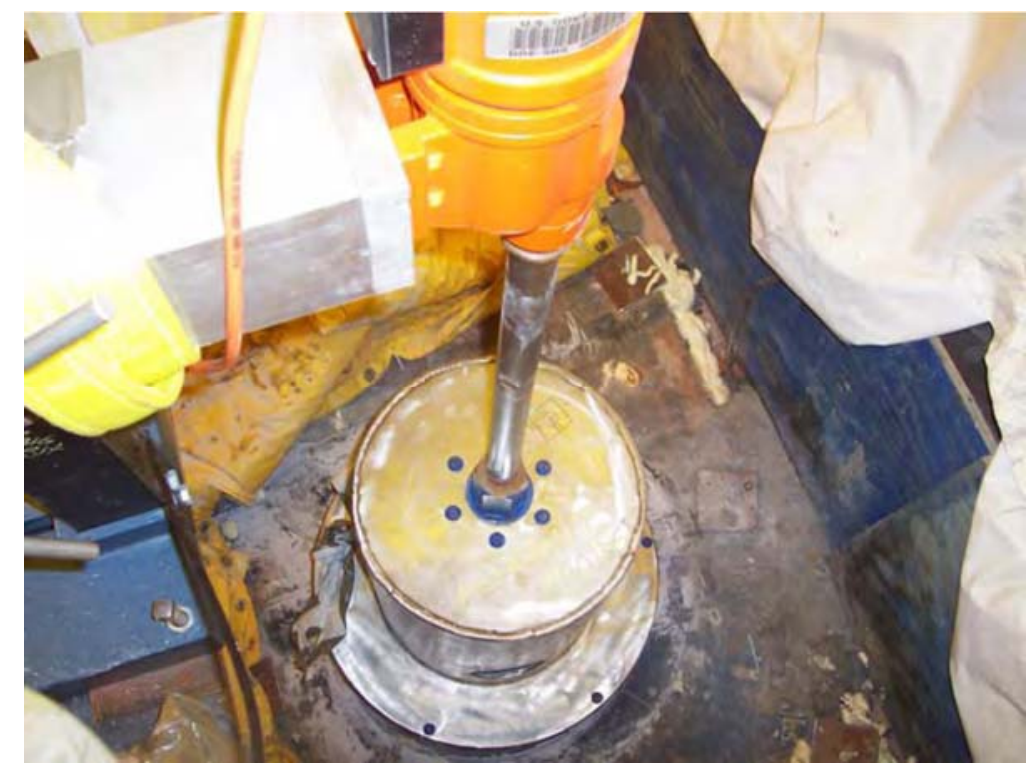

Figure 4-3. Core Drilling of New Mechanical Cleaning Riser in Tank 18

The successful performance of grinding spent zeolite and residual sludge in tanks 18 and 19 at SRS has shown that the Hockmeyer ${ }^{\circledR}$ grinder is capable of performing size reduction on HLW streams with a hardness of zeolite and the variability of sludge. In addition, research has shown the high potential for the use of similar mechanical grinders for particle size reduction processing. Use of this technology at SRS allowed retrieval and transfer of the waste with no downstream impact to HLW processing.

Application of this or any other device at DOE sites will require evaluating the load limit above the tank and may also require the construction of a support platform. Further evaluations involving slurry simulants more representative of Hanford tank waste would be required due to the differences in chemical processes used at the two sites. The SRS application was performed on predominantly zeolite and the residual sludge solids. Since the technology was used for a dedicated short campaign, equipment longevity assessments were not performed and would be required prior to considering possible future application.

This case study also shows the potential for in tank elutriation of fast settling particles. However, it is not known how much of the zeolite resin was transferred during tank retrieval, so this study should not be used to demonstrate that elutriation will preclude transfer of large particulates. In addition, the subsequent retrieval efforts after elutriation highlights a major disadvantage of in-tank elutriation in handling the large particles remaining in the tank.

\subsection{SRS SCIX Operations for CST Grinding}

SRS has spent considerable effort into grinding of sludge, zeolite (UOP IE-95), and Crystalline SilicoTitanate (CST, UOP IonSiv IE-911) due to the particle size limit of 177 microns for sampling and processing in the DWPF Chemical Processing Cell (CPC). ${ }^{53}$ Experience, sampling, and mixing and erosion studies set a limit for the largest particle size introduced in the feed stream at 177 microns, which is from the glass forming frit added in the DWPF. Testing with larger sized particles led to Hydragard sampler pluggage. This is the current basis for the 177 micron limit on any new product streams entering DWPF. 
The procured frit is sized 75-178 micron, and studies, sampling, and experience has indicated this is the largest expected and seen particle size to date. The 177 micron limit is derived from the DWPF Waste Acceptance Criteria, which set the limit based on the largest frit size introduced into the process.

Proposed application and evaluation of coupled chemical-mechanical particle size reduction has been performed at the SRS over the last decade and a half in support of the DWPF for the purpose of processing HLW and Tank Farm Operations. These coupled chemical-mechanical particle size reduction systems typically involved grinders as the mechanical means of particle size reduction.

As part of the SCIX program, in 2010 Savannah River Remediation (SRR) contracted Vitreous State Laboratory (VSL) of the Catholic University of America (CUA) to review available grinding technologies (rod mill, concentric tooth mill, immersion bead mill) for suitability for installation in a riser of a large tank. ${ }^{54}$ The results of that review were that EnergySolutions (ES)/VSL recommended further evaluation of Dispersion Reactor by IKA ${ }^{\circledR}$ Works, Inc. (a dispersion mixer with a three stage grinding system of rotor/stator generators), a Hockmeyer ${ }^{\circledR}$ Immersion Mill (a stirred ball mill), and Ultrasonic Wet Milling. ${ }^{55}$ Testing was performed with the three grinding technologies for the purpose of grinding CST (a cesium sorbent media).

The work performed based on SRS initiatives to support SCIX applications as identified by SRR $^{56}$, indicate that concentrations of up to $25 \mathrm{wt} \%$ solids could be handled without plugging when applying a higher velocity recirculative side stream in closed circuit (multiple pass) mode using a chabazite slurry simulant (recirculating line with a side stream to the grinder). The testing cited in the work involved several rotor/stator sets with different grinding clearances. However, clogging of the inlet was experienced at $25 \mathrm{wt} \%$ concentration and when finer rotor/stator sets were employed than that in Dispax Reactor DR2000/5. Additionally, wear data was found to suggest that the coarser rotor/stator sets did little of the grinding work. In this study grinding to specification was performed within a few minutes (performing at $10 \mathrm{gpm}$ ) to approximately 15 micron mean diameter (bimodal size distribution with little change after initial grinding) with slightly greater than $2 \%$ by volume oversized (larger than 38 microns).

Based on the evaluation, ES/VSL recommended that SRR proceed with the Hockmeyer immersion mill as the preferred design concept. A number of advantages for the SRR application were identified:

- A similar concept has been used at SRR tanks for processing of zeolite without significant limitations identified;

- Test data showed the mill was capable of grinding the simulant to small enough size within reasonable times; and

- The immersion mill concept was considered to be less complex and required fewer components than other grinding options. (It was noted that sonication had the potential to challenge the immersion mill with respect to simplicity of configuration; however, the sonication technology was less developed and had not been proven for this application, and therefore would have a higher risk associated with its installation.)

It was noted that the wear data were insufficient to predict equipment lifetimes. Premature wear could require frequent replacement of equipment (grinding media, basket, screens and shaft bushing).

A prior study ${ }^{57}$ also produced good mechanical particle size reduction evaluation information. Two vendors were selected to demonstrate methods of mechanical particle size reduction based on a review of existing literature of mechanical particle size reduction and experience at DOE sites. ${ }^{58}$ These were IKA Works, Inc. ${ }^{\circledR}$ in Wilmington, North Carolina and Micro-Grinding Systems, Inc. ${ }^{\circledR}$ in Little Rock, Arkansas, that manufactured rotor-stator and vibratory-kinetic energy (VKE) grinders, respectively for this performance evaluation. 
Similar to the Hanford K Basin objective, the work scope for demonstration was to reduce as-received CST to two maximum particle size requirements: a) a maximum particle size of 177 microns ( 80 mesh); and, b) a maximum particle size of 20 microns in an open circuit configuration (single pass). As noted in the report, 177 micron particles were achieved, but 20 micron particles were not successfully achieved without significant production of fines. Particles as large as 88 microns remained after testing.

As noted within this citation, the IKA ${ }^{\circledR}$ grinder reduces particle size by passing slurry through a series of concentric rotating and stationary gear teeth sets at high speed with a small clearance between the rotating and stationary sets. Size reduction is controlled by the gear teeth spacing and slurry flow. The MicroGrinding grinder performs particle size reduction by passing slurry flow through a vibrating bed of colliding cylinders and particle size is controlled by adjusting slurry flow, slurry solids concentration, and grinding medium. As such, the $\mathrm{VKE}^{\circledR}$ grinder must be specifically designed and tested for the intended waste stream. Key findings identified from this study are that:

- Both devices could be operated effectively with solids concentrations up to $10 \mathrm{wt} \%$ and possibly greater;

- $\quad$ the IKA ${ }^{\circledR}$ grinder requires a side stream as well as initiation of fluid flow through the device, prior to introduction of slurry, to mitigate inlet plugging; and

- the Micro-Grinding ${ }^{\circledR}$ grinder could favorably handle concentrations greater than $10 \mathrm{wt} \%$. The vendor indicated that the mill will operate more efficiently at higher concentrations of solids, as high liquid to solids ratios tend to cushion the grinding action of the mill.

In summary, the Micro-Grinding ${ }^{\circledR}$ grinder could handle greater solids concentrations than the IKA ${ }^{\circledR}$ grinder, without the requirement to apply a side stream for inlet plugging mitigation, but would possibly require concentration of feed slurry (via hydrocyclone separator or other applicable method) to maintain grinding effectiveness in situations involving waste feed with low solids concentration $(<10 \mathrm{wt} \%)$.

Another proposed application developed by SRS employed a grinding module as part of the SCIX System as documented by SRNL Researchers. ${ }^{59}$ The grinder module in this proposed system was part of the batch sludge preparation waste treatment subsystem. The proposed grinding module was comprised of a sand pump and grinder configured in a closed-circuit fashion.

A later study performed by SRS in support of application and evaluation of coupled chemical-mechanical particle size reduction drew similar conclusions as discussed previously regarding mechanical particle size reduction. ${ }^{59}$ This study also indicated that the IKA ${ }^{\circledR}$ grinder was the preferred grinder because of its satisfactory performance based on testing applied to a slurry comprised of zeolites. It was found to provide good control over maximum particle size in an open circuit (single pass) configuration (unimodal distribution with a maximum particle size of $<37$ microns). It was also found to provide low grinder device wear, good heat dissipation, and acceptable particle size distribution. ${ }^{58}$ The systems were effectively tested at $10 \mathrm{wt} \%$ solids and have the potential to work with higher solids loadings. The vendor claims higher efficiencies at these higher loadings.

Application of this or any other device at DOE sites will require evaluating the load limit above the tank and may also require the construction of a support platform. Further evaluations involving slurry simulants more representative of Hanford tank waste would also be required. Equipment longevity assessments were not performed as part of this study and would be required prior to considering possible future application. A potential disadvantage to the system is the requirement for a side stream to mitigate inlet plugging. 


\section{5 $\underline{\text { SRS SCIX Operations for CST Grinding using Sonication }}$}

As part of the CST grinding study, work was performed by the $\mathrm{VSL}^{56}$ to perform additional size reduction tests in support of a technology development plan for the grinder unit operations to be used in the SCIX process. The research by VSL was performed on the possibility of using Sonication particle size reduction technology on a sample of CST. Sonication uses high intensity ultrasonic energy to break up friable materials. A typical system includes a power supply that introduces sonic perturbations in the carrier fluid in the ultrasonic frequency range, typically $20 \mathrm{kHz}$. The pressure waves propagate the solution, which provides sufficient energy deposition to cause cavitation and bubble formation. The bubbles continue to grow under assault from the sonic field, eventually causing a violent implosion. The energy released during this implosion is sufficient to cause friable particles to break apart, leading to particle size reduction.

Testing was performed on CST with an initial PSD of 30-60 mesh (250-600 microns). After thirty seconds of sonication in bench scale testing, the resulting mean particle size by volume produced was 9.7 microns. Testing indicated that the mechanism of break-up was erosion not fracture. VSL suggested additional testing, with the goal of transferring greater energy into the liquid to provide greater particle reductions. Testing was performed in a batch process, and not in a continuous flow cell.

The lab setup used at the VSL is shown in Figure 4-4:

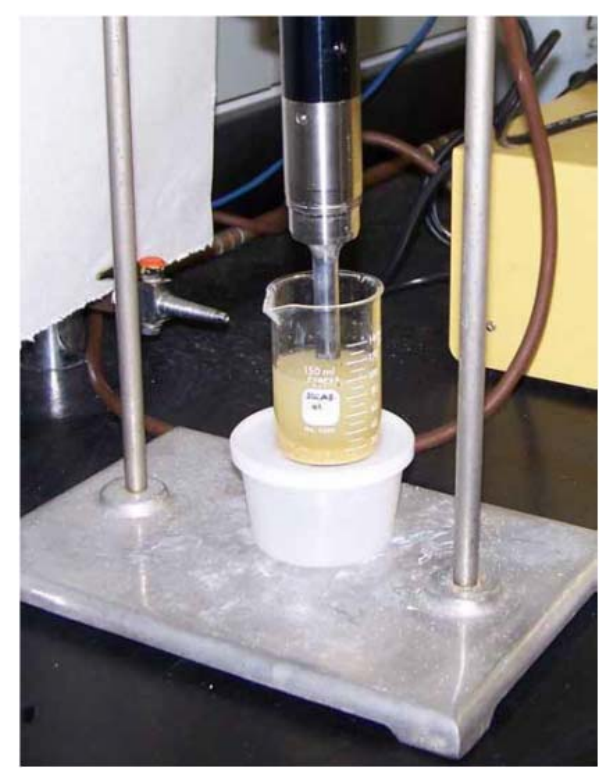

Figure 4-4. VSL Lab Sonication Test

A vendor was identified that produces equipment for sonication, or Ultrasonic Wet Milling. Heilscher Ultrasonics $^{\circledR}$ produces equipment from bench top scale to production size for particle size reduction. Results are available by request from their website ${ }^{60}$ concerning ultrasonic wet milling of titanium dioxide $\left(\mathrm{TiO}_{2}\right)$ and might support the additional consideration of this technology. 


\subsection{Mixer Effects on PSD of SRS HLW Simulants}

Fluid undergoes shear when one area of fluid travels with a different velocity relative to an adjacent area. Mixers are designed to develop various amounts of shear to promote mixing. Although all mixers impart shear by definition, some mixers are specifically designed to impart high shear forces. High-shear mixers use a rotating impeller or high-speed rotor, sometimes in concert with a stator, to create flow and shear resulting in the breakdown of agglomerates. Typical high shear mixers utilize the rotor/stator concept or a simple toothed disk and are designed to impart high shear. Key design factors include the diameter of the rotor, spacing between rotor and stator, rotational speed and the time in the mixer.

A Rushton (vertically mounted blades) turbine mixer is typically used to disperse gases in a liquid and waste and fiber processing in pulp and paper industries. They produce a unidirectional radial flow, with areas of high shear.

In 2012, researchers at SRNL performed rheology studies to determine the effects of a Rushton impeller mixer on the rheology of kaolin and xanthan gum based simulants. ${ }^{61}$ The simulants were composed of kaolin (up to $32.5 \mathrm{wt} \%$ ), and xanthan gum (up to $3 \mathrm{wt} \%$ ). The researchers found significant particle size reduction occurring during mixing using $22.5 \mathrm{wt} \%$ kaolin (other concentrations were not reported). The shift is shown below in Figure 4-5.

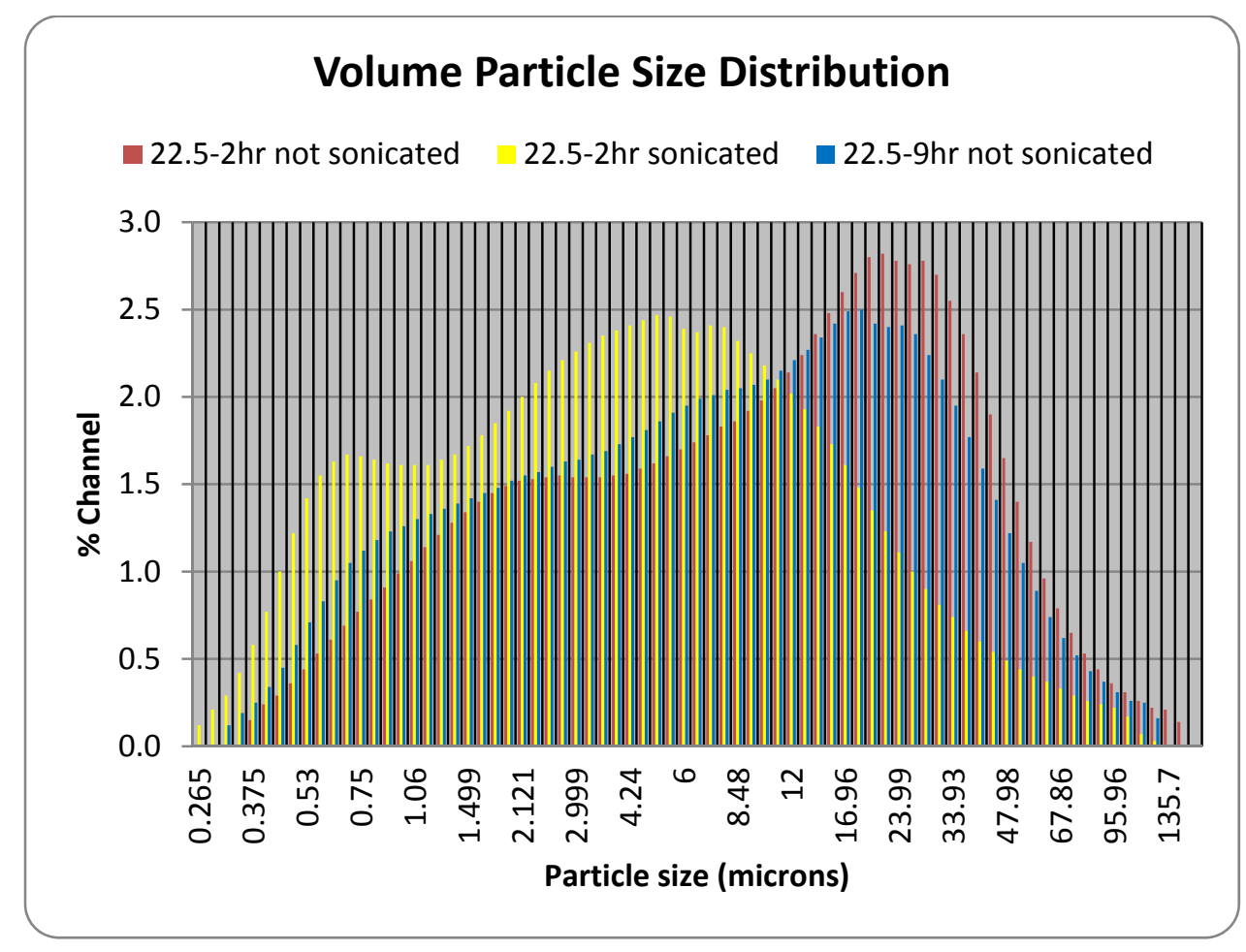

Figure 4-5. Mixer Effect on 22.5 wt\% Kaolin

Tests were performed on the $22.5 \mathrm{wt} \%$ kaolin samples for 2 and 9 hours of mixing. The results show particle size reduction during the mixing research. The researchers also noted that additional PSD shifting towards much smaller particle sizes was achieved through the use of sonication post mixing. This suggested to the researchers that shear induced particle size reduction has a limit in reducing particle sizes. 
An additional study was performed by SRNL to ascertain the impact of production methods (including mechanical shearing) on a DWPF Sludge Batch 3 simulant. ${ }^{36}$ This is detailed after the 2012 study.

The intention of the second SRNL study was to determine the best method of producing a DWPF simulated sludge based on the physical properties of the sludge. In the process, the effects of agitation/mixing on the PSD of a simulated DWPF slurry were determined. This testing used a Silverson ${ }^{\circledR}$ L4RT-A dispersion mixer using a rotor/stator generator rotating at 5000 RPM for one hour. The change in PSD is shown below in Figure 4-6.

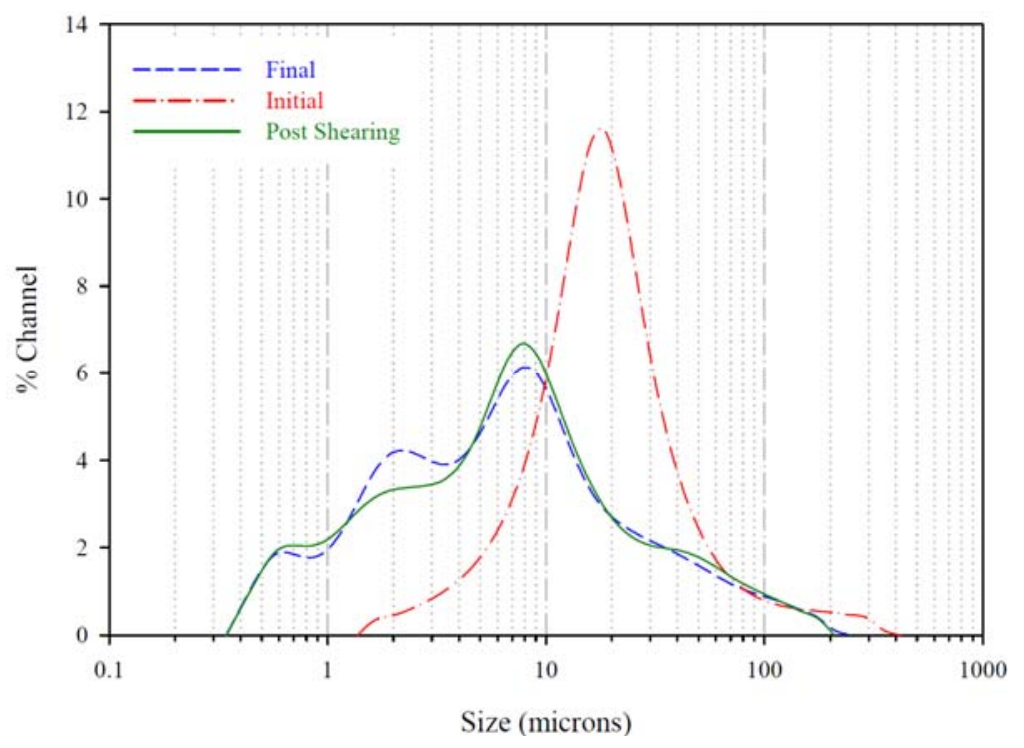

Figure 4-6. PSD Shift after One Hour of High Shear Mixing

Mechanical mixing (using a Rushton mixer in this study) was shown to be able to contribute to particle size reductions necessary for conditioning of waste slurries for WTP pretreatment. While time dependent impacts on the particle size reduction were not a direct goal of this set of studies, a later study ${ }^{62}$ with limited data did not show signs of particle growth after treatment. A blade mixer is capable of being installed in-tank, and consequently is a candidate for use in slurry conditioning prior to transport or within the HLW receipt processing tank. A rotor stator concept or other high shear mixer can also be used inside a tank for at tank or near tank processing.

To be effective, this mixer design would require full exposure to tank contents. Based on the Hanford Tank geometries, this may require the installation of mixers placed in several locations. Additional research is required to determine the shear effects on rheology pre-transfer.

\subsection{Hydrocyclone for DWPF Decontamination Frit Separation}

Hydrocyclone technology was considered for application in DWPF for separation of liquid from frit. As part of the DWPF operation, glass-filled canisters are decontaminated with a slurry of frit and water; this decon frit is then labeled as spent frit. This mixture of spent frit and water must then be sent to the Slurry Mix Evaporator (SME) tank before another canister can be decontaminated. Each canister decontamination results in generation of approximately 2000 gallons of water with about $1 \mathrm{wt} \%$ of spent frit. The large amount of water must be boiled off before the SME can be transferred to the Melter Feed 
Tank (MFT). Since the SME nominally processes five canisters worth of material with each batch, its process must be periodically interrupted, thus cutting down on its efficiency. If the spent frit mixture handling could be decoupled from the SME operation or if most of the mixture water could be removed before a transfer, then the facility could operate more effectively. Thus, hydrocyclone technology was evaluated for this application.

SRNL designed and tested a Spent Frit Decanter/De-coupler System. ${ }^{39}$ This system was to have a capacity to retain approximately seven canisters worth of spent frit while removing most of the water. The proposed design included a hydrocyclone to separate the spent frit from the water and a decanting reservoir to hold this frit. Initial small-scale testing determined that the decoupling and decanting was possible; however, the process improvement was not pursued by DWPF and they will be evaluating potential improvements in this area as funding allows. In any case, the results of this can be useful in applying the hydrocyclone to other segregation needs.

A test was performed to evaluate a hydrocyclone with varying frit loadings into a frit and water slurry that could be expected in plant operation. This test used slurries with frit loadings of $1 / 4 \mathrm{wt} \%, 4 \mathrm{wt} \%, 8 \mathrm{wt} \%$, $15 \mathrm{wt} \%, 25 \mathrm{wt} \%, 35 \mathrm{wt} \%$, and $45 \mathrm{wt} \%$. The slurry flow rate for the spent frit system was approximately $100 \mathrm{gpm}$ and tested flow rates were $70 \mathrm{gpm}, 90 \mathrm{gpm}$, and $110 \mathrm{gpm}$ in 3 -inch schedule 40 piping. The lowest flow of 70 gpm was used to make sure frit settling did not occur and confound the test results. Knowing the expected slurry flow rates, the pumping capacity of the Canister Decontamination Cell system, and the frit particle sizes, a 6-inch hydrocyclone was chosen for evaluation. The internal dimensions of the device are shown in Figure 4- $7^{39}$ : 
SRNL-STI-2013-00472

PNNL-23030

Revision 0

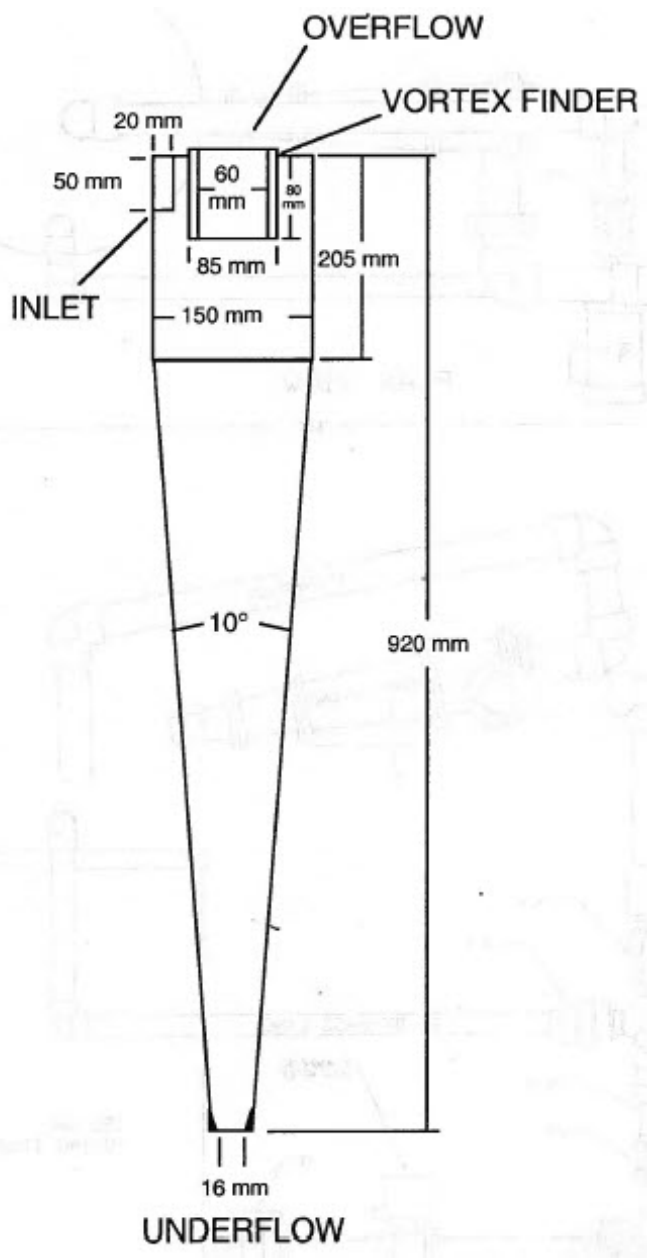

Figure 4-7. Internal Dimensions of Warman Hydrocyclone Tested

These following results are based on a "six-inch" hydrocyclone operating between 70 gpm and 110 gpm:

- $2 \%$ by volume loss through underflow with water only feed;

- $\quad>97 \mathrm{wt} \%$ solids removal observed with up to $8 \mathrm{wt} \%$ frit loading;

- Solids removal rate drops as frit loading decreases and was approximately liner (for example, at $15 \mathrm{wt} \%$ frit, removal was $90 \%$ while it was only $25 \%$ at $45 \mathrm{wt} \%$ frit);

- Particle separation was most effective at frit loadings $<15 \mathrm{wt} \%$ with particles $>74$ microns primarily found in the separated solids and particles $<74$ microns primarily found in the separated liquid, but the separated liquid had only a small percentage of particles; and

- At frit loading $>15 \mathrm{wt} \%$, significant quantities of large particles ( $>74$ microns) were found in both the separated solids and separated liquid streams.

\subsection{Screening/Sieving of Hanford Ion Exchange Resin}

SRNL performed sieving operations in support of Hanford River Protection Project (RPP) Ion Exchange research. ${ }^{63}$ The work was performed as a pretreatment of the resin prior to the laboratory studies. Shown below in Figure 4-8 is the general arrangement used for the sieving operation and a photo of the actual sieving being performed is shown in Figure 4-9. 
SRNL-STI-2013-00472

PNNL-23030

Revision 0

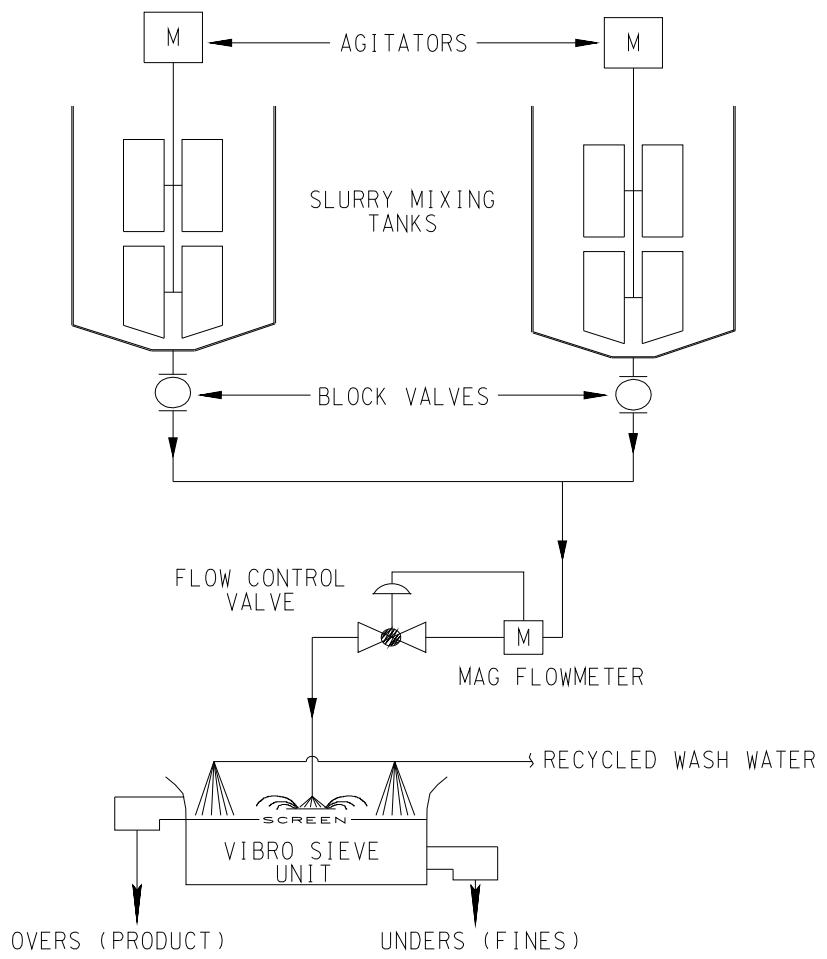

Figure 4-8. Sieving Piping and Instrument Diagram

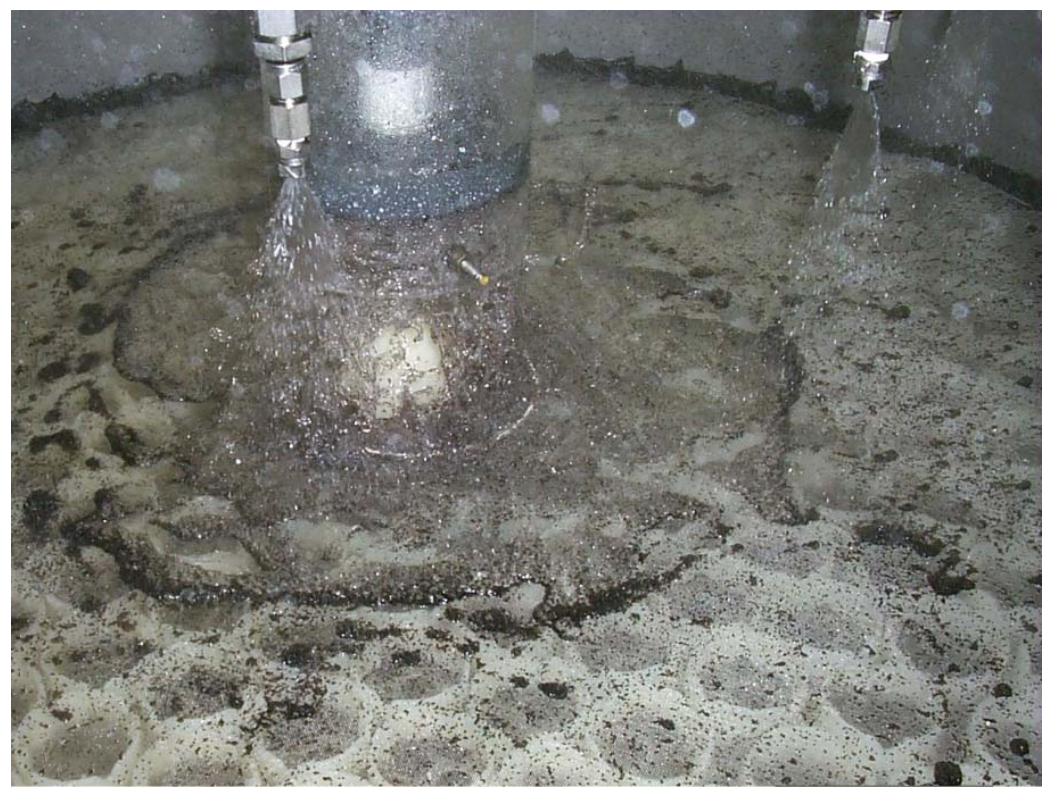

Figure 4-9. Sieving of Resin 
The sieve used was a SWECO ${ }^{\circledR}$ XS48 48" diameter round vibratory sieve. The original resin pretreatment required a PSD of 20/30 mesh fraction. By definition, this specification implied a resin PSD where the fraction $<30$ mesh ( $<600$ microns) and the fraction $>20$ mesh ( $>850$ microns) are each less than $1 \%$ by weight, i.e. $98 \%$ by weight of the particles will be within the range of 600 to 850 microns. This criterion was changed, and an ultimate criterion of 18/40 mesh fraction was determined to be appropriate. This translates to a resin PSD where fraction $<40$ mesh $(<425$ microns $)$ and the fraction $>18$ mesh $(>1000$ microns) are each less than $1 \%$ by weight, i.e. $98 \%$ by weight of the particles will be within the range of 425 to 1000 microns. This was successfully achieved.

Information from the Sweco ${ }^{\circledR}$ website $^{64}$ provides an illustration of applications of a vibratory sieve in Figure 4-10. 
SRNL-STI-2013-00472

PNNL-23030

Revision 0

\section{Separation Processes}

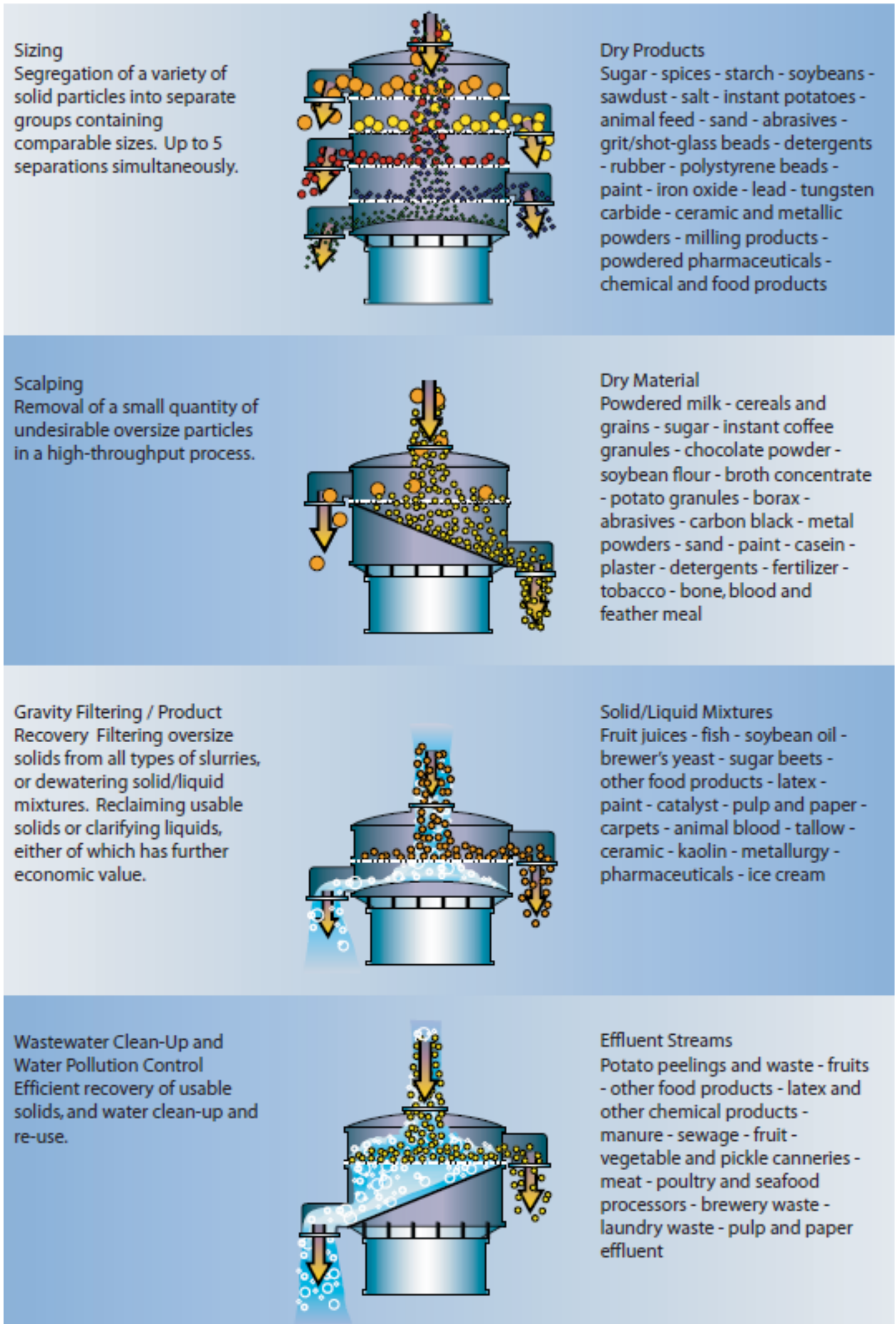

Figure 4-10. Applications of Vibratory Sieve 
SRNL-STI-2013-00472

PNNL-23030

Revision 0

\subsection{Slurry Pump Modifications Proposed by Curtiss Wright Flow Company-SMP Vendor}

Curtiss Wright Flow Control Company is currently working with Washington River Protection Solutions (WRPS) personnel in developing a new Hanford Submersible Transfer Pump (HSTP). In collaboration with that work, Curtiss Wright has proposed several design modifications ${ }^{65}$ to their line of pumps that can perform some engineered particle size reduction and separation. They considered four methods to accomplish particle size reduction and separation. These included:

- Aggressively limit number of particles transferred;

- Use of separator to limit maximum particle size transferred;

- Size Reduction through integrated grinder; and

- Maximize particle size transferred through pump.

A model of the pump they have proposed is shown below in Figure 4-11.

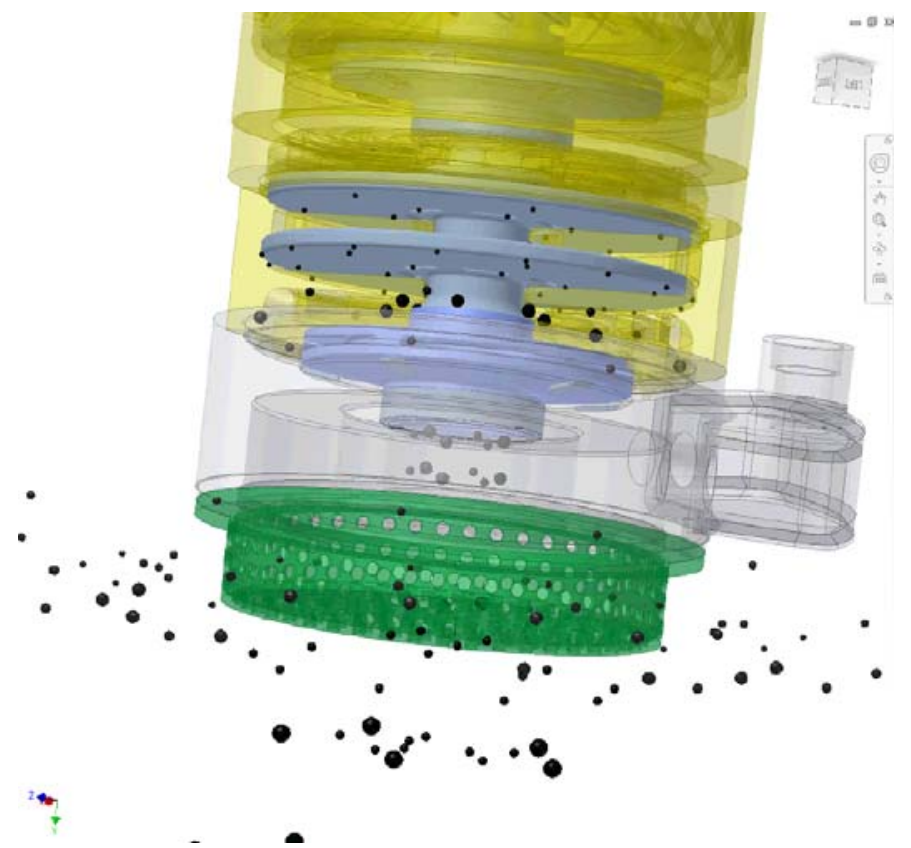

Figure 4-11. Curtiss Wright Flow Control Company Modified Mixer Pump Model

Curtiss Wright proposed accomplishing these tasks through a variety of design changes, including:

- Inlet Auger (actively draws particles into intake);

- Suction Screen Shielding (engineered design to minimize or maximize inlet velocities);

- In Line Particle Grinder/Crusher (integrated grinder);

- Bypass Mixing Jets (Inter-stage Bypass to entrain additional particles through impinging jets);

- Rotating Particle Separator (Redirect flow based on particle densities); and

- Rotating Filter (Similar to that used in the SCIX testing). 
They identified potential pitfalls to be overcome through development work, including:

- Wear,

- Plugging/Fouling,

- Changing Slurry Properties,

- Changing Particle Constituents,

- Throughput/Particle Size Balance,

- Optimum Size/Speed,

- Manufacturing, and

- Material Selection.

The modifications suggested by Curtiss Wright, if successfully implemented, would provide a significant contribution to both particle size reduction and separation.

However, the disadvantage to a modified slurry pump to provide size reduction would be the inability to discontinue size reduction while still slurrying the waste, i.e. overgrinding considerations. In addition, there is no certainty that the proposed changes by Curtiss Wright will be effective without significant research and development.

\subsection{0 $\underline{\text { AWRS using Grinding and Segregation }}$}

Fazio \& Gibbons documented the development of the AWRS. ${ }^{24}$ The AWRS was a demonstration of DOE developed technology where all components had been tested at full scale and were designed for conditions in the WVDP HLW tanks. The AWRS was designed and fabricated for installation into WVDP tanks should waste removal criteria not be met using the proposed mobilization and retrieval methods. This device was intended to eliminate the need for a mobilization pump to suspend particles in solution for retrieval and to decrease the amount of water required for retrieval. This work was performed under the direction of West Valley Nuclear Services (WVNS).

The AWRS consisted of a second generation mass tool delivery (MTD) assembly based on previous lessons learned, telescopic arm and jet pump assembly, modified G-012/G-012A transfer pump assembly, grinder-separator assembly, booster pump assembly, and a remote control skid assembly that was capable of being inserted down a 24" diameter tank riser. Retrieved waste was drawn through the new transfer column (provided with the AWRS) to a grinder-separator assembly. A hydrocyclone separator diverted small ( $<50$ microns) particles and about $90 \%$ of the water around the grinder. The large-particles in the hydrocyclone underflow stream were size-reduced in a VKE grinder. The small-particle overflow stream (from the hydrocyclone separator) and size-reduced particle stream (from the grinder) were combined at the outlet of the grinder and then transferred to the WVDP Vitrification Facility with the assistance of the booster pump assembly. As such, the grinder was applied in an open circuit (single pass) fashion. The grinder-separator assembly was comprised of a $\mathrm{VKE}^{\circledR}$ vibratory rod mill unit and was a commercially available design from MicroGrinding ${ }^{\circledR}$ Systems, Inc.

An advantage of the $\mathrm{VKE}^{\circledR}$ mill (grinder), identified in this citation, is the generation of much higher impact, or grinding forces, than ball mills or other similar media mills, which are based on the gravity force generated by falling balls or rods impacting the material to be size-reduced. As identified, $\mathrm{VKE}^{\mathbb{B}}$ mills are believed to generate greater impact forces through the rapid vibration of a motor-driven grinding chamber.

Full scale testing of the AWRS revealed that the use of a jet pump with the suction head at the tank bottom eliminated the need for a mobilization pump to suspend particles in solution for retrieval. Particle 
sizes up to $0.5 \mathrm{~cm}(0.2 \mathrm{inch})$ were removed from the test tank. The grinder-separator assembly successfully met a requirement that $90 \%$ of the particles passing through the grinder outlet be smaller than 200 microns. Associated sampling results showed that $99 \%$ of the solids were reduced below the required 200 micron size.

Application of this or any other device at DOE sites will require evaluating the load limit above the tank and may also require the construction of a support platform. Further evaluations involving slurry simulants more representative of Hanford tank waste would also be required as original testing was performed on zeolite size reduction and transfer exclusively. Equipment longevity assessments were not performed as part of this study and would be required prior to considering possible future application.

\subsection{Summary of Case Studies}

Nuclear waste has been effectively size reduced with homogenizers and media mills. Size segregation has been performed less often, but testing with simulants has shown the potential for hydrocyclones to be effective. Typically, an open grinding circuit was utilized in a once through operation for most of the case studies.

None of the case studies attempted to reduce particle sizes to a median size, typically a maximum particle size was specified. The size reduction processes reviewed typically had resulted in a maximum particle size smaller than the 310 microns that has been proposed for the Hanford feed ${ }^{\mathrm{v}}$. Attempts to achieve very small particles after grinding often resulted in production of a large number of fines. Wear was noted for some of the applications, but the length of operation for most of the case studies was too short to identify maintenance issues with the equipment utilized.

\footnotetext{
v 24590-WTP-ICD-ENG-13-0001, "ICD-19 Interface Change Form”, draft, has been approved by Washington River Protection
} Solutions (WRPS) and WTP but is currently with ORP for approval. 


\subsection{Conclusions}

Over the years, significant research has been performed on slurry particle size reduction, segregation, and solids separation technologies, particularly those technologies appropriate to nuclear waste disposal. Efforts by PNNL, SRNL, and others have helped personnel better understand the possible benefits of different technologies.

To meet the precondition requirements established in the Interface Control Document (ICD) for Waste Feed (ICD-19) and the proposed 310 micron maximum particle size limit ${ }^{\mathrm{vi}}$, SRNL/PNNL reviewed existing technologies, commercial technologies not currently applied to a nuclear environment, and technologies in use or studied for use in a nuclear environment, particularly those technologies designed for waste slurry conditioning. Because of the significant unknowns (actual feed composition, final feed conditioning requirements, insertion point in the Hanford flowsheet), SRNL/PNNL maintained flexibility in the analysis to be inclusive of technologies which may prove appropriate as feed composition, process flowsheets, and/or requirements change.

The technologies considered are applicable for conditioning the waste to meet the current waste acceptance criteria of HLW Feed to WTP and are based on the current knowledge of the waste feed properties and the current requirements for particle size in the WTP ICD-19 and the proposed 310 micron maximum particle size limit. The technologies considered most promising for Hanford application are further subdivided into those applicable to size reduction and those applicable to solids segregation.

Size reduction technologies that appear promising include:

- Stirred media mills,

- Homogenizers, and

- Some grinding technologies appear to have promise but are untested with nuclear waste.

The solids segregation technologies that appear most promising include hydrocyclones and screening. Hydrocyclones have replaced screening in many applications in the mineral industry, but screening has an advantage in separation efficiency. This advantage in separation efficiency may make screening a better option for the Hanford waste treatment.

A combined size reduction and solids segregation technology process that appears promising involves:

- Initial size separation of the effluent from the primary transfer pump using a centrifugal screener, with the oversized particles diverted to a size reduction process.

- Size reduction of the oversized particles using an immersion grinder mill, and then recycle of the feed to the centrifugal screener.

o The immersion grinder mills could utilize one of the following technologies: Stirred ball mill (similar to the Hockmeyer used for Tank 18/19 zeolite grinding) or a homogenizer (similar to the IKA ${ }^{\circledR}$ grinder used for the WVDP).

Centrifugal pumps will be used to mobilize the sludge during waste retrieval and in preparation for feeding the WTP. The pumps will apply shear to the particles resulting in some size reduction, especially in loose agglomerates. However, the pumps may be less efficient than other processes, may not be able to achieve fine particle sizes, and may be ineffective on hard particles. The potential also exists that over-

vi24590-WTP-ICD-ENG-13-0001, "ICD-19 Interface Change Form”, draft, has been approved by Washington River Protection Solutions (WRPS) and WTP but is currently with ORP for approval. 
shearing could occur resulting in negative impacts on slurry rheology. Therefore, the impact of the pumps must be considered when selecting the size reduction/solid segregation technology.

Testing of any proposed grinding circuit will be required to ensure that the specified equipment can achieve the targeted particle size without causing excessive fines and to determine the appropriate operating parameters for the system once installed.

It is noted that the final particle size specification for the WTP WAC is still being refined as technical issues are being resolved for the processing facilities. As discussed in Section 1.4, testing for the DWPF facility and the potential introduction of new product streams in the DWPF has led to changes in the DWPF WAC that currently limits new product streams to a maximum particle size of 177 microns. This was the maximum particle size for frit that allowed for acceptable mixing, erosion, and sampling. A draft maximum particle size limit of 310 microns is under review for the HLW feed to the PT facility.

Changes to the final particle specification, including the selected methods for controls, could impact the selection for the type of grinding circuit as well as the individual components in the circuit. Processing options such as direct HLW vitrification could lead to significant changes in the particle size requirements and the technologies would need to be reassessed for applicability.

The laboratories have provided an initial screening of the available technologies for performing size reduction and solids segregation in a radioactive slurry environment. Additional information on how the system will fit with the Hanford flowsheet and on performance testing in this application is required prior to performing a final selection of equipment to be used for size reduction/segregation:

- Finalized particle size requirements for the treated feed

The particle size specification is currently in draft form and is still under review. In addition, changes in processing strategy (e.g. direct HLW or the technical studies being performed to resume PT engineering, procurement, and construction) could impact the final particle size required. While it is possible to design a size reduction process with some flexibility to handle changes in the final particle size specification, the resulting system will be somewhat more complex than a system designed with a set particle size specification.

- Characterization of the feed after retrieval

The characterization of the feed stream is critical to properly designing the size reduction/segregation system. For example, a better understanding of the percentage of the feed that must be ground to size would help to properly size the grinding circuit to meet throughput requirements.

Once the required information is available, a down select should be performed with input from the national laboratories, system engineering, operations, and the necessary stakeholders. This down select process should select a primary and secondary option for the size segregation and the grinding processes. Testing of the proposed grinding circuit should then be performed to evaluate the effectiveness and robustness of the circuit in a flowsheet representative of what will be used at Hanford prior to installation. The testing should include a RAMI evaluation. Once the testing is complete, a final selection of the size reduction/segregation system can be performed. 
SRNL-STI-2013-00472

PNNL-23030

Revision 0

\subsection{References}

1. Defense Nuclear Facility Safety Board, Pulse Jet Mixing at the Waste Treatment and Immobilization Plant, DNFSB Recommendation 2010-2, (December 17, 2010).

2. U.S. Department of Energy (DOE), Response Letter from S. Chu to P.S. Winokur for DNFSB Recommendation 2010-2, Washington, D.C. (February 10, 2011).

3. U.S. Department of Energy, Department of Energy Plan to Address Waste Treatment and Immobilization Plant Vessel Mixing Issues, Implementation Plan for Defense Nuclear Facilities Safety Board Recommendation 2010-2, Revision 0, Washington, D.C. (2011).

4. J. E. Meacham, et. al., One System Evaluation of Waste Transferred to the Waste Treatment Plant, RPP-RPT-51652, Revision 0, Washington River Protection Solutions, LLC, Richland, WA (June 2012).

5. Office of River Protection, Low Temperature Waste Forms Coupled with Tc Removal, Waste Feed Acceptance, and Alternative Flow Sheets and Technologies, IEWO M0SRV00091, Revision 1, Department of Energy - Office of River Protection (May 9, 2013).

6. Office of River Protection, Low Temperature Waste Forms Coupled with Tc Removal, Deep Sludge Gas Release Events Waste Feed Acceptance, and Alternative Flow Sheets and Technologies, IEWO M0ORV00090, Revision 1, Department of Energy - Office of River Protection (May 9, 2013).

7. C. C. Herman and S. H. Reboul, Task Technical and Quality Assurance Plan for Strategic Initiatives Related to Hanford Waste Treatment and Immobilization Plant (WTP) Feed Acceptance and Qualification Strategy, SRNL-RP-2013-00364, Savannah River National Laboratory, Aiken, SC (2013).

8. K. P. Lee, B. E. Wells, P. A. Gauglitz, and R. A. Sexton, Waste Feed Delivery Mixing and Sampling Program Simulant Definition for Tank Farm Performance Testing, RPP-PLAN-51625, Revision 0, River Protection Project, Richland, WA (2012).

9. B. E. Wells, D. E. Kurath, L. A. Mahoney, Y. Onishi, J. L. Huckaby, S. K. Cooley, C. A. Burns, E. C. Buck, J. M. Tingey, R. C. Daniel, and K. K. Anderson, Hanford Waste Physical and Rheological Properties: Data and Gaps, PNNL-20646, 2011.

10. J. W. Olson, ICD 19 - Interface Control Document for Waste Feed, 24590-WTP-ICD-MG-01019, Revision 5, Waste Treatment Plant, Richland, WA (2011).

11. E. Slaathaug, ICD 19 - Interface Control Document for Waste Feed, 24590-WTP-ICD-MG-01019, Revision 6, Waste Treatment Plant, Richland, WA (2013).

12. B. E. Wells, Simulant Development for Hanford Tank Farms Double Valve Isolation (DVI) Valves Testing, PNNL-22121, Pacific Northwest National Laboratory, Richland, WA (2013).

13. J. A. Bamberger, J. R. Bontha, H. E. Adkins, C. A. Burns, B. E. Wells, J. Blanchard, K. M. Denslow, M. S. Greenwood, and G. P. Morgan, Hanford Tank Farms Waste Certification Flow 
SRNL-STI-2013-00472

PNNL-23030

Revision 0

Loop Test Plan for Instrument Evaluation, PNNL-18936, Pacific Northwest National Laboratory, Richland, WA (2010).

14. Requisition 244607, Design of Hanford Submersible Transfer Pump, 2012.

15. RPP-5346 Rev. 2, Waste Feed Delivery Transfer System Analysis, 2002.

16. F. C. Bond, Third Theory of Comminution, Mining Eng. Trans., AME, 193. 484-194 (1952).

17. J. A. Holmes, A Contribution to the Study of Comminution, a Modified Form of Kick's Law, 1957.

18. R. P. von Rittinger, Textbook of Mineral Dressing, Ernst and Korn, Berlin (1867).

19. F. Kick, Das Gasetz der proportionalen Widerstände und seine Anwendung, Liepzig (1885).

20. J. W. Schlanz, Grinding: An overview of Operation and Design, North Carolina University, Minerals Research Laboratory, Asheville, NC (1987).

21. B. A. Wills, Wills' Mineral Processing Technology - An Introduction to the Practical Aspects of Ore Treatment and Mineral Recovery, ISBN: 978-0-7506-4450-1, Julius-Kruttschnitt Mineral Research Centre, Published by Elsevier Ltd., Oxford, UK (2006).

22. B. E. Abulnaga, Slurry Systems Handbook, ISBN: 0-07-137508-2, The McGraw-Hill Companies, New York, NY (2002).

23. W. L. McCabe, J. C. Smith, and P. Harriot, Unit Operations in Chemical Engineering, McGrawHill Book Company, New York, New York, $4^{\text {th }}$ Edition (1985).

24. DOE/EM-0607, Advanced Waste Retrieval System - Tank Focus Area, Innovative Technology Summary Report, Prepared for U.S. Department of Energy, Office of Environmental Management, Office of Science and Technology, (September 2001).

25. R. DiBiase, R. R. Borisch, and R. A. Humphrey, West Valley Demonstration Project - Design Criteria, WVNS-DC-045, Revision 1, West Valley Nuclear Services Co., NY (February, 1987).

26. D. J. McCabe, L. L. Hamm, S. E. Aleman, D. K. Peeler, C. C. Herman, and T. B. Edwards, High Level Waste System Impacts from Small Column Ion Exchange Implementation, WSRC-TR2005-00034, Revision 0, Savannah River National Laboratory, Aiken, SC (August 18, 2005).

27. G. A. Diener, R. K. Mohr, I. L. Pegg, and T. H. Huff, Small-Scale Testing of Potential Small Column Ion Exchange (SCIX) Grinder Technologies, ${ }^{(1)}$ Energy Solutions, ${ }^{(2)}$ Vitreous State Laboratory, Catholic University of America, ${ }^{(3)}$ Savannah River Remediation.

28. Handbook of Non-Ferrous Metal Powders-Technologies and Applications, edited by O. D. Neikov, S. S. Naboychenko, G. Dowson, 2009, ISBN 978-1-85617-422-0.

29. Website, http://www.unionprocess.com/tech_papers/ChooseTheRightGrindingMill.pdf. 
30. K. Kwade, Specific Energy Consumption, Stress Energy, and Power Draw of Stirred Media Mills and Their Effect on the Production Rate, Advances in Comminution proceedings, Edited by SK Kawatra, ISBN-13: 978-0-87335-246-8, pp 99-114, Published by Society for Mining, Metallurgy, and Exploration, Inc., (2006).

31. J. K. Lichter, and H. G. Davey, Selection and Sizing of Ultrafine and Stirred Grinding Mills, Advances in Comminution proceedings, Edited by SK Kawatra, ISBN-13: 978-0-87335-246-8, pp 69-85, Published by Society for Mining, Metallurgy, and Exploration, Inc. (2006).

32. I. J. Karrassik, W. C. Krutzch, W. H. Fraser, and J. P. Messina. 1986 Pump Handbook. $2^{\text {nd }}$ Edition. McGraw-Hill Book Company. New York, NY.

33. Weir Slurry Division, Slurry Pumping Manual, $1^{\text {st }}$ edition, Warman International LTD, Todmorden, Lancashire, UK (2002).

34. J. Yue and B. Klein, Effects of Bead Size on Ultrafine Grinding in a Stirred Bead Mill, Advances in Comminution proceedings, Edited by SK Kawatra, ISBN-13: 978-0-87335-246-8, pp 87-98, Published by Society for Mining, Metallurgy, and Exploration, Inc. (2006).

35. G. Armantrout, W. Brummond, T. Clausen, B. Hobson, C. Herman, D. Herman, D. Hiland, D. Pak, Technical Status of the Plutonium Ceramification Test Facility, Waste Management 2000, March 1, 2000

36. R. E. Eibling, Impact of Simulant Production Methods on the Physical Properties of DWPF Sludge Batch 3 Simulant, WSRC-TR-2004-00578, Westinghouse Savannah River Company, Aiken, SC (2005).

37. Svarovsky, Hydrocyclones, Technomic Publishing Co., Inc. (1984).

38. R. Pickford, editor, Hydrocyclones, 2nd International Conference on Hydrocyclones, Bath, England, 19-21 (September, 1984).

39. M. R. Duignan, Final Report: DWPF Glass Frit and Water Separation Test, WSRC-TR-9800107, Westinghouse Savannah River Company, Aiken, SC (1998).

40. V. G. Renner and H. E. Cohen, "Measurement and Interpretation of Size Distribution of Particles within a Hydrocyclone", Trans. Inst. Min. and Extr. Met, 87, C139-C145 (1978).

41. G. G. Chase and E. Mayer, Filtration, Kirk-Othmer Encyclopedia of Chemical Technology, Edited by Arza Seidel, et. al., ISBN-13: 978-0-47123-896-6, John Wiley \& Sons, Inc., Hoboken, NJ (2013).

42. D. R. Precechtel and M. J. Packer, Evaluation of Process for Sludge Particle Size Reduction, HNF-SD-SNF-TI-051, Revision 0, Duke Engineering and Services Hanford, Richland, WA (March 18, 1997).

43. S. Kelly Jr. and D. C. Meess, Thorex Processing and Zeolite Transfer for High-Level Waste Stream Processing Blending, West Valley Nuclear Services Company, Inc., DOE/NE/44139-82, (July, 1997). 
SRNL-STI-2013-00472

PNNL-23030

Revision 0

44. S. Barnes, WVDP Slurry Grinding Experience Request: Literature Review of Technologies/Equipment for Sludge/Slurry Particle Segregation and Size Reduction. Message to Gary L Smith, 12 June, 2013. E-mail.

45. L. E. Rykken, High-Level Waste Characterization at West Valley, West Valley Nuclear Services Company, Inc., DOE/NE/44139-14, (June 2, 1986).

46. D. Meess, WVDP Slurry Grinding Experience Request: Literature Review of Technologies/Equipment for Sludge/Slurry Particle Segregation and Size Reduction. Message to Gary L Smith. 13 June, 2013. E-mail.

47. B. A. Hamm, Tank Farm Zeolite Historical Review and Current Inventory Assessment, CBUPIT-2005-00099, Westinghouse Savannah River Company, Aiken, SC (2005).

48. R. Eibling, et. al., Potential Impact of Blending Residual Solids from Tanks 18/19 Mounds with Tank 7 Operations, WSRC-STI-2007-00113, Savannah River Technology Center, Aiken, SC (2007).

49. Industrial Wastewater Closure Module for the Liquid Waste Tanks 18 and 19 F-Area Tank Farm, SRR-CWDA-2010-00003, Revision 1, Savannah River Site, Aiken, SC (2010).

50. T. Huff, Mechanical Cleaning of SRS Tanks 18 and 19, LWO-LWE-2009-00133, Savannah River Site, Aiken, SC (2009).

51. T. Huff, Trip Report for Hockmeyer Immersion Ball Grinder, SRR-SCIX-2010-00015, Savannah River Site, Aiken, SC (2010).

52. T. H. Huff, TMR Phase II Demonstration Summary, LWO-LWE-2008-00065, Savannah River Site, Aiken, SC (2008).

53. J. W. Ray, Waste Acceptance Criteria for Sludge, ARP, and MCU Process Transfers to 512-S and DWPF, X-SD-G-00008, Revision 11, Savannah River Site, Aiken, SC (April 2013).

54. Energy Solutions/VSL, Modular Salt Processing Support, M-SOW-H-00203, Revision 2, Washington DC.

55. R. A. Callow, G. A. Diener, R. K. Mohr, and I. L. Pegg, Defense Waste Processing Facility (DWPF) Grinder Evaluation Report, RPT-5539-ME-0003, Revision 0, EnergySolutions, Washington DC (June 2010).

56. R. K. Mohr, I. L. Pegg, R. A. Callow, and G. A. Diener, Data Summary Report-Small Column Ion Exchange (SCIX) Grinder Testing, VSL-10S2100-1, EnergySolutions, Washington DC (2010).

57. R. C. Odom and F. G. Smith III, CST Particle Size Reduction Test, WSRC-TR-2000-00350, Westinghouse Savannah River Company, Aiken, SC (2000). 
SRNL-STI-2013-00472

PNNL-23030

Revision 0

58. F. G. Smith, III and M. A. Baich, CST Particle Size Reduction: Consultation and Literature Review, SRT-PCC-2000-0008, Savannah River Technology Center, Aiken, SC (March 7, 2000).

59. D. F. Bickford, G. D. Creech, and D. C. Beam, Confirmation of Small Column Ion Exchange Crystalline Silicotitanate (CST) Grinder Configuration and Estimation of Treatment Cycle, WSRC-TR-2005-00282, Westinghouse Savannah River Company, Aiken, SC (2005).

60. Website, http://www. hielscher. com/technolo. htm\#Ultrasonic_Wet_Milling

61. E. K. Hansen, A. D. Marzolf, and K. R. Hera, SRNL-EM Vane Rheology Results, SRNL-STI2012-00519, Savannah River National Laboratory, Aiken, SC (2012).

62. A.I. Fernandez, SRNL-STI-2010-00307, "Sludge Batch 6 Supplemental SRAT Runs: Effects of Yield Stress and Cycle Time Increase", August 2010

63. M. D. Fowley, et. al., Ion Exchange Testing with Superlig®644 Resin, WSRC-TR-2003-00514, Westinghouse Savannah River Company, Aiken, SC (2004).

64. Website, http://www.sweco.com/products_screener_round.html

65. P. E. Stover and E. Conaway, Submersible Transfer Pump - Particle Processing Potential, Presentation by Curtiss Wright Flow Control Company Personnel, 2012.

66. E. Saldivar, Jr., Savannah River Site Waste Removal Program-Past, Present, and Future, WSRC-TR-2002-00059, Westinghouse Savannah River Company, Aiken, SC (2002).

67. P. N. Bhatt and T. B. Caldwell, Operational Challenges in Mixing and Transfer of High Yield Stress Sludge Waste - 10263, SRR-CES-2009-00043/WM2010-10263, Savannah River Remediation, Aiken, SC (2010).

68. J. R. McCullough, SRS Sludge Mixer \& Transfer Pumps, SRR Presentation, Savannah River Remediation, Aiken, SC (2009).

69. C. L. Sharpe and D. B. Stefanko, TNX/HLW Long Shaft Pumps 1995-2000, WSRC-TR-200100313, Westinghouse Savannah River Company, Aiken, SC (2001).

70. M. R. Duignan, C. A. Nash, and P. S. Townson, "Pilot-scale Cross-flow Filtration for a Radioactive Waste Simulant with High Solids Concentration and Sodium Molarity", Paper No. 302 , Proceeding of the $4^{\text {th }}$ International Conference of Multiphase Flow, New Orleans, LA (May 27 - June 1, 2001).

71. M. R. Duignan, C. A. Nash, and P. S. Townson, "Cross-flow Filtration with a Shear-thinning Organic-based Slurry", Paper No. 303, Proceedings of the $4^{\text {th }}$ International Conference of Multiphase Flow, New Orleans, LA (May 27 - June 1, 2001).

72. M. R. Duignan, C. A. Nash, and P. S. Townson, "Cross-flow Filtration with a Shear-thinning Organic-based Slurry", Journal of Thermal and Fluid Science, 26 pp. 683-691 (2002). 
73. J. R. Zamecnik, M. A. Baich, M. R. Duignan, C. A. Nash, and M. R. Poirier, "Modeling the Filtration of a Hanford Site Tank 241-AN-102 Waste Sample at Bench and Pilot Scales", Paper No. 124b, Proceedings of the 2004 AIChE Spring National Meeting, New Orleans, LA (April 25-29, 2004).

74. M. R. Duignan, M. R. Williams, H. A. Abodishish, T. J. Steeper, and P. S. Townson, "Mixing Effects on the Precipitation and Cross Flow Filtration of a Hanford Simulated Precipitated Radioactive Waste", Paper No. 124c, Proceedings of the 2004 AIChE Spring National Meeting, New Orleans, LA (April 25-29, 2004).

75. M. R. Duignan and J. R. Zamecnik, "Cross-flow Filtration during the Washing of a Simulated Radioactive Waste Stream", Paper No. FEDSM2005-77286, Proceeding of the 2005 ASME Fluids Engineering Summer Meeting, Houston, TX (June 19-23, 2005).

76. J. R. Zamecnik, M. R. Duignan, and M. R. Williams, "Separations of a Simulated Waste Stream in a Pilot Waste Treatment Plant", Paper 181d, 2005 AIChE Spring Meeting, Atlanta, GA (April 10-14, 2005).

77. M. R. Duignan and S. Y. Lee, "Cross-flow Ultrafiltration Scaling Considerations", Paper No. FEDSM2006-98492, ASME International's $2^{\text {nd }}$ Joint U. S. -European Fluids Engineering Conference, Miami, FL (July 17-20, 2006).

78. C. E. Johnson, C. A. Nash, and M. R. Duignan, Crossflow Filter Investigations to Improve SRS and Hanford Waste Treatment Plant Operations, EM Waste Processing Technical Exchange, Atlanta, GA (2010)

79. M. R. Duignan, C. A. Nash, M. R. Poirier, and C. E. Johnson, "Performance Improvement of Cross-Flow Filtration for High Level Waste Treatment", Paper No. 11189, WM2011, Phoenix. AZ (2011)

80. M. R. Duignan, Final Report: Pilot-Scale Cross-flow Filtration Test -Envelope A + Entrained Solids, BNF-003-98-0221, Savannah River Site, Aiken, SC (2000).

81. M. R. Duignan, Pilot-Scale X-Flow Filtration Test-Env $C+$ Entrained Solids + Sr/TRU, BNF003-98-0226, Savannah River Site, Aiken, SC (2000).

82. M. R. Duignan, Final Report: Pilot-scale Cross-flow Ultrafiltration Test using a Hanford Site Tank 241-AN-102 Waste Simulant, WSRC-TR-2003-00204, Savannah River Technology Center, Aiken, SC (2003).

83. M. R. Duignan, et. al., Interim Report: RPP-WTP Semi-Integrated Pilot Plant - Campaign I, WSRC-TR-2004-000201, Savannah River Site, Aiken, SC (2004).

84. M. R. Duignan, J. R. Zamecnik, and M. R. Williams, Final Report: RPP-WTP Semi-Integrated Pilot Plant, WSRC-TR-2005-00105, Savannah River Site, Aiken, SC (2005).

85. D. J. McCabe, Evaluation and Ranking of the Tank Focus Area Solid Liquid Separation Needs, WSRC-TR-95-0337, Savannah River Site, Aiken, SC (1995). 
SRNL-STI-2013-00472

PNNL-23030

Revision 0

86. M. F. Morrissey and L. O. Dworjanyn, Initial Technical Basis for Late Washing Filter Cleaning, WSRC-RP-92-925, Savannah River Technology Center, Aiken, SC (1992).

87. C. A. Nash, Filtration of Tank 48H Contents with a Cells Unit Filter, WSRC-TR-95-0483, Savannah River Technology Center, Aiken SC (1995).

88. C. A. Nash, H. H. Saito, and W. R. Wilmarth, Strontium-Transuranic Precipitation and Crossflow Filtration of 241-AN-201 Large C, WSRC-TR-2000-00506, Savannah River Technology Center, Aiken, SC (2000).

89. C. A. Nash and J. Siler, Filtration of Nonradioactive Hanford Waste Simulants, SRTC-BNFL016, Savannah River Technology Center, Aiken, SC (1997).

90. M. Poirier, Improving the Filtration of Sludge/Monosodium Titanate Slurries by the addition of Flocculants, WSRC-TR-2001-00175, Savannah River Technology Center, Aiken, SC (2001).

91. M. R. Poirier, et. al., Filtration, Washing, and Leaching of a Hanford AY-102/C-106 Sample, WSRC-TR-2003-000240, Savannah River Site, Aiken, SC (2003).

92. M. R. Poirier, et. al., Development of a Crossflow Filter to Remove Solids from Radioactive Liquid Waste: Comparison of Test Data with Operating Experience - 9119, SRNL-STI-200800492, Savannah River National Laboratory, Aiken, SC (2008).

93. J. L. Siler, M. R. Poirier, D. J. McCabe, and T. C. Hazen, Fouling of Ceramic Filters and ThinFilm Composite Reverse Osmosis Membranes by Inorganic and Bacteriological Constituents, WSRC-MS-91-350, Savannah River Laboratory, Aiken, SC (1991).

94. J. L. Steimke, C. M. Hart, and S. E. Sponseller, Results from Tests of Du Pont Crossflow Filter, WSRC-TR-94-0332, Savannah River Technology Center, Aiken, SC (1994).

95. W. Walker, Hanford Underground Storage Tank Waste Filtration Process Evaluation, WSRC·TR·97·00353, Savannah River Site, Aiken, SC (1997).

96. W. Walker, Oak Ridge National Laboratory Melton Valley Storage Tanks Waste Filtration Process Evaluation, WSRC-TR-97-00354, Savannah River Technology Center, Aiken, SC 1997).

97. J. R. Zamecnik and M. A. Baich, Evaluating the Effects of Tri-butyl Phosphate and Normal Paraffin Hydrocarbon in Simulated Low-Activity Waste Solution on Ultrafiltration. Technical Report WSRC-TR-2002-00108, Savannah River Site, Aiken, SC (2002).

98. J. R. Zamecnik, et. al., AN-102 Simulant Sr/TRU Precipitation and Ultrafiltration. Technical Report WSRC-TR-2003-00056, Savannah River Site, Aiken, SC (2003).

99. J. R. Zamecnik, et. al., Filtration of Hanford Site Tank 241-AN-102 Waste Sample with Alternate Sr/TRU Precipitation Conditions at Bench and Pilot Scales, WSRC-MS-2003-00756, Savannah River Site, Aiken, SC (2004). 
SRNL-STI-2013-00472

PNNL-23030

Revision 0

100. J. R. Zamecnik, et. al., Tank 241-AY-102 Simulant Development, Ultrafiltration, and Washing. WSRC-TR-2003-00547, Savannah River Site, Aiken, SC (2004).

101. C. E. Johnson and M. R. Duignan, Crossflow Filtration: Literature Review, SRNL-STI-201100013, Savannah River National Laboratory, Aiken, SC (2011).

102. M. R. Duignan, C. A. Nash, M. R. Poirier, and C. E. Johnson, Performance Improvement of Cross-Flow Filtration for High Level Waste treatment, SRNL-STI-2010-00486, Savannah River National Laboratory, Aiken, SC (2011).

103. R. Peterson, J. Billing, C. Burns, R. Daniel, P. Schonewill, and R. Shimskey, Parameters Impacting Crossflow Filter Performance of Hanford Tank Waste Simulants, (November 2010).

104. D. T. Herman, Rotary Filter 1000 Hour Sludge Washing Test, SRNL-STI-2011-00008, Savannah River National Laboratory, Aiken, SC (2008).

105. H. J. Huber, Compendium of Completed Testing in Support of Rotary Microfiltration at Savannah River Site and Hanford, RPP-RPT-49753, River Protection Project, Richland, WA (2011).

106. D. T. Herman, M. D. Fowley, and D. B. Stefanko, Testing of Dual Rotary Filter System, SRNLSTI-2011-00466, Savannah River National Laboratory, Aiken, SC (2011).

107. M. R. Poirier, D. T. Herman, D. B. Stefanko, and S. D. Fink, Testing of a Rotary Microfilter to Support Hanford Applications, WSRC-STI-2008-00339, Savannah River National Laboratory, Aiken, SC (2008).

108. CCI Thermal Technologies, Inc., Nuclear Filtration \& Systems, 3L Filters Information, http://enertech.cwfc.com/brandproducts/spokes/PDF/3Lfilters/3Lfilters engineered-filtrationsystems.pdf

109. K. Rubow, Porous Metal Filters for Gas and Liquid Applications in the Nuclear Industry, WM SYM-9556, (2009).

110. H. B. Shah, and J. M. Gillam, Technical Assumptions and Bases for the Sludge Preparation Process, CBU-PIT-2005-00207, Revision 0, Westinghouse Savannah River Company, Aiken, SC (2005).

111. Perry's Chemical Engineering Handbook, Eighth Addition, Section 22. 5, Industrial Wastewater Management

112. D. C. Bumgardner, Tank 51 Sludge Settling Rate, CBU-PIT-2005-00117, Westinghouse Savannah River Company, Aiken, SC (2005).

113. L. A. Ledbetter, Hydrogen Retention Rates in Slurried Sludge, WSRC-TR-2004-00077, Revision 0, Westinghouse Savannah River Company, Aiken, SC (2004).

114. M. R. Poirier, M. A. Norato, and S. D. Fink, Evaluating Centrifuges for Solid-Liquid Separation in the SRS Salt Processing Program, WSRC-TR-2001-00555, (2001). 
SRNL-STI-2013-00472

PNNL-23030

Revision 0

115. G. J. Lumetta, Caustic Leaching of Chemically Reconstituted Hanford Tank Sludges: Results of FY 1995 Studies, TWRSPP-95-047, Pacific Northwest National Laboratory, Richland, WA (1995).

116. E. J. Weber, Aluminum Hydroxide Dissolution in Synthetic Sludges. DP-1617, Savannah River Laboratory, Aiken, SC (1982).

117. D. J. Temer and R.Villarreal, Sludge Washing and Alkaline Leaching Tests on Actual Hanford Tank Sludge: FY 1997 Results, LAUR-97-2889, Los Alamos National Laboratory, Los Alamos, NM (1997).

118. G. J. Lumetta, B. M. Rapko, J. Liu, D. J. Temer, and R. D. Hunt, Washing and Caustic Leaching of Hanford Tank Sludge: Results of FY 1998 Studies, PNNL-12026, Pacific Northwest National Laboratory, Richland, WA (1998).

119. G. J. Lumetta, J. Carson, L. P. Darnell, L. R. Greenwood, F. V. Hoopes, R. L. Sell, S. I. Sinkov, C. Z. Soderquist, M. W. Urie, and J. J. Wagner, Caustic Leaching of Hanford Tank S-110 Sludge; PNNL-13702, Pacific Northwest National Laboratory, Richland, WA (2001).

120. G. J. Lumetta, L. P. Darnell, P. A. Garza, L. R. Greenwood, B. M. Oliver,D. E. Rinehart, D. R. Sanders, C. Z. Soderquist, T. Trang-Le, M. W. Urie, and J. J. Wagner, Caustic Leaching of Hanford Tank T-110 Sludge, PNNL-13956, Pacific Northwest National Laboratory, Richland, WA (2002).

121. S. K. Fiskum, E. C. Buck, R. C. Daniel, K. Draper, M. K. Edwards, T. L. Hubler, L. K. Jagoda, E. D. Jenson, A. E. Kozelisky, G. J. Lumetta, P. J. MacFarlan, B. K. McNamara, R. A. Peterson, S. I. Sinkov, L. A. Snow, and R. G. Swoboda, Characterization and Leach Testing for REDOX Sludge and S-Saltcake Actual Waste Sample Composites, PNNL-17368, Pacific Northwest National Laboratory, Richland, WA (2008).

122. S. K. Fiskum, J. M. Billing, J. V. Crum, R. C. Daniel, M. K. Edwards, R. W. Shimskey, R. A. Peterson, P. J. MacFarlan, E. C. Buck, K. Draper, and A. E. Kozelisky, Characterization, Leaching, and Filtration Testing of Ferrocyanide Tank Sludge (Group 8) Actual Waste Composite, PNNL-18120, Pacific Northwest National Laboratory, Richland, WA (2009).

123. R. W. Shimskey, J. M. Billing, E. C. Buck, R. C. Daniel, K. Draper, M. K. Edwards, J. G. Geeting, R. T. Hallen, E. D. Jenson, A. E. Kozelisky, P. J. MacFarlan, R. A. Peterson, L. A. Snow, and R. G. Swoboda, Filtration and Leach Testing for REDOX Sludge and S-Saltcake Actual Waste Sample Composites, PNNL-17965, Pacific Northwest National Laboratory, Richland, WA (2009).

124. G. J. Lumetta, E. C. Buck, R. C. Daniel, K. Draper, M. K. Edwards, S. K. Fiskum, R. T. Hallen, L. K. Jagoda, E. D. Jenson, A. E. Kozelisky, P. J. MacFarlan, R. A. Peterson, R. W. Shimskey, S. I. Sinkov, and L. A. Snow, Characterization, Leaching, and Filtration Testing for Bismuth Phosphate Sludge (Group 1) and Bismuth Phosphate Saltcake (Group 2) Actual Waste Sample Composites, PNNL-17992, Pacific Northwest National Laboratory, Richland, WA (2009). 
125. M. K. Edwards, J. M. Billing, D. L. Blanchard, E. C. Buck, A. J. Casella, A. M. Casella, J. V. Crum, R. C. Daniel, K. Draper, S. K. Fiskum, L. K. Jagoda, E. D. Jenson, A. E. Kozelisky, P. J. MacFarlan, R. A. Peterson, R. W. Shimskey, L. A. Snow, and R. G. Swoboda, Characterization, Leaching, and Filtration Testing for Tributyl Phosphate (TBP, Group 7) Actual Waste Sample Composites, PNNL-18119, Pacific Northwest National Laboratory, Richland, WA (2009).

126. G. J. Lumetta and B. M. Rapko, Washing and Alkaline Leaching of Hanford Tank Sludges: A Status Report, PNL-10078, Pacific Northwest Laboratory, Richland, WA (1994).

127. G. J. Lumetta, B. K. McNamara, E. C. Buck, S. K. Fiskum, and L. A. Snow, "Characterization of High Phosphate Radioactive Tank Waste and Simulant Development", Environ. Sci. Technol, 43, 7843-7848 (2009).

128. S. H. Reboul, D. R. Click, and E. K. Hansen, Particle Size Analysis of Tank 12 Sludge Samples, SRNL-L3100-2009-00200, Savannah River National Laboratory, Aiken, SC (2009).

129. M. S. Hay, K. Adu-Wusu, and D. J. McCabe, Determination of the Fraction of Gibbsite and Boehmite Forms of Aluminum in Tank 51H Sludge, WSRC-STI-2008-00366, Savannah River National Laboratory, Aiken, SC (2008).

130. H. H. Burns, D. J. Adamson, Z. H. Qureshi, and T. J. Steeper, In-Tank Elutriation Test Report and Independent Assessment, SRNL-STI-2011-00227, Savannah River National Laboratory, Aiken, SC (2011).

131. D. Squier, K Basin Sludge/Resin Bead Separation Test Report, HNF-3132, (1998).

132. K. J. Cantrell, et. al., Hanford Tank 241-S-112 Residual Waste Composition and Leach Test Data, PNNL-17593, Pacific Northwest National Laboratory, Richland, WA (2008).

133. W. B. Barton, Caustic Cleaning for Waste Tank Heel Removal, WRPS-41324-VA, Waste Processing Technical Exchange, Denver, (May 19, 2009).

134. Mineral Processing, Recent Advances and Future Trends, p 572, 1995,

135. J. N. Brooke and R. A. Peterson, Counter Current Decantation Washing of HLW Sludge, WSRC-MS-97-0048, (March 1997). 
SRNL-STI-2013-00472

PNNL-23030

Revision 0

Appendix A. SRS Slurry Pumps 
Radioactive waste at SRS was generated from the chemical separations facilities and is present in the tank farms as undissolved solid compounds and water-soluble salts. Since the first waste receipt in Tank 1F in 1954, the site has generated over $530,000 \mathrm{~m}^{3}$ (140 million gallons) of high-level nuclear waste. Evaporation operations reduced this volume to the present inventory of about $136,000 \mathrm{~m}^{3}$ (36 million gallons). The waste was stored in 49 underground waste tanks in $\mathrm{F}$ and $\mathrm{H}$ area. Two of the original 51 tanks were operationally closed in 1997. An additional two tanks were closed in 2012. While stored in the tanks, the undissolved solids settle and accumulate on the bottom of the tanks. The liquid volume has been and continues to be reduced by evaporating excess water. The concentrated salts crystallize, forming hard (but porous) saltcake. Tank farm facilities also pre-treat the accumulated sludge and salt solutions to facilitate further processing at other SRS treatment facilities (i.e., DWPF, Saltstone Disposal Facility, Modular Caustic Side Solvent Extraction Facility (MCU), Effluent Treatment Facility, and the future Salt Waste Processing Facility). These treatment facilities convert the sludge and supernatant to more stable forms suitable for permanent disposal. ${ }^{66,67}$

Over the years, SRS has tested and operated several different slurry pumping technologies. These include:

* Transfer Pumps (TP)

$>$ Telescoping Transfer Pump (TTP), Hazelton Pumps

* Telescoping Transfer Jet (TTJ)

* Goulds Pump (GP)

* Pit Bull Pump (PB)

* Tsurumi Pumps

* Mixing Pumps-Long Shaft Pumps

$>$ Lawrence Slurry Pump (LPI, Advanced Design Mixer Pump)

$>$ Bingham Willamette Slurry Pump, Now Sulzer Bingham (BW)

$>$ Standard Pumps

$>$ Quad Volute Pumps

* Submersible Mixer Pump (SMP)

$>$ Flygt Mixer

$>$ Curtis Wright

The major pumps used effectively in service in the SRS H Tank Farm are shown below in Figure A- 1.

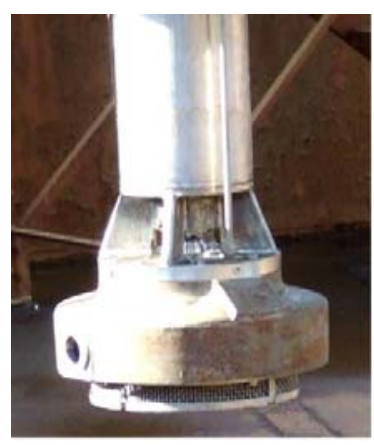

standard slurry pump

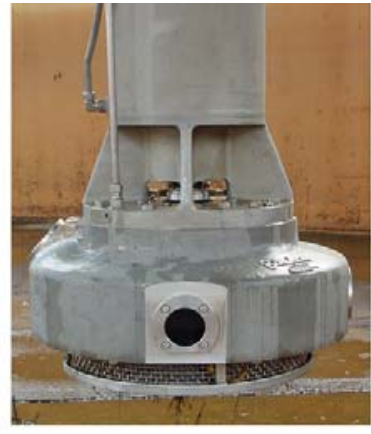

quad volute slurry pump

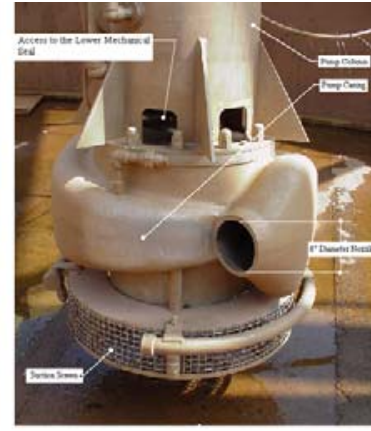

advance

design

mixer

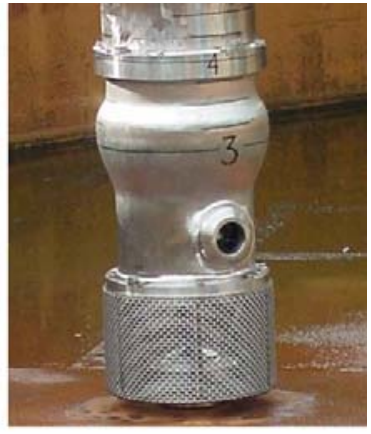

submersible mixer pump

Figure A- 1. Current SRS Slurry Pump Designs. ${ }^{68}$ 
SRNL-STI-2013-00472

PNNL-23030

Revision 0

The typical installation schematic is shown below in Figure A- 2 .

- Overhung Centrigual (45 installed)

- Length 45'

- Volute Diameter 24" \& 36"

- Total Flow 1200 \& 5200 gpm

- Flow Velocity $109 \& 84 \mathrm{ft} / \mathrm{s}$

- Speed 1800 - $2200 \mathrm{rpm}$

- Motor 150 \& $300 \mathrm{hp}$

- Weight 13,500 \& 18,600 lbs

- Mixed and Radial Flow Impellers

- Two opposing discharge nozzles

- Upper/Lower Mechanical Seals

- Variable Speed \& Direct-on-Line

- Slip Ring / Brush Assembly

- Water Cooled Sleeve Bearings (350 gal column)

- Tank Top Structural Steel Supported

- Lead Shield Ring Around Column

- Rotated by Turntable $-360^{\circ}$

- Manufacturers: Sulzer Pumps, Lawrence

Pumps, Floway

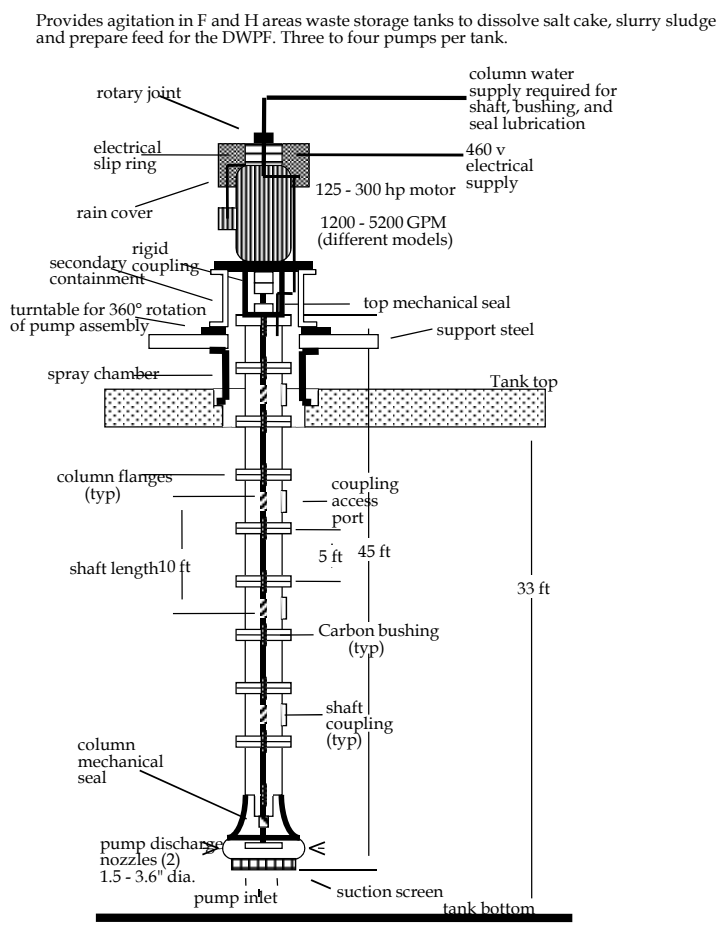

Figure A- 2. SRS Tank Farm Slurry Pump Schematic

Additionally, the SRS Tank Farm has been using the newer SMP design, which allows close coupling of the motor and pump impeller. This is shown below in Figure A- 3. 
SRNL-STI-2013-00472

PNNL-23030

Revision 0

- Canned Motor Design (7 installed)

- Total Flow $7602 \mathrm{gpm}$

- Flow Velocity $80.2 \mathrm{ft} / \mathrm{s}$

- Speed 400 - 1400 rpm

- Motor $305 \mathrm{Hp}$

- Torque $1226 \mathrm{ft}$-lbs

- Weight $9600 \mathrm{lbs}$

- Variable Speed

- Product Cooled

- Floor Supported or Hung

- $51 \mathrm{ft}$. length

- $\quad 18^{\prime \prime}$ Pipe Column

- Rotated by Turntable $-200^{\circ}$

- Manufacturer: Curtiss-Wright

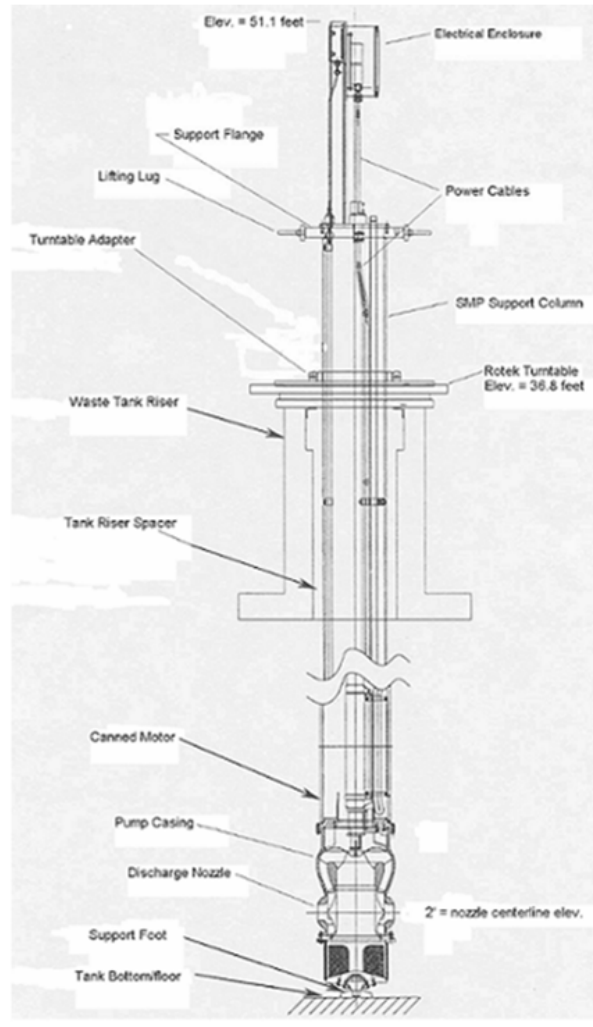

Figure A- 3. SRS Tank Farm Submersible Mixer Pump. ${ }^{68}$

Table A-1 shows the dates and locations for the use of these different pump technologies. 
Table A- 1. Historical Information for the Use of Slurry Pumps at the SRS ${ }^{66}$

\begin{tabular}{|c|c|c|c|c|c|c|}
\hline $\begin{array}{l}\text { Tank } \\
\text { No. }\end{array}$ & Waste Type & $\begin{array}{l}\text { Waste } \\
\text { Remova } \\
\text { I Date }\end{array}$ & $\begin{array}{l}\text { Waste } \\
\text { Removed } \\
\text { (KGal) } \\
\end{array}$ & $\begin{array}{l}\text { Heal } \\
\text { Remaining } \\
\text { (KGal) }\end{array}$ & Slurry Mixing Technology & $\begin{array}{l}\text { Transfer } \\
\text { Method }\end{array}$ \\
\hline $1 \mathrm{~F}$ & Sludge & 1969 & 34 & 7 & Water Sluicer(4) & \\
\hline $2 \mathrm{~F}$ & Sludge & 1966 & 44 & 5 & Water Sluicer(4) & \\
\hline $3 \mathrm{~F}$ & Sludge & 2001 & 67 & 5 & Water Sluicer(4) & \\
\hline $8 \mathrm{~F}$ & Sludge & 1985 & 180 & 15 & LPI (4) & TTP \\
\hline \multirow[t]{2}{*}{$17 \mathrm{~F}$} & Sludge/Salt & 1997 & 373 & 10 & $\mathrm{BW}(3)$ & TTP \\
\hline & Sludge Heel & 1987 & 10 & 2 & Flygt Mixer/Water Sluicer & TTP \\
\hline $18 \mathrm{~F}$ & Sludge & 1982 & 518 & 42 & $\mathrm{BW}$ & TTP \\
\hline \multirow[t]{2}{*}{$19 \mathrm{~F}$} & Salt & 2000 & 1000 & 33 & NA & TTJ \\
\hline & Sludge/Zeolite Heel & 1983 & 18 & 15 & Flygt Mixer & $\mathrm{GP} / \mathrm{PB}$ \\
\hline \multirow[t]{2}{*}{$20 \mathrm{~F}$} & Salt & 1983 & 1000 & 2 & & TJ \\
\hline & Sludge Heel & 1983 & 2 & 1 & BW & TJ \\
\hline $33 \mathrm{~F}$ & Salt & 1983 & 99 & 4 & NA & \\
\hline $9 \mathrm{H}$ & Sludge & 1966 & 38 & 5 & Water Sluicer & \\
\hline \multirow[t]{2}{*}{$10 \mathrm{H}$} & Sudge & 1967 & 58 & 5 & Water Sluicer & \\
\hline & Salt & 1980 & 284 & & NA & TJ \\
\hline $11 \mathrm{H}$ & Sludge & 1969 & 176 & 49 & Water Sluicer & \\
\hline $14 \mathrm{H}$ & Sludge & 1968 & 80 & 18 & Water Sluicer & \\
\hline $15 \mathrm{H}$ & Sludge & 1982 & 125 & 245 & $\mathrm{BW}$ & TP \\
\hline \multirow[t]{2}{*}{$16 \mathrm{H}$} & Sludge/Heel & 1979 & 67 & 1 & $\mathrm{BW}$ & TP \\
\hline & & 1980 & 1 & 0 & Chemical Cleaning & TP \\
\hline $21 \mathrm{H}$ & Sludge & 1986 & 205 & 14 & $\mathrm{BW}$ & TP \\
\hline \multirow[t]{2}{*}{$22 \mathrm{H}$} & Salt & 1986 & 900 & 0 & NA & TP \\
\hline & Sludge & 1986 & 78 & 21 & BW & TP \\
\hline \multirow[t]{2}{*}{$24 \mathrm{H}$} & Salt/Heel & 1981 & 1000 & 11 & NA & TTJ \\
\hline & Sludge & 1985 & 0 & 11 & Chemical Cleaning & TTJ \\
\hline $40 \mathrm{H}$ & Sludge Processing & 1987 & 400 & & LPI & TTP \\
\hline $42 \mathrm{H}$ & Sludge Processing & 1983 & 400 & & LPI & TTP \\
\hline $51 \mathrm{H}$ & Sludge Processing & 1983 & 400 & & LPI & TTP \\
\hline
\end{tabular}

BW=Bingham Willamette slurry pump, GP=Goulds Pump, LPI=Lawrence Slurry Pump, NA=Not Applicable, $\mathrm{PB}=$ Pit Bull Pump, TP=Transfer Pump, TTJ=Telescoping Transfer Jet, TTP=Telescoping Transfer Pump

The results of the use of slurry pumps at the Savannah River Site in a nuclear environment have been successful during the slurrying campaigns performed in terms of cost, schedule, and Design Basis concerns. The original slurry pumps (Long Shaft Pumps), which cost approximately $\$ 1.5$ million each, have gone from an initial cycle life of 90 total days of operation to 12 months of total operation.

Problems encountered for Long Shaft Pumps over the years include the following ${ }^{69}$.

- Journal Bearing Design Deficiencies;

- Column Resonance Issues;

- Shaft Resonance Issues;

- Mounting Resonance Issues;

- Manufacturing deficiencies in Impellers;

- Impeller Hydraulic Optimization Requirements; and

- Decontamination Issues.

Problems encountered for Submersible Mixer Pumps over the years include:

- Flush water must be initiated to prevent in-leakage of tank contents into pump housing;

- Resonance issues for the shaft corrected during pre-operational checks on site;

- Startup procedure detailed to prevent in-leakage, and maximum pumping performance can only be obtained by removing flush water lines;

- The tank level must be at a location sufficient to prevent in-leakage prior to startup; 
- Impeller optimization was required over the years, including the development of quad volute pumps, pumps originally designed with 4 nozzles but modified to have only two nozzles due to inadequate flow generation;

- Ventilation filters frequently required replacement due to soaking from aerosolized mists; and

- Decontamination Issues.

Original life limitations on the pumps resulted from bearing failure and mechanical seal failures (generally attributed to vibration issues). These problems were successfully addressed by changing over to stellite tilt pad bearings. Long shaft pumps have since provided a longer life. 
SRNL-STI-2013-00472

PNNL-23030

Revision 0

Appendix B. Solids-Liquid Separations at SRS 
The SRS has employed the use of solids separation technologies for many years to pretreat radioactive waste in the process of developing HLW and LAW waste streams. Although this method is not a particle size segregation technology, it has proven beneficial to achieving the required preconditioning of waste slurries prior to transfer to the different stream waste handling facilities. This process could be used as a method of improving grinding circuit efficiencies by increasing the solids concentration of the feed stream to the grinder.

Filtration as a separation technology is a physical separation process, whereby particles are removed from the fluid stream and retained by the filtration media when the particulate suspension passes through a single-layer screen, a multiple-layer screen, or a porous, permeable medium. ${ }^{41}$ Three basic collection mechanisms involving filters are inertial impaction, interception, and diffusion. Inertial impaction and interception are the dominating mechanisms for collection of large particles, while collection by diffusion is very important for fine particles. This separation technique is simple and has a high efficiency in collecting particles of all sizes. However, in this type of separation method, a high pressure drop may develop as a result of the accumulation of collected particles in the filter, which may yield high energy consumption and require high material strength of filters for the operations.

This technology is further classified into cake and depth filtration. Cake filtration involves the deposition of particles on the front surface of imposed media. Examples of cake filtration include fabric filters, sieves, and membrane filters. Depth filtration involves the collection of particles as they transit the imposed media. Examples include packed beds, meshes, fluidized beds, and fiber filters. Both mechanisms incur increasing pressure drops as particle collection increases, and consequently require periodic replacement or cleaning.

An additional solids separation technology is gravity settling followed by decanting. Settle/Decant is based on using gravity to allow larger particles to settle out of a slurry. The supernate is then decanted and passed on to the next process while the solids are retained in the original vessel. Settle/Decant allows for effective solids/liquid separation.

\section{Cross-Flow Filtration}

The intent of cross-flow filtration is to perform a concentration process on liquid slurry to produce concentrated slurry and supernatant waste streams, providing a cost savings in later processing operations. Cross-flow filtration is a key process step in waste treatment facilities to separate undissolved solids from slurries. Cross-flow filtration is similar to a dead end filtration in that there are no moving parts necessary for operation, but additional valving and piping is required for back-pulse operations. However, there is the added convenience (for Radioactive Service) of allowing cleaning of the filter in place with the wall shear stress from the cross-flow of slurry and with a periodic back pulse. A back pulse is the process of temporarily reversing (pulsing) the filtrate flow to help push the filter cake off the porous surface. The basic concept for cross-flow filtration is shown below in Figure B- 1 . 
SRNL-STI-2013-00472

PNNL-23030

Revision 0

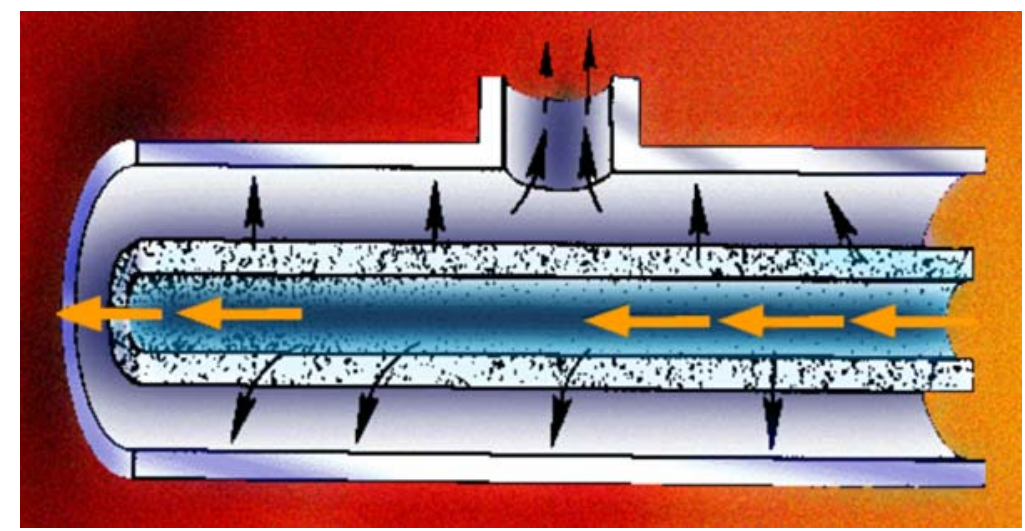

Figure B- 1. Cross-Flow Filtration Concept

At Hanford, the PT will employ cross-flow filtration to support caustic and oxidative leaching processes to pretreat Tank Farm waste. This will include the separation of high-level waste solids from the lowactivity liquid stream, and the washing/re-concentration operations following the leaching process(es).

A number of studies have been performed on this technology, including testing on simulants. ${ }^{70-101}$ A WM2011 paper identified several issues and resolutions for the use of cross-flow filtration ${ }^{102}$ and an overview of technical issues with the use of cross-flow filtration of simulants at Hanford was presented by R. Peterson, et. al. ${ }^{103}$.

From these studies, issues identified in simulant testing for cross-flow filtration included fouling causation and resolution, back pulse techniques for optimization, optimization of cake development, further study of scouring techniques, and cleaning requirements.

The SRS has successfully used cross-flow filtration in a nuclear environment for many years as part of their waste processing and conditioning pretreatment of the salt stream (LAW) for the DWPF vitrification plant. The filtration system is used to filter salt solution with MST. Each filtration campaign begins filtering at $12 \mathrm{gpm}$, and slowly reduces to $5 \mathrm{gpm}$ over a two week period. This is a result of increased solids feed concentration and general fouling of the filter.

A second filter downstream of the cross flow has been installed (secondary filter) that is designed to catch large particles that might result from breakthrough of the primary cross-flow system. Although this second filter should not foul (downstream of cross-flow filtration system), experience has shown that this filter does foul over time at a rate similar to the main filtration system. SRS is currently investigating the reasons for this fouling.

\section{$\underline{\text { Advantages }}$}

Cross-flow filtration is a mature technology that has been demonstrated to be a solid/liquid separation technology that is very suitable for use in a nuclear environment, as demonstrated at the SRS. It is cleanable in-situ, and can be engineered for particle size requirements as required by the WTP waste handling and acceptance criteria. 


\section{$\underline{\text { Disadvantages }}$}

The principal disadvantage of cross-flow filtration is that to obtain good separation, while minimizing depth fouling, a small pore size rating is needed, e. g. 0.1 micron, leading to low filtrate flux rates. However, by increasing the filter area, i.e. more and longer filter tubes, the overall filtration rate can be increased. Increasing the amount of tubes to meet the throughput requirements may result in a significant footprint.

\section{Rotary MicroFiltration}

The rotary filter operates on the same theory as a cross-flow filter. The operation of the rotary filter allows the tangential velocity seen at the membrane to be decoupled from the pump. The use of the turbulence promoters imparts additional shear at the membrane surface to minimize filter cake build up.

The SpinTek ${ }^{\circledR}$ high shear rotary filter has 25 filter disks covered with sheet membranes. The filter area of each disk is $0.96 \mathrm{ft}^{2}$. The disks are physically mounted on and are hydraulically connected to a common hollow rotating shaft. The entire stack of membrane disks is enclosed within a vessel. Feed is introduced into the filter vessel through the inlet on the side of the vessel wall. A pressure is set in the tank by restricting the outlet flow typically using a gate valve on the concentrate piping. This applied pressure forces liquid through the filters on the filter disk. Between each disk is a set of baffles or turbulence promoters. These turbulence promoters cause strong currents and eddies at the surface of the membrane inhibiting the formation of a filter cake. Filtrate flows through the media and along a mesh inside the disk into the hollow shaft. The filtrate then flows through the shaft to the rotary joint which allows the spinning shaft to couple to stationary piping. The concentrated slurry exits the vessel through an outlet on the bottom.

The SpinTek ${ }^{\circledR}$ rotary microfilter has been developed by SpinTek Filtration ${ }^{\circledR}$ and SRNL for the purpose of deployment into radioactive service in the DOE complex. This technology is an inherent part of the SCIX process discussed earlier in this report. Rotary microfiltration was originally part of a down select technology, in addition to cross-flow filtration, as part of an in-tank or near tank supplemental process treatment. Additional studies were performed to consider the use of this technology for sludge washing applications. ${ }^{104}$ The rotary microfiltration technology was different from cross-flow filtration in that there exists a disconnect between filtrate flux and feed velocity, i.e. filtrate flux is only dependent on transmembrane pressure, filter fouling, and temperature.

In the testing for SRS sludge washing, several items of interest were identified. These included:

- Vibration levels approached $8 \mathrm{~mm} / \mathrm{s}$ and were a strong function of the frame mounting configuration.

- Subsequent tests have demonstrated vibrations to be less than $2 \mathrm{~mm} / \mathrm{s}$;

- Filtrate turbidity of less than 1 NTU;

- Even mechanical seal wear patterns were observed after 1000 hours of operation;

- A keyway stress concentration, in conjunction with shaft misalignment, led to a failed journal bearing, which led to a design change and no further issues have been reported; and

- Process changes were identified to improve operation of the Rotary MicroFilter. ${ }^{104}$

The basic principle for RMF is shown in the Figure B- 2 and Figure B- 3. 
SRNL-STI-2013-00472

PNNL-23030

Revision 0

Promoters, shaped like wagon wheels, induce the turbulence needed to prevent rotational flow $\rightarrow$ reduced filter fouling

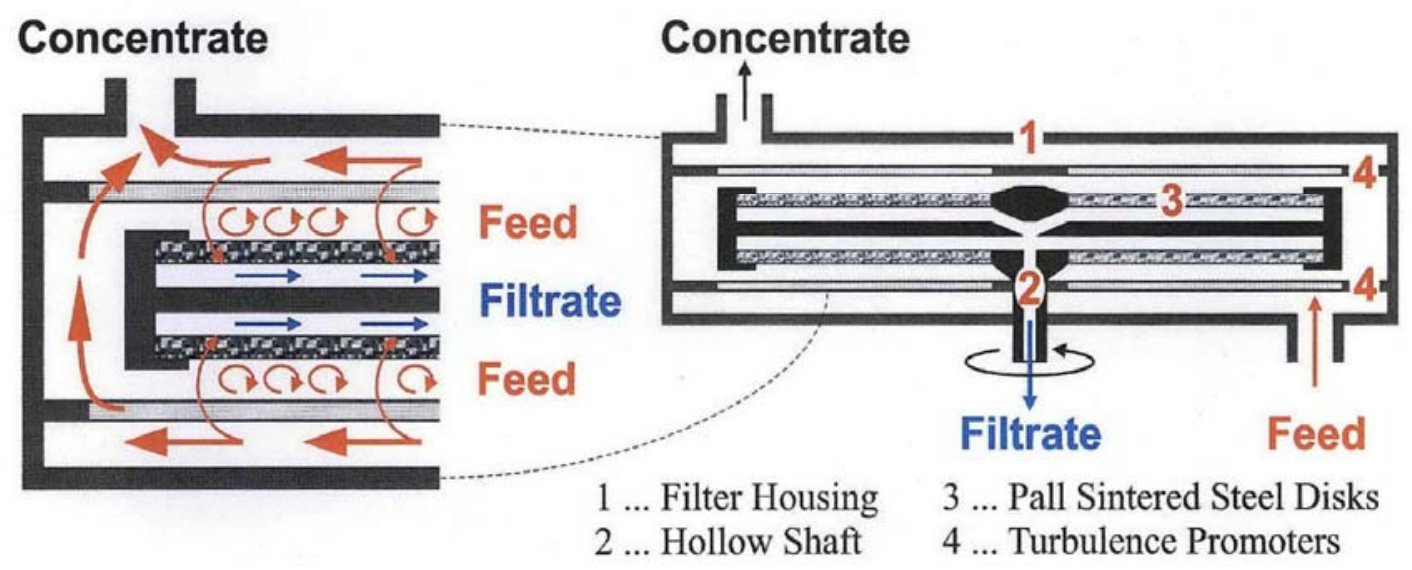

Figure B- 2. Principle of Filtration for SpinTek ${ }^{\circledR}$ System
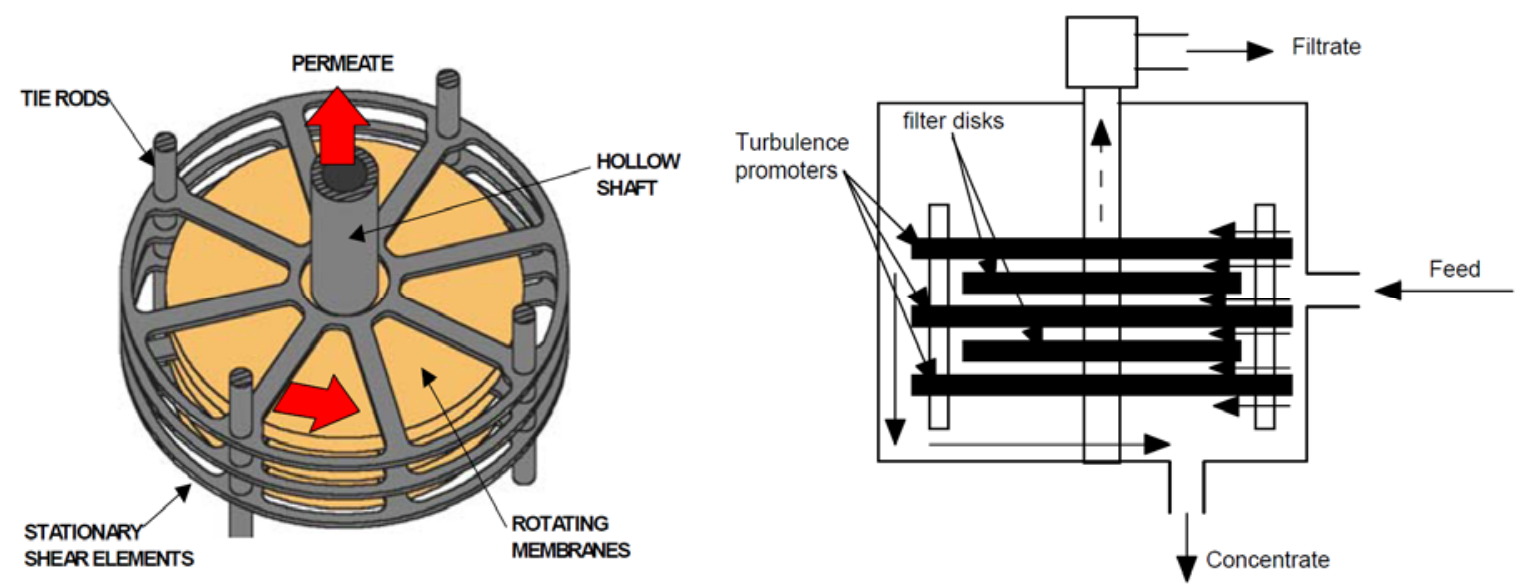

Figure B- 3. Diagram of Rotary Filter Principle of Operation

Several studies have been performed on simulated and real waste at the SRNL and Hanford, and two studies have been performed on actual waste from the Hanford Tank Farm. ${ }^{105-107}$ The Hanford studies indicated that the technology had a technology readiness level (TRL) of 4 (TRL 4 refers to completed "component and/or system validation in laboratory environment").

In actual waste testing, several areas of operability in a nuclear environment were identified, including the expected filtration rate, the achievable clarification of feed, and cleaning requirements necessary to restore filtrate flow during testing. 


\section{$\underline{\text { Advantages }}$}

The advantage of the rotary microfilter compared to other membrane processes results from the high shear acting on the boundary layer next to the membrane. This shear greatly reduces fouling of the membrane surface and increases fluid flow through the membrane. Pressure is decoupled from the feed flow rate, allowing more control over the driving force pressure and independent control of the shear applied to the filter cake resulting in reduced pump requirements. This feature allows the direct application of shear force with a magnitude significantly greater than that available in conventional membrane systems and results in the ability to operate effectively with undissolved solids. The membranes rotate at a tip speed of $60 \mathrm{ft} / \mathrm{s}$ in close proximity to the turbulence promoters. For comparison, previous cross-flow filter testing used axial velocities ranging from 3 to $25 \mathrm{ft} / \mathrm{s}$.

An additional advantage to the rotary microfilter is the compact size. A full scale 25 disk filter unit (nominally 25 square feet of filtration area) is approximately 16.5 inches in diameter and approximately 6 feet tall including the motor.

RMF technology has been sufficiently tested on both simulated and real waste to provide a high level of technology maturity. RMF may provide a method of size segregation for WTP Feed to meet ICD-19 criteria for transfers from the HTF to WTP facilities. RMF technology is currently slated for installation in an actual waste tank environment at the SRS as part of the SCIX process discussed earlier in this report.

\section{$\underline{\text { Disadvantages }}$}

The disadvantage to the rotary filter include that the filter has not been deployed in full scale radioactive operations for high level waste. It has not established a track record for durability and maintenance in this environment.

\section{Cylindrical Element Pressure Filter (Candle)}

Cylindrical Element (Candle) Filters are barrier type filters and work by dead end filtration. A candle filter is a process filter, mainly used for the recovery of process residues from liquid streams. It almost always has a vertical cylindrical housing, inside which a multitude of cylindrical filter elements, closed at the bottom end, are suspended from a tube plate. Flow of liquid is from the outside of the element to its inside. The filtering element can be almost any kind of cylindrical structure, but is ideally a rigid, smooth-surfaced tube of porous metal, plastic or ceramic.

Cylindrical Element (Candle) Filters are barrier type filters used extensively in commercial industries for a variety of dead end filtration size separation requirements.

Nuclear Industrial use includes:

- Reactor Coolant Systems;

- Coolant Water Make-up;

- Condensate Treatment;

- Steam Generator Blow Down;

- Spent Fuel Pool Water Cleanup;

- Radwaste Cleanup; and

- Ion Exchange Resin Fines Capture. ${ }^{108}$

The basic concept behind Candle filters is shown below in Figure B- 4. 
SRNL-STI-2013-00472

PNNL-23030

Revision 0

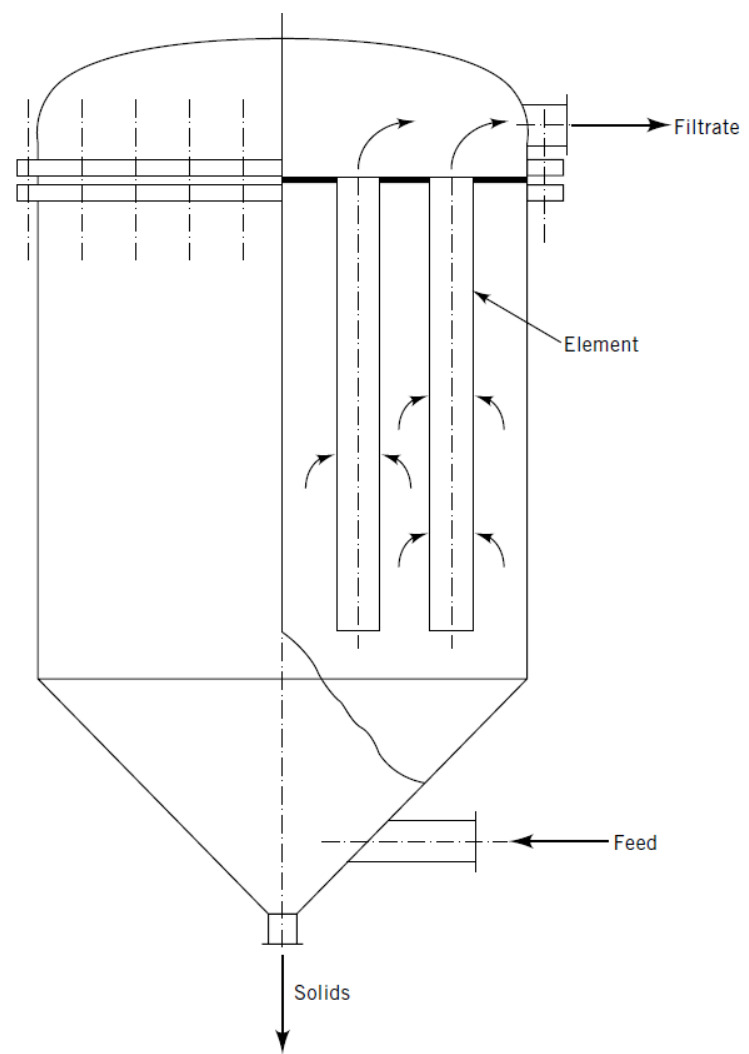

Figure B- 4. Cylindrical Element (Candle) Pressure Filter

There are several filter configurations used in candle filtration systems. These include:

1.) Outside-in filtration: traditional liquid/solids barrier separation occurs on the outer perimeter of a closed-end tubular filter element (LSP). A gas-assisted pneumatic hydro-pulse backwash has proven to be the most effective cleaning method for sintered porous metal filters.

2.) Inside-out filtration: solid/liquid barrier separation occurs on the inside of a closed-end tubular filter element (LSI). LSI backwash modes include:

a. Full shell slurry backwash;

b. Empty shell slurry backwash;

c. Empty shell and empty element wet cake backwash; and

d. Empty housing wet cake discharge.

3.) Inside-out Multimode filtration: liquid/solids (barrier or cross-flow) separation occurs on the inside of open-ended tubular filter element (LSM and LSX). Elements are sealed within two tube sheets, as shown in Figure B- 5. This is filtration with multi-option top or bottom feed inlet. The LSM filter, with a feed re-circulation feature, has proven itself in several continuous loop reactor systems. The downward velocity controls the cake thickness of the catalyst with the lower the velocity, the thicker the resulting cake. Filter backwash modes are similar to LSI backwash modes and also includes a bump-and-settle type backwash that allows concentration of solids without draining the filter element or housing. Continuous loop reactor systems may not require backwashing. 
SRNL-STI-2013-00472

PNNL-23030

Revision 0

These configurations are shown below in Figure B- 5. ${ }^{109}$
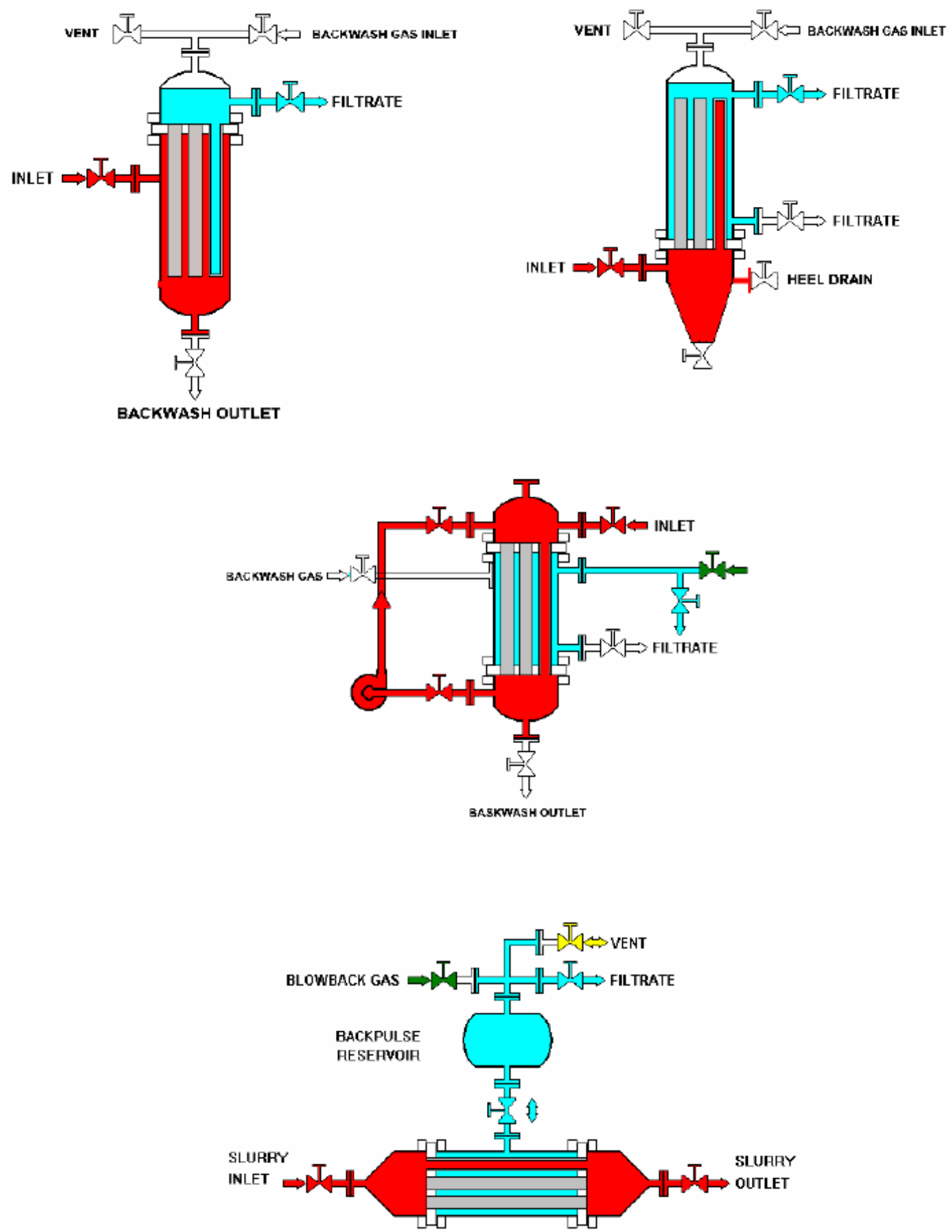

Figure B- 5. Schematic of filter configurations for liquid process system applications

NOTE: Outside- in filtration - LSP (top left), inside-out filtration - LSI (top right), multi-mode flow LSM (middle) and cross-flow - LSX (bottom). ${ }^{109}$ 
SRNL-STI-2013-00472

PNNL-23030

Revision 0

\section{$\underline{\text { Advantages }}$}

The advantage of candle filters is that they are very simple to operate and reliable.

\section{$\underline{\text { Disadvantages }}$}

As particle loading increases, the use of candle filters becomes more problematic, and the use of crossflow or rotary filtration systems is considered. Candle filters are required to be replaced (or cleaned) once fully loaded, and as such may not be a good candidate for slurry particle size separation. Candle filters can be cleaned in-situ through back pulsing, but particles will tend to become imbedded over time in the substrate media, and consequently the filter recovery from high pressure drop becomes an issue. ${ }^{109}$

\section{Settle/Decant}

Settle/Decant is employed at SRS as part of sludge washing and preparation. Sludge washing involves the addition of water (or other chemicals as needed for corrosion control) to the sludge followed by settling and decanting. The purpose of sludge washing is to lower the sodium salt content of the sludge and to increase the undissolved solids concentration of the sludge. Typically, a sludge is washed two to five times to lower the sodium concentration to $1 \mathrm{M}$ in the supernate and to increase undissolved solids content to as high as possible based upon the rheological properties (limited by equipment needed to mix and pump the slurry). In this manner the water and soluble solids are removed while the undissolved solids remain.

SRS prepares High Level Waste Sludge batches in a nominal 1 million gallon capacity carbon steel waste tank (Tank 51). The waste is washed by mixing inhibited water with the sludge using four Quad Volute Slurry Pumps. The wash water is added to dilute the concentration of the supernatant (soluble salt solution) from $>5 \mathrm{M}$ to nominally $1 \mathrm{M}$ sodium. After mixing is complete, gravity settling is used to separate the undissolved solids from the supernatant. The settling time can vary dramatically from one sludge batch to another, depending on the sludge settling rate. Once the undissolved solids have settled, the supernatant is removed by pumping it to another waste tank. This process of washing, settling, and pumping can be repeated as needed to produce the targeted sludge batch composition. The time to prepare a typical sludge batch varies from 4-7 months, depending on the rheology, degree of washing and undissolved solids target of the final sludge product. ${ }^{110}$

\section{$\underline{\text { Advantages }}$}

The main advantage for gravity settling or thickening is that it is a very simple way to separate undissolved solids from soluble solids. It is used extensively in the waste treatment industries to settle solids in large tanks and ponds. ${ }^{11}$ At SRS gravity settling is accomplished in existing waste tanks so new facilities did not have to be constructed. 
SRNL-STI-2013-00472

PNNL-23030

Revision 0

\section{Disadvantages}

There are a number of disadvantages of gravity settling. Every sludge waste tank at SRS and Hanford has a different chemical composition, particle size distribution, undissolved solids concentration, and other factors that impact the settling rate of the undissolved solids. Some slurries are very slow settling, which requires a longer settling time and extends the processing time for each sludge batch. If a sludge batch preparation time is excessive, it would lead to an interruption in production for downstream processing facilities. ${ }^{112}$ To date, no flocculent has been added during SRS sludge processing to improve the settling rate, primarily to eliminate downstream processing issues.

A second disadvantage of gravity settling of radioactive waste is that hydrogen is being constantly generated by radiolysis. If the sludge is allowed to settle long enough, hydrogen could be trapped in the sludge and accumulate to form a potentially flammable mixture. To prevent this build-up of hydrogen, the tank is mixed periodically in tanks with mixing. If the settling time is slower than the time required for remixing, much smaller batches of sludge would need to be prepared, potentially limiting downstream sludge processing. ${ }^{113}$

\section{Centrifuge in Radioactive Waste Tank Farm}

Research was performed at the SRNL in 2002 to address the possible use of a continuous centrifuge (Centrifuge/Decanter) in replacing cross-flow filter systems used in the pretreatment for the proposed MCU facility. ${ }^{63}$ The intent of the testing was to determine if a continuous centrifuge process could remove sufficient quantities of undissolved solids to meet a clarified turbidity limit of 5-10 Nephelemetric Turbidity Units (NTU). The conclusions indicated that the centrifuge tested did not meet the clarified solution criterion. However, the authors' suggested that the use of the centrifuge with a polishing filter could provide a solid-liquid separation on the order of $0.25 \mathrm{gpm} / \mathrm{ft}^{2}$ filter flux rate. They further suggested the use of a two-stage centrifuge, the first stage similar to the tested unit (centrifuge/decanter), with the second stage consisting of a disk centrifuge. This combination would provide a method for effectively removing small, slow settling particles.

The study provided details of installed centrifuge/decanters in the nuclear industry. This is shown below in Table B- $1 .{ }^{114}$ 
Table B- 1. Nuclear Industry Installations of Centrifuge/Decanter Systems ${ }^{114}$

\begin{tabular}{|c|c|c|c|c|c|c|c|}
\hline Customer & Country & Contractor & Machine & Qty. & Year & Location & Type \\
\hline Euroatom & Italy & & CRPX 207 SGV & 1 & 1966 & RL & Disk \\
\hline RCN, Petten & Netherlands & & BRPX 213 SFD & & 1971 & WD & Disk \\
\hline Toshiba & Japan & & BRPX 213 SGV & 2 & 1975 & PP & Disk \\
\hline Coarso & Italy & & CRPX 207 SGP & 2 & 1978 & PP & Disk \\
\hline EIR & Switzerland & & BRPX 213 SGV & 1 & 1978 & RL & Disk \\
\hline Mühlenberg & Switzerland & & BRPX 207 SGV & 2 & 1978 & PP & Disk \\
\hline Benznau & Switzerland & & BRPX 207 SGV & 1 & 1978 & PP & Disk \\
\hline Toshiba & Japan & & BRPX 213 SGV & 2 & 1980 & PP & Disk \\
\hline Toshiba & Japan & & BRPX 417 SGV & 2 & 1980 & PP & Disk \\
\hline Toshiba & Japan & & BRPX 213 SGV & 2 & 1981 & PP & Disk \\
\hline Toshiba & Japan & & BRPX 417 SGV & 2 & 1981 & PP & Disk \\
\hline Toshiba & Japan & & BRPX 417 SGV & 1 & 1981 & PP & Disk \\
\hline KKW Isar 1 & Germany & Siemens & BRPX 213 SGV-34 & 1 & 1981 & PP & Disk \\
\hline KKW Brunsbüttel & Germany & Siemens & BRPX 213 SGV-34 & 1 & 1982 & PP & Disk \\
\hline Nersa & France & & BRPX 213 SGV & 1 & 1983 & PP & Disk \\
\hline KKW Phillipsburg 1 & Germany & Siemens & BRPX 207 SGV-34 & 1 & 1983 & PP & Disk \\
\hline KKW Phillipsburg 1 & Germany & Siemens & BRPX 213 SGV-34 & 1 & 1983 & PP & Disk \\
\hline KKW Phillipsburg 1 & Germany & Siemens & KWNX 416 S-31G & 1 & 1983 & PP & Decanter \\
\hline KKW Phillipsburg 2 & Germany & Siemens & BRPX 213 SGV-34 & 1 & 1983 & $\mathrm{PP}$ & Decanter \\
\hline KKW Phillipsburg 2 & Germany & Siemens & KWNX 416 S-31G & 1 & 1983 & PP & Decanter \\
\hline Toshiba & Japan & & BRPX 413 SGD & 2 & 1983 & PP & Disk \\
\hline KKW Isar 2 & Germany & Siemens & BRPX 213 SGV-34 & 1 & 1985 & PP & Disk \\
\hline KKW Isar 2 & Germany & Siemens & KWNX 416 S-31G & 1 & 1985 & PP & Decanter \\
\hline Idreco & Italy & & BRPX 213 SGV & 3 & 1985 & $\mathrm{PP}$ & Disk \\
\hline KKW Neckarwestheim & Germany & Siemens & BRPX 213 SGV-34 & 1 & 1985 & PP & Disk \\
\hline KKW Neckarwestheim & Germany & Siemens & KWNX 416 S-31G & 1 & 1985 & PP & Decanter \\
\hline KKW Brockdorf & Germany & Siemens & BRPX 213 SGV-34 & 1 & 1985 & PP & Disk \\
\hline KKW Brockdorf & Germany & Siemens & KWNX 416 S-31G & 1 & 1985 & PP & Decanter \\
\hline KKW Emsland & Germany & Siemens & BRPX 213 SGV-34 & 1 & 1985 & PP & Disk \\
\hline KKW Emsland & Germany & Siemens & KWNX 416 S-31G & 1 & 1985 & $\mathrm{PP}$ & Decanter \\
\hline KKW Obrigheim & Germany & & BRPX 213 SGV-34 & 1 & 1986 & PP & Disk \\
\hline KKW Obrigheim & Germany & & KWNX 416 S-31G & 1 & 1986 & PP & Decanter \\
\hline KKW Würgassen & Germany & & BRPX 213 SGV-34 & 2 & 1987 & PP & Disk \\
\hline KKW Karlstein & Germany & & NX 309 & 1 & 1987 & RL & Decanter \\
\hline KKW Grohnde & Germany & & CHPX 510 SGD-34 CG & 1 & 1990 & PP & Disk \\
\hline KKW Grohnde & Germany & & KWNX 416 S-31G & 1 & 1990 & $\mathrm{PP}$ & Decanter \\
\hline KKW Phillipsburg 1 & Germany & Siemens & CHPX 510 SGD-34 CG & 1 & 1990 & PP & Disk \\
\hline KKW Phillipsburg 1 & Germany & Siemens & KWNX $416 \mathrm{~S}-31 \mathrm{G}$ & 1 & 1990 & PP & Decanter \\
\hline KKW Karlstein & Germany & & KWNX 409 S-31G & 1 & 1992 & RL & Decanter \\
\hline KKW Isar 1 & Germany & & BRPX 213 SGV-34 CG & 1 & 1992 & PP & Disk \\
\hline ABB Atom & Sweden & & KWNX 416 & 1 & 1994 & $\mathrm{PP}$ & Decanter \\
\hline KKW Rheinsberg & Germany & Siemens & KWNX 416 & 1 & 1995 & PP & Decanter \\
\hline Teollisuuden Voima Oy & Finnland & & KWNX 416 & 1 & 1995 & PP & Decanter \\
\hline Teollisuuden Voima Oy & Finnland & & CHPX 510 & 1 & 1995 & $\mathrm{PP}$ & Disk \\
\hline Sage Brno (Temelin) & Czech Rep. & & KWNX 418 & 1 & 1996 & PP & Decanter \\
\hline Sage Brno (Temelin) & Czech Rep. & & CHPX 513 & 1 & 1996 & $\mathrm{PP}$ & Disk \\
\hline Teollisuuden Voima Oy & Finnland & & KWNX 416 & 1 & 1996 & PP & Decanter \\
\hline Teollisuuden Voima Oy & Finnland & & CHPX 510 & 1 & 1996 & PP & Disk \\
\hline Zwilag Würenlingen & Switzerland & BWB & BTPX 205 SGD-34 CDP & 1 & 1997 & WD & Disk \\
\hline Yonggwang 5 & Korea & HPA & CHPX 517 SGV-34 CGR & 1 & 1997 & $\mathrm{PP}$ & Disk \\
\hline Yonggwang 5 & Korea & HPA & KWNX 418 S-31 & 1 & 1997 & PP & Decanter \\
\hline Yonggwang 6 & Korea & HPA & CHPX 517 SGV-34 CGR & 1 & 1997 & PP & Disk \\
\hline Yonggwang 6 & Korea & HPA & KWNX 418 S-31 & $\begin{array}{c}1 \\
62\end{array}$ & 1997 & PP & Decanter \\
\hline \multirow[t]{3}{*}{ Key to location: } & $\mathrm{RL}$ & & Research lab & & & PP & Power Plant \\
\hline & WD & & Waste Disposal & & & & \\
\hline & WD & & Waste disposal & & & & \\
\hline
\end{tabular}


SRNL-STI-2013-00472

PNNL-23030

Revision 0

Appendix C. Chemical Size Reduction 
An additional means for performing size reduction is through chemical treatment. Relevant information available regarding particle size reduction via chemical processing is briefly explored. Two general possibilities are considered: 1) treatment with sodium hydroxide (caustic leaching) and 2) a combined acid/caustic treatment.

Caustic leaching will likely be required on several of the HLW tanks (sludges) to allow for successful formulation and processing of a borosilicate glass waste form. Currently, the plan is to perform this treatment with the PT. With the chemical treatment that occurs through the sodium hydroxide addition and heating to elevated temperatures, some size reduction may occur. Since the process may be required for certain batches, the added benefit of size reduction (in addition to reduction in Al concentration) should be explored.

The intent of acid dissolution is to process dissolved sludge solution through solvent extraction to concentrate the radioactive portion of the waste into a very small volume for vitrification. In the combined acid/caustic leaching approach, the sludge solids were sequentially: 1) leached with $\mathrm{NaOH}, 2$ ) dissolved in nitric acid (with HF, if necessary), and 3) re-neutralized and leached with $\mathrm{NaOH} .{ }^{115}$ This option is no longer being pursued, but it could prove useful for size reduction of particles that are not amenable to size reduction by mechanical means.

\section{Caustic Leaching of Hanford Waste}

Caustic $(\mathrm{NaOH})$ leaching is the baseline method for pretreating Hanford tank waste solids containing high concentrations of aluminum prior to HLW vitrification. This process is designed to remove a large fraction of the Al, which is present in large quantities in Hanford tank sludges. The Al will be removed by converting aluminum oxides/hydroxides to sodium aluminate. For example, boehmite and gibbsite are dissolved according to the following equations. ${ }^{116}$

$$
\begin{gathered}
\mathrm{AlOOH}(\mathrm{s})+\mathrm{NaOH}(\mathrm{aq}) \rightarrow \mathrm{NaAlO}_{2}(\mathrm{aq})+\mathrm{H}_{2} \mathrm{O} \\
\mathrm{Al}(\mathrm{OH})_{3}(\mathrm{~s})+\mathrm{NaOH}(\mathrm{aq}) \rightarrow \mathrm{NaAlO}_{2}(\mathrm{aq})+2 \mathrm{H}_{2} \mathrm{O}
\end{gathered}
$$

A significant portion of the $\mathrm{P}$ is also expected to be removed from the sludge by the metathesis of waterinsoluble metal phosphates to insoluble hydroxides and soluble $\mathrm{Na}_{3} \mathrm{PO}_{4}$; for example, iron(III) phosphate reacts with $\mathrm{NaOH}$ in the following way.

$$
\mathrm{FePO}_{4}(\mathrm{~s})+3 \mathrm{NaOH}(\mathrm{aq}) \rightarrow \mathrm{Fe}(\mathrm{OH})_{3}(\mathrm{~s})+\mathrm{Na}_{3} \mathrm{PO}_{4}(\mathrm{aq})
$$

Similar metathesis reactions can also occur for insoluble sulfate salts, allowing the removal of sulfate from the HLW stream.

There is a vast literature related to the testing of the caustic leaching process. ${ }^{117-126}$ Based on the known chemistry, caustic leaching should impact the following types of phases potentially present in the Hanford tank solids:

- Aluminum hydroxides/oxides - e.g., gibbsite and boehmite;

- Water-insoluble metal phosphates;

- Water-insoluble metal sulfates; and

- Chromium-containing phases. 
Although there is not extensive literature regarding the effects of caustic leaching on particle size distribution, the data only represent the effects on entire population of particles present. Inferences regarding specific types of particles are difficult to make. One of the most comprehensive characterizations of Hanford tank waste solids before and after caustic leaching was performed on bismuth phosphate sludge (Group 1) and bismuth phosphate saltcake (Group 2). ${ }^{124}$ The results of this study will be discussed to illustrate the difficulty encountered in using existing data in the literature to determine the specific particle size reduction achieved by caustic leaching.

Advantages of the upstream chemical size reduction/conditioning may include:

- Current waste tank mixing equipment could be used and is required;

- Mechanical/structural interface with the current waste tanks would be minimal; and

- Chemical treatment may be compatible/enhancement to WTP processes but will depend on the type of treatment and location for the treatment.

Characterization of water-washed Group 1 solids indicated the phosphorus is primarily present as an amorphous $\mathrm{Fe}(\mathrm{III})$ phosphate material, and that this is the primary species that reacts with $\mathrm{NaOH}$ during caustic leaching. ${ }^{127}$ Other elements present include $\mathrm{Bi}, \mathrm{Cr}, \mathrm{Na}, \mathrm{Si}$, and $\mathrm{U}$. Figure $\mathrm{C}-1$ presents the PSD before and after treatment of the Group 1 with $\mathrm{NaOH}$. The data show a substantial increase in the percentage of larger particles (on a percent volume basis). It is impossible to tell from the data exactly what effect leaching had on the original particles present. Likely, for the $\mathrm{Bi}$, Si, and $\mathrm{U}$ phases present, caustic leaching had little effect since these species would not be expected to react with $\mathrm{NaOH}$. These "original" particles might be reflected in the peaks in the PSD at 0.6 and 4 microns. The primary reaction that occurs for the Group 1 solids is the metathesis of $\mathrm{Fe}$ (III) phosphate to $\mathrm{Fe}$ (III) hydroxide which can be described by the following reaction:

$$
\mathrm{FePO}_{4}(\mathrm{~s})+3 \mathrm{NaOH}(\mathrm{aq}) \rightarrow \mathrm{Fe}(\mathrm{OH})_{3}(\mathrm{~s})+\mathrm{Na}_{3} \mathrm{PO}_{4}(\mathrm{aq})
$$

The post-leaching PSD suggests that the iron(III) hydroxide particles that are formed are much larger than the original iron(III) phosphate particles; or, they are much more highly agglomerated. 
SRNL-STI-2013-00472

PNNL-23030

Revision 0

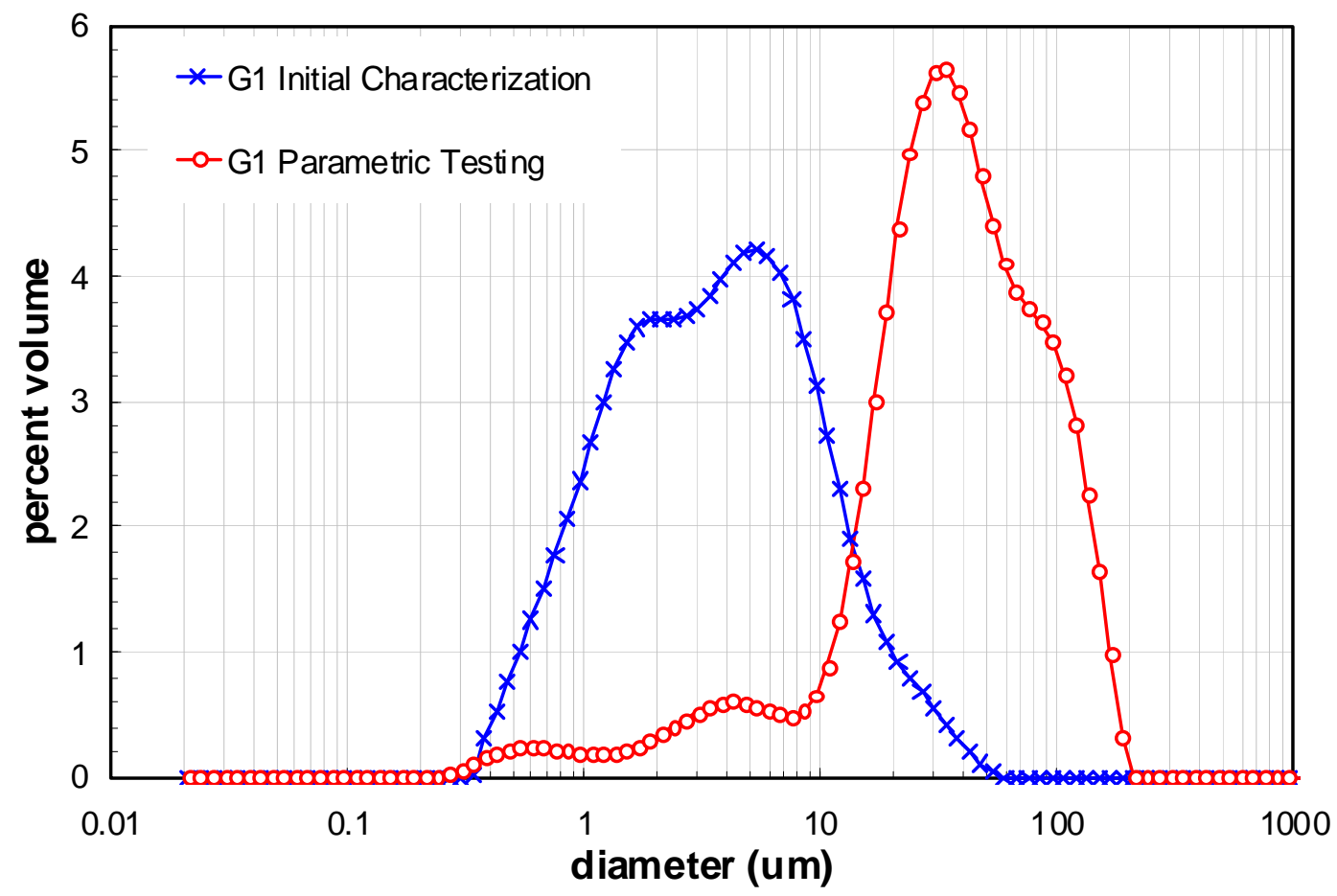

Figure C- 1. Influence of Caustic Leaching and Washing on the Group 1 ( $\mathrm{BiPO}_{4}$ sludge) Waste PSD

Characterization of the water-insoluble Group 2 solids indicated gibbsite, cancrinite, and amorphous iron(III) phosphate to be major components. As was the case with the Group 1 solids, the amorphous iron(III) phosphate phase was converted to iron(III) hydroxide per Eq. 3 during caustic leaching. Gibbsite was dissolved during the caustic leaching (Eq. 2). Fourier transform infrared (FTIR) spectroscopic examination suggested that the cancrinite was converted to a different aluminosilicate phase. Also, the FTIR examination revealed that the phosphorus remaining in the leached solids was present as hydroxyapatite, $\mathrm{Ca}_{5}(\mathrm{OH})\left(\mathrm{PO}_{4}\right)_{3}{ }^{124}$ Figure C- 2 presents the PSD before and after treatment of the Group 2 solids with $\mathrm{NaOH}$. The caustic-leaching and washing operations reduced the fractional contribution of 2- to 20-micron particles, while the fractional contribution of $0.2-$ to 2-micron particles increased. The overall result was a reduction in particle size. But again, it is not possible to definitively determine what caused the shift in the PSD. The particles associated with gibbsite would have entirely disappeared during leaching. If these particles were on the larger end of the initial PSD range, that would explain the overall decrease in PSD after leaching. On the other hand, by analogy to what was observed for the Group 1 solids, conversion of $\mathrm{FePO}_{4}$ to $\mathrm{Fe}(\mathrm{OH})_{3}$ would have led to larger particles. However, the very large particles observed for leached Group 1 solids were not seen for the leached Group 2 solids. 
SRNL-STI-2013-00472

PNNL-23030

Revision 0

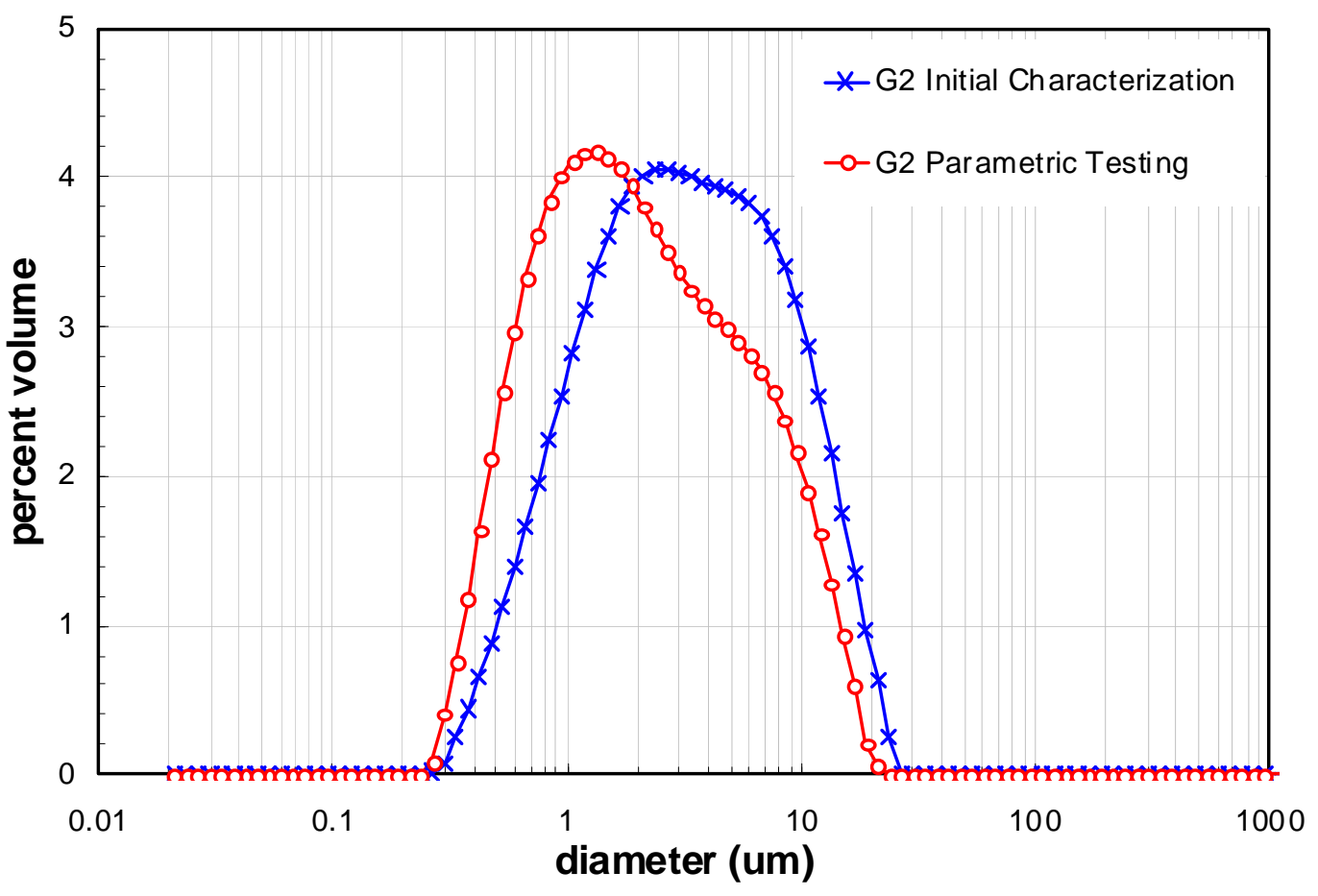

Figure C- 2. Influence of Caustic Leaching and Washing on the Group 2 (BiPO ${ }_{4}$ salt cake) Waste Solids PSD

The above two examples indicate that the effect of caustic leaching on the PSD can be unpredictable. A net increase in the particle size might occur, or a net decrease might occur, depending on the particular type of waste. Attributing the effects to a particular phase present in the solids is difficult based on the data available.

\section{Aluminum Dissolution at SRS}

A study was performed by SRNL ${ }^{128}$ that documented the effect of aluminum dissolution of waste from Tank 12 of the SRS Tank Farm on particle size. The waste solids have been estimated to contain approximately $97 \%$ boehmite solids based on X-ray diffraction analyses and a SRNL leaching test. ${ }^{129}$ The study with Tank 12 found that there was a slight decrease in particle size, as shown in Figure C- . 
SRNL-STI-2013-00472

PNNL-23030

Revision 0

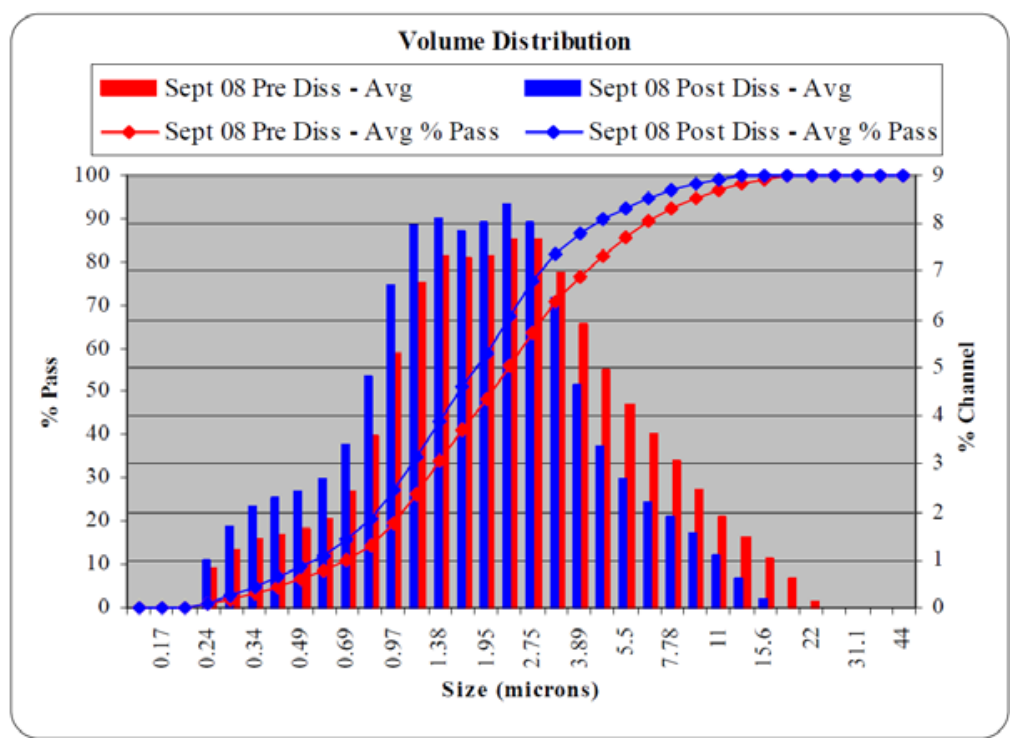

Figure C- 3. Mean Volume Distributions for Sept ’08 Pre- and Post-Dissolution Samples

This reduction in particle size was not a surprise, given that an appreciable fraction of the undissolved solids dissolved during the aluminum dissolution process. It should be noted that the slurry mixing pumps were operated continuously during the dissolution process and some or all of the size reduction could be due to the shearing of the sludge by the pumps.

\section{$\underline{\text { Advantages }}$}

The advantages of caustic leaching are that it is part of the baseline technology when performed in the PT facility. Performing size reduction with a caustic leaching step in the tank farm would eliminate addition of size reduction equipment and could aid in retrieval of the waste from the tank. In addition, this process is not expected to increase the amount of fines.

\section{$\underline{\text { Disadvantages }}$}

The disadvantage is the extent of size reduction is not known with this process and some testing would be required with the various Hanford waste types under the proposed processing conditions to determine whether the size reduction effect will be sufficient. Caustic leaching of selected Hanford waste has led to an increase in particle size. 
SRNL-STI-2013-00472

PNNL-23030

Revision 0

Appendix D. Alternative Size Segregation Technologies 


\section{Elutriation}

Elutriation uses moving fluid, usually in upflow, to separate fast settling particles from slow settling particles. Tank processing at Hanford Site in 2007 led to an observation that elutriation might be useful in the disposition of waste tanks there. A tank had been treated with large quantities of $50 \mathrm{wt} \%$ caustic and later rinsed with water jets. The tank was later observed to contain large particles of gibbsite and very little radioactive material. The treatment apparently removed most of the radioactive material and increased the size of the size of the gibbsite particles. If this process were successfully developed fairly clean gibbsite could be grouted in tanks. To support development of the combined caustic treatment and elutriation in Hanford Waste Tanks, SRNL researchers in 2011 tested in-tank elutriation ${ }^{130}$ as a method for segregating fast settling and slow settling particles in a waste tank. Fast settling solids were left insitu, with the proposed idea of grouting the remaining solids in place, or possibly diluting out and transferring the remaining solids by a sluicing operation. This concept was a method of solids segregation in a batch environment, but on a large scale.

The proposed process requires the intermediate processing steps of washing and caustic (50 wt.\%) additions, followed by the elutriation step. Studies performed at the SRNL have suggested that elutriation can be an applied and controlled process. Studies to ascertain the effects of hindered settling, where the interaction of particles in a fluid creates a slower moving mixture than would normally be expected based on free settling theory, needs to be considered for technology implementation. There are practical limits to the use of elutriation in a waste tank. Liquid motion is generated by a jet and the strong velocity gradients make control more difficult. Also hindered settling depends on the local concentration of solids and there are large variations in concentration when a tank is being agitated by a jet.

Additional resin elutriation was performed at the Hanford Tank Farm in 1998, and was documented in Report HNF-3132. ${ }^{131}$ This non-radioactive work detailed the ability of an elutriation column to remove $95 \%$ by mass of a resin bead solid composition.

Based on the S-112 experience, WRPS proposed emptying waste tanks that contained large quantities of soluble salts and undissolved solids. Radioactivity is believed to be generally concentrated in the slower settling very small particles/compounds, and WRPS suggested removing them preferentially to the larger particles/compounds of higher settling velocities. Though this stated goal was not fully realized, the goal of removing large quantities of simulated radioactive type particles/compounds was realized. Elutriation was proposed to remove the denser radionuclides (the inadvertent elutriation suggested that though denser, might not necessarily be faster settling). Large quantities of Gibbsite were also removed during this Hanford process (not a stated goal, but occurring with no negative associated effects).

In the SRNL work, various parameters were controlled to identify causal relationships leading to optimized results, including the rotation of the pump heads, mixing jet pump flowrate, the nozzle velocities, and variations in suction tube sizes and elevations. The greatest dependency was identified as the mixing jet pump flowrate.

Pictures of the testing apparatus and results are given below in Figure D- 1 and Figure D- 2. 
SRNL-STI-2013-00472

PNNL-23030

Revision 0

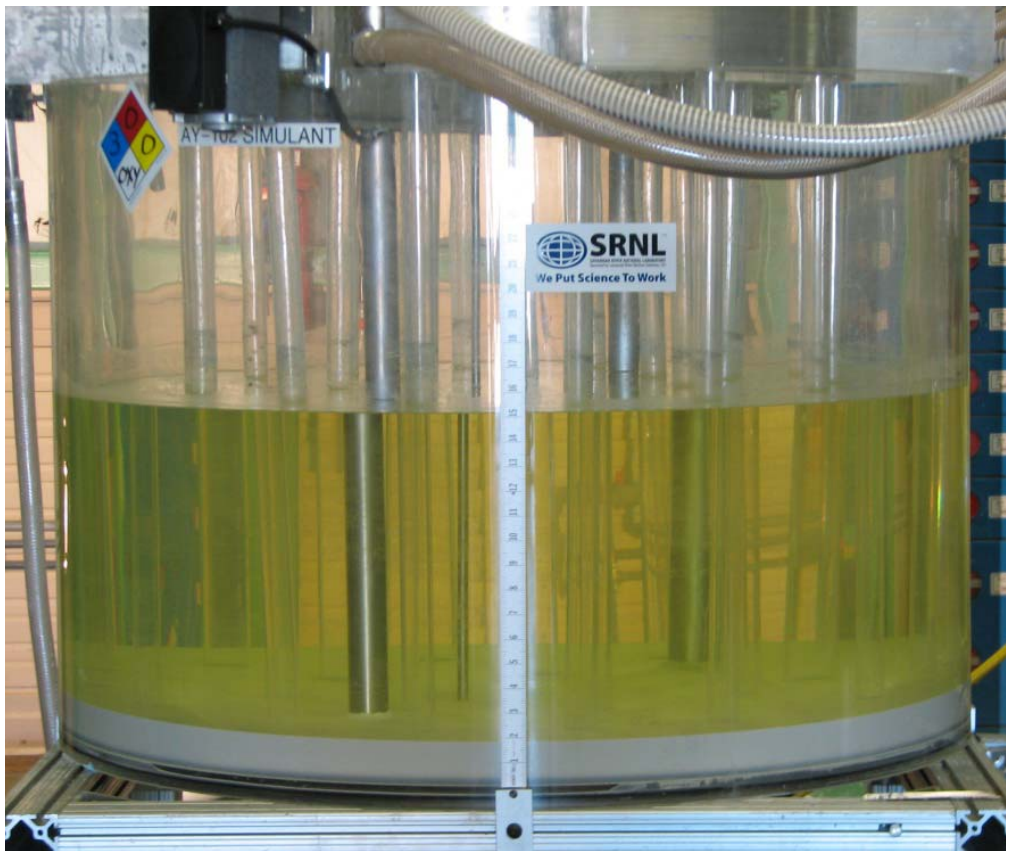

Figure D- 1. Initial Tank Solids Presentation Prior to Testing

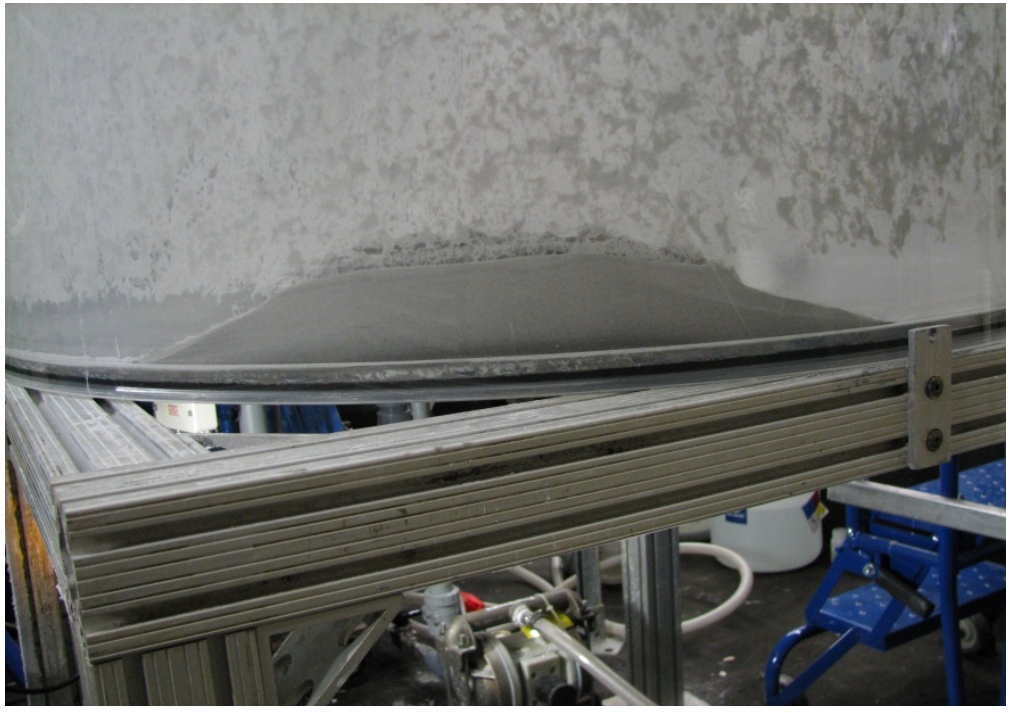

Figure D- 2. Final Heel Deposition with Optimized Parameters

The study found that gibbsite $\left(\mathrm{Al}(\mathrm{OH})_{3}\right)$ was left in the tank. It was determined that this process allowed the removal of slow settling particles ( $\mathrm{SG}<\sim 2.5$, size 30 microns), while leaving the fast settling particles (size 100 microns) in tank.

Conclusions from the report suggested that more research was required, analytical and experimental, on additional postulated waste simulants. ${ }^{130}$ The authors' also recommended the investigation of hydrocyclones as a further size segregation technique. They indicated the hydrocyclone separation would 
be a more precise and efficient separation method. Additional research on hydrocyclone separation has been discussed earlier in this report.

Additionally, the report documented work performed at the Hanford Waste Tank Complex, Tank S$112^{132-133}$, during a retrieval process occurring in 2007 that involved an inadvertent elutriation process. The particles remaining in the tank after the inadvertent elutriation were $\sim 100$ microns or larger.

The study found the possibility existed to allow the removal of bulk fluid and slow settling particles, with the idea of an additional processing step to remove faster settling particles. Previous work has been focused on salt waste tanks, but its potential to process slurry waste tanks is significant. In conjunction with other processing, this could provide an initial processing step for additional size segregation processes in tank.

A recommendation from the SRNL work concluded that In-Tank Elutriation was best suited for salt waste tanks, with the comment that additional chemical analyses of actual sludge is required to determine suitability of use on other type waste tanks. Pretreatment by the addition of large quantities of caustic solution is a significant disadvantage for this concept. Additional washing of solution will be required to remove phosphate and oxalate, which would otherwise precipitate with the caustic treatment.

\section{Counter-current Decantation}

Counter-current solids washing is a common process in the minerals processing and chemical industries. ${ }^{134}$ Washing circuits can be designed using thickeners, filters or centrifuges. Realizing the special needs of nuclear work and the low processing rates required, a Counter-current Decantation (CCD) circuit was proposed for washing and concentration of SRS sludge. ${ }^{135}$

The proposed design consisted of six seven-foot tall conical decanters in series as shown in Figure D- 3. The sludge to be washed would be pumped into the first decanter and then pumped from one decanter to the next requiring six pumps. The wash solution would then be pumped to the last, and highest, decanter and then returned to each of the lower decanters by gravity. The design for washing SRS sludge specified a $5 \mathrm{gpm}$ wash solution feed and a $3 \mathrm{gpm}$ washed sludge washing rate. This rate is considerably faster than the $<1$ gpm wash rate of the settle/decant processing in a million gallon waste tank. The washing was designed to reduce the sodium concentration of the supernatant from $5 \mathrm{M}$ to $0.25 \mathrm{M}$. Typical SRS wash targets currently are 1-2 M sodium, which could be done in 3-4 decanters based on the 1997 analysis. ${ }^{135}$ 
PNNL-23030

Revision 0

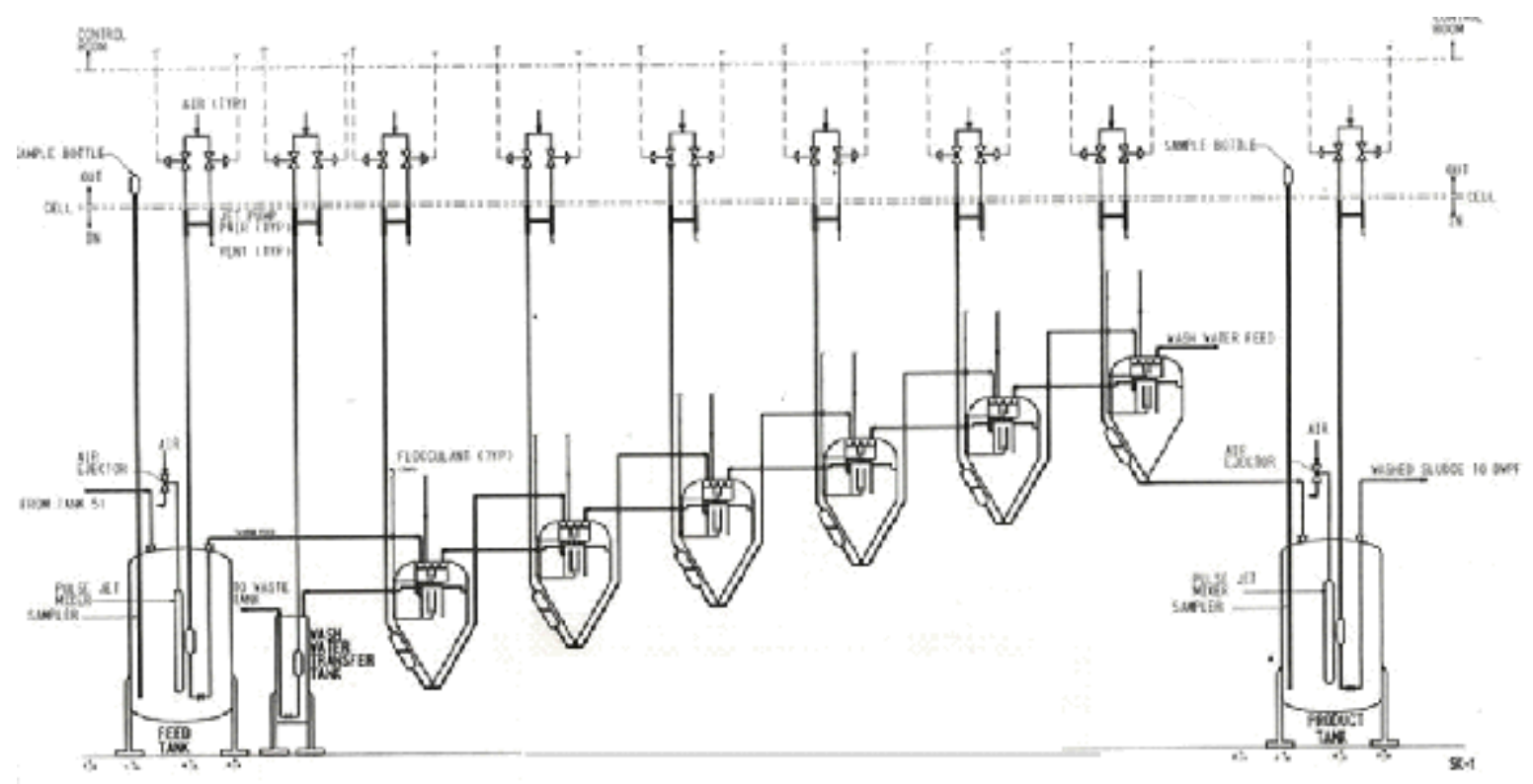

Figure D- 3. Six Stage Counter-current Decantation Circuit for SRS Sludge Washing

\section{$\underline{\text { Advantages }}$}

Advantages for the CCD include potentially higher sludge processing rates along with a greatly reduced wash water requirement. An obvious advantage is that a purpose built facility can be smaller, faster and more flexible.

\section{$\underline{\text { Disadvantages }}$}

Disadvantages for the CCD include the number of tanks and thus footprint required. Settling must be rapid for this to be feasible so a flocculating agent may be required depending on the particle size requirements. If required, flocculation is counterproductive to the process by potentially agglomerating smaller particles that may have started with the required specification and enlarged them such that they are now out of spec. Additionally, the flocculating concentration and/or agent may have to change from sludge tank to sludge tank to maximize the production of each feed batch. The addition of a flocculating agent also has the potential for causing issues in other processing facilities. The spent wash solution would likely contain fragments or decomposition products of the flocculating agent and the washed sludge would likely contain the bulk of the flocculating agent and its decomposition products. This has the potential to add a considerable amount of organic to the melter feed which may impact the Reduction/Oxidation potential of the melter feed, flammability of the melter off gas, and the potential for flocculating agent decomposition products being present in the melter off gas condensate. The throughput of a CCD will be dependent on slurry rheology. As a result, extensive testing might be needed for each waste tank to find the right flocculating agent/rheology modifiers for efficient processing. 
SRNL-STI-2013-00472

PNNL-23030

Revision 0

Appendix E. Additional Documents Reviewed 
1. U.S. Department of Energy, Office of River Protection, P. J. Certa, P. A. Empey, and M. N. Wells, River Protection Project System Plan, ORP-11242, Revision 6, Richland, Washington, 2011.

2. G. K. Allen, Hanford Tank Waste Operations Simulation (HTWOS) Version 6.6.1 Model Design Document, RPP-17152, River Protection Project, Richland, WA (2011).

3. G. Stachowiak and A. Batchelor. Engineering Tribology, ISBN 10 0-7506-7836-4, ButterworthHeinemann, Waltham, Massachusetts, (2005).

4. B. E. Wells, P. A. Gauglitz, and D. R. Rector, Comparison of Waste Feed Delivery Small Scale Mixing Demonstration Simulant to Hanford Waste, PNNL-20637, Pacific Northwest National Laboratory, Richland, WA (2012).

5. J. R. Jewett, S. D. Estey, L. Jensen, N. W. Kirch, D. A. Reynolds, and Y. Onishi, Values of Particle Size, Particle Density, and Slurry Viscosity to Use in Waste Feed Delivery Transfer System Analysis, RPP-9805, River Protection Project, Richland, WA (2002).

6. 24590-WTP-GPG-M-0058, Design Guide: Minimum Flow Velocity for Slurry Lines, WTP Project Doc. No. 24590-WTP-GPG-M-0058, (2006).

7. 24590-WTP-DB-ENG-01-001, Basis of Design, Rev 1Q

8. D. E. Carl, West Valley Demonstration Project Vitrification Process Equipment Functional and Checkout Testing of Systems (facts), DOE/NE/44139-64, (1990).

9. J. Paul and D. K. Ploetz, System Description WVNS-SD-65 - Cold Chemical System - System 65, WVNS-SD-65, Revision 6, West Valley Nuclear Services Co., Inc., NY (April 27, 1999).

10. B. M. Rapko, G. J. Lumetta, and M. J. Wagner, Washing and Caustic Leaching of Hanford Tank Sludges: Results of FY 1995 Studies, PNL-10712, Pacific Northwest Laboratory, Richland, WA (1995).

11. G. J. Lumetta, M. J. Wagner, F. V. Hoopes, and R. T. Steele, Washing and Caustic Leaching of Hanford Tank C-106 Sludge, PNNL-11381, Pacific Northwest National Laboratory, Richland, WA (1996).

12. B. M. Rapko and M. J. Wagner, Caustic Leaching of Composite AZ-101/AZ-102 Hanford Tank Sludge, PNNL-11580, Pacific Northwest National Laboratory, Richland, WA (1997).

13. G. J. Lumetta, I. E. Burgeson, M. J. Wagner, J. Liu, and Y. L. Chen, Washing and Caustic Leaching of Hanford Tank Sludge: Results of FY 1997 Studies, PNNL-11636, Pacific Northwest National Laboratory, Richland, WA (1997).

14. S. H. Reboul, et. al., Sludge Batch 7 (SB7) Washing Demonstration to Determine Sulfate/Oxalate Removal Efficiency and Settling Behavior, SRNL-STI-2010-00697, Rev 0, Savannah River National Laboratory, Aiken, SC (2010).

15. E. T. Ketusky, Bulk Oxalic Acid Cleaning (BOAC), SRR-LWE-2010-00271, Savannah River Remediation, Aiken, SC (2010), 
SRNL-STI-2013-00472

PNNL-23030

Revision 0

16. H. Q. Colleran and J. M. Gillam, Flowsheet for Sludge Batch 8, LWO-LWE-2011-00217, Rev 0, Savannah River Remediation, Aiken, SC (2010),

17. F. F. Fondeur, F. M. Pennebaker, and S. D. Fink, The Hydrothermal Reactions of Monosodium Titanate (MST), Crystalline Silicotitanate (CST) and Sludge in the Modular Salt Process (MSP): A Literature Survey, SRNL-STI-2010-00682, Savannah River National Laboratory, Aiken, SC (2010).

18. T. Huff, M. Rios-Armstrong, R. Edwards, and D. Herman, Small Column Ion Exchange Design and Safety Strategy, WM2011 11325 Presentation, (2011).

19. C. J. Martino, M. R. Poirier, F. F. Fondeur, and S. D. Fink, Flocculating, Settling, and Decanting for the Removal of Monosodium Titanate and Simulated high-Level Waste Sludge from Simulated Salt Superanate, WSRC-TR-2001-00413, Westinghouse Savannah River Company, Aiken, SC (2001).

20. M. E. Stone, Evaluation of GE Flocculant Test Kit with SB4 Simulant, SRNL-ITS-2005-00299, Savannah River National Laboratory, Aiken, SC (2005).

21. Contract WB02048A Rotary Microfilter 10 Day Test Report, 6/21/13.

22. J. R, Bontha, H. E. Adkins, K. M. Denslow, J. J. Jenks, C. A. Burns, P. P. Schonewill, G. P. Morgen, M. S. Greenwood, J. Blanchard, T. J. Peters, P. J. Macfarlan, E. B. Baer, and W. A. Wilcox, Test Loop Demonstration and Evaluation of Slurry Transfer Line Critical Velocity Measurement Instruments, PNNL-19441, Revision 0, Pacific Northwest National Laboratory, Richland, WA (2010).

23. E. L. Paul, V. A. Atiemo-Obeng, and S. M. Kresta, Handbook of Industrial Mixing Science and Practice, John Wiley \& Sons, Inc., Hoboken, NJ (2004).

24. A. P. Poloski, H. E. Adkins, J. Abrefah, A. M. Casella, R. E. Hohimer, F. Nigl, M. J. Minette, J. J. Toth, J. M. Tingey, and S. T. Yokuda, Deposition Velocities of Newtonian and Non-Newtonian Slurries in Pipelines, PNNL-17639, WTP-RPT-175, Revision 0, Pacific Northwest National Laboratory, Richland, WA (2009).

25. RPP-40149-VOL1, Integrated Waste Feed Delivery Plan, Volume 1 - Process Strategy, Rev. 2, Washington River Protection Solutions, LLC, Richland, WA (2012).

26. RPP-40149-VOL2, Integrated Waste Feed Delivery Plan, Volume 2 - Campaign Plan, Rev. 2, Washington River Protection Solutions, LLC, Richland, WA (2012).

27. RPP-40149-VOL3, Integrated Waste Feed Delivery Plan, Volume 3 - Project Plan, Rev. 2, Washington River Protection Solutions, LLC, Richland, WA (2012).

28. M. He and E. Forssberg, "Influence of Slurry Rheology on Stirred Media Milling of Limestone", Advances in Comminution proceedings, Edited by SK Kawatra, ISBN-13: 978-0-87335-246-8, pp 243-260, Published by Society for Mining, Metallurgy, and Exploration, Inc. (2006). 


\section{Distribution:}

\section{SRNL}

S. L. Marra, 773-A

T. B. Brown, 773-A

S. D. Fink, 773-A

C. C. Herman, 773-A

E. N. Hoffman, 999-W

D. H. McGuire, 999-W

F. M. Pennebaker, 773-42A

W. R. Wilmarth, 773-A

Records Administration (EDWS)

D. J. Adamson, 999-W

M. J. Cercy, 773-42A

M. R. Duignan, 786-5A

K. M. Fox, 999-W

E. K. Hansen, 999-W

D. T. Herman, 735-11A

D. P. Lambert, 999-W

R. A. Leishear, 736-A

M. R. Poirier, 773-42A

S. H. Reboul, 773-42A

M. L. Restivo, 773-42A

D. B. Stefanko, 704-25G

M. E. Stone, 999-W

\section{$\underline{\text { SRR }}$}

S. C. Smith, 704-17S

J. R. McCullough, 241-121H

DOE-SR

P. R. Jackson

PNNL

R. D. Peterson

G. L. Smith

B. E. Wells

G. J. Lumetta

C. W. Enderlin

H. E. Adkins $\underline{\text { DOE-ORP }}$

D. H. Alexander

J. A. Diediker

T. W. Fletcher

B. J. Harp

C. C. Harrington

A. A. Kruger

J. Shuen

I. Wheeler

W. R. Wrzesinski

WTP

A. V. Arakali

S. M. Barnes

P. A. Benson

G. M. Duncan

M. R. Hamlet

J. Markillie

WRPS

S. T. Arm

C. Burrows

T. W. Crawford

W. G. Ramsey

P. L. Rutland

S. A. Saunders

D. H. Shuford

K. H. Subramanian

M. G. Thien

L. E. Thompson 